\title{
A Study of Selected Piano Works by Two Living Composers: David Gordon Duke and Stefan Young
}

Wei Chen Lin

Follow this and additional works at: https://researchrepository.wvu.edu/etd

\section{Recommended Citation}

Lin, Wei Chen, "A Study of Selected Piano Works by Two Living Composers: David Gordon Duke and Stefan Young" (2015). Graduate Theses, Dissertations, and Problem Reports. 6091.

https://researchrepository.wvu.edu/etd/6091

This Dissertation is protected by copyright and/or related rights. It has been brought to you by the The Research Repository @ WVU with permission from the rights-holder(s). You are free to use this Dissertation in any way that is permitted by the copyright and related rights legislation that applies to your use. For other uses you must obtain permission from the rights-holder(s) directly, unless additional rights are indicated by a Creative Commons license in the record and/ or on the work itself. This Dissertation has been accepted for inclusion in WVU Graduate Theses, Dissertations, and Problem Reports collection by an authorized administrator of The Research Repository @ WVU.

For more information, please contact researchrepository@mail.wvu.edu. 


\title{
A STUDY OF SELECTED PIANO WORKS BY TWO LIVING COMPOSERS: DAVID GORDON DUKE AND STEFAN YOUNG
}

\author{
Wei Chen Lin \\ A Doctoral Research Project submitted to \\ The College of Creative Arts \\ at \\ West Virginia University \\ In partial fulfillment of the requirements for the degree of
Doctor of Musical Arts
in \\ Piano Performance
}
James Miltenberger, D.M.A., Committee Chair and Research Advisor Peter Amstutz, D.M.A
William Haller, D.M.A
Bernie Schultz, Ph.D.
Andrea Houde

School of Music
Morgantown, West Virginia
2015

Keywords: David Gordon Duke; Stefan Young; Piano

Copyright 2015 Wei Chen Lin 


\section{ABSTRACT \\ A Study of Selected Piano Works by Two Living Composers: David Gordon Duke and Stefan Young}

\section{Wei Chen Lin}

This research project is to introduce piano compositions by two living composers: David Gordon Duke and Stefan Young. The specific repertoire chosen for this study includes the following: Preludes (1980s), Postcards (1980s), and Sonatina (1977) by David Duke; and Prelude (1991), From the Dark Woods (1991), Meditation (2002), and La Guitarra (1993) by Stefan Young. This paper explores aspects of piano pedagogy and performance such as: (1) the basic technical approach; (2) suggestions for specific sound production; (3) interpretation of complex meters; (4) recommendations for pedaling and fingering; (5) observations of dynamics and articulations. The material discussed spans a broad range of technical challenges from elementary to advanced levels. The choice of the works of these two composers is intended to give teachers as well as students additional options for repertoire selection. Moreover, these pieces provide effective first engagement with contemporary music and are a viable substitute for some standard works that feature similar twentieth-century compositional techniques and ideas. It is hoped that this study will encourage pianists to appreciate music of their own time and place, thus fostering the continuing support and development of new music. 


\section{Acknowledgements}

I would like to thank several people who have embarked on this journey with me. First, I would like to thank God for his grace and my parents for their unconditional encouragement and support. I am indebted to my piano mentor, committee chair, and research advisor, Dr. James Miltenberger, for his patience and scholarly advice. My appreciation is also extended to the other members of my graduate committee for their assistance and suggestions: Dr. Peter Amstutz, Dr. William Haller, Dr. Bernie Schultz, and Professor Andrea Houde. Finally, a special thank you to David Gordon Duke and Stefan Young for providing their insight about their lives and music through interviews and e-mail correspondence. 


\section{TABLE OF CONTENTS}

Abstract

Acknowledgements

CHAPTER

I. INTRODUCTION 1

Purpose of the Study 1

Need for the Study $\quad 2$

Limitations of the Study $\quad 2$

Related literature 3

II. DAVID GORDON DUKE 5

Brief Biography 5

Pedagogical and Performance Analysis of the Selected Piano Pieces

2.1 Preludes 8

2.2 Postcards 27

2.3 Sonatina 41

$\begin{array}{lll}\text { III. STEFAN YOUNG } & 61\end{array}$

Brief Biography 61

Pedagogical and Performance Analysis of the Selected Piano Pieces

3.1 Prelude 64

3.2 From the Dark Woods 69

$\begin{array}{lll}3.3 & \text { Meditation } & 74\end{array}$

$\begin{array}{lll}3.4 & \text { La Guitarra } & 80\end{array}$

IV. SUMMARY AND RECOMMENDATIONS 86

$\begin{array}{ll}\text { Summary } & 86\end{array}$

Recommendation for Further Study $\quad 89$

$\begin{array}{lr}\text { SELECTED BIBLIOGRAPHY } & 90\end{array}$ 


\title{
A STUDY OF SELECTED PIANO WORKS BY TWO LIVING COMPOSERS: DAVID GORDON DUKE AND STEFAN YOUNG
}

\section{CHAPTER I}

\author{
$\underline{\text { Introduction }}$
}

In traditional musical education, students are expected to study various stylistic periods of music. It is common for a student who has ten years of piano study to play much of the classic repertoire by Bach, Beethoven, Mozart, Chopin, Schumann, Bartók, Kabalevsky, and others. Classical training of young pupils often neglects playing works by contemporary composers. Certainly, all piano students should study and perform recent works in order to become well-rounded musicians. Many living composers recognize the importance of writing in contemporary idioms and using a new musical language for young pianists. By studying and playing a variety of modern pieces, students will hear and gradually come to understand how contemporary composers organize sounds for expressive purposes. This process will hopefully lead students to appreciate the music of their own time and place.

\section{Purpose of the Study}

The purpose of this study is to provide a performance and pedagogical analysis for selected piano works by two living composers: David Gordon Duke and Stefan Young. The specific repertoire chosen for this study includes Duke's Preludes (1980s), Postcards (1980s), and Sonatina (1977). In addition, the music to be analyzed from Young's collection includes: Prelude (1991), From the Dark Woods (1991), Meditation (2002), and La Guitarra (1993). Both composers were born in the mid-1900s. Their music represents various styles, ranging from 
classical traditions to contemporary idioms. It is the author's goal to foster the continuing support and development of new music through the study of these pieces.

\section{Need for the Study}

Many of David Gordon Duke's compositions have been published. His Sonatina, commissioned by Vivienne Rowley in 1977, was published by the Waterloo Music Company in 1985. The other two sets of compositions, Preludes and Postcards, were written in the 1980s and will be published in 2015 .

Two of Stefan Young's piano works, Meditation and La Guitarra, were dedicated to his former students and served as pedagogical studies. Two of the remaining works in this research project, From the Dark Woods and Prelude, were commissioned by New Jersey Music Teacher's Association (NJMTA) in 1991. None of these pieces has been published.

The author particularly chooses these two composers as the subjects of the research because the author had the good fortune to study music theory with them during previous degrees. They supported the students in their musical endeavors. They also established high standards for the class and treated every student with courtesy and kindness. The author fondly remembers their unique sense of humor, which made the theory class enjoyable. Both of them maintain a low profile in their career but they are dedicated to educating and mentoring young pupils. There has been no research to date on any of these piano pieces. It is the author's goal to bring awareness to students and teachers that these are creative compositions that can be incorporated into the overall piano repertoire.

\section{Limitation of the Study}

This study is limited to pedagogical and performance-related discussions of the seven compositions mentioned above. The analyses of these pieces focus on aspects such as the basic 
technical approach, suggestions for specific sound production, interpretation of complex meters, recommendations for pedaling and fingering, and observations of dynamics and articulations. This document is not intended as an in-depth historical or theoretical study of these works, but rather as an analysis of their work and its value for younger performers.

\section{$\underline{\text { Related Literature }}$}

The resources for biographical and background information about David Gordon Duke within this document are from the Encyclopedia of Music in Canada and personal interviews with the composer. Little has been written about his solo piano works. The book that is most relevant to this study is the 2015 Celebration Series Perspective: Handbookfor Teachers. ${ }^{1}$ This book presents selected piano literature from the Baroque to the present time that is used for the Royal Conservatory Music Development Program (MDP). ${ }^{2}$ Some of Duke's miniatures are mentioned and discussed. The dissertation that is most relevant to this study is the 2005 dissertation by Christopher Charles Hahn. ${ }^{3}$ This dissertation presents a selection of early elementary to early advanced-level piano repertoire by Canadian composers written between 1970 and 2004. Although Duke and his compositions are mentioned often, none of the selected works in this research is discussed in Hahn's dissertation.

In 1983, Susan C. Ross wrote an article about Duke for The Music Scene magazine. It talks about Duke's life and how his career is divided into "unequal thirds- teaching, composition, and writing." His works have been influenced by a number of divergent traditions. Duke

\footnotetext{
${ }^{1}$ Cathy Albergo, Reid Alexander, and Marvin Blickenstaff, Celebration Series Perspectives: Handbook for Teacher, 4th ed. (Oakville, ON: The Frederick Harris Music Co. Limited, 2015).

${ }^{2}$ http://www.musicdevelopmentprogram.org/ (accessed August 31, 2015).

${ }^{3}$ Christopher Charles Hahn, "Canadian Pedagogical Piano Repertoire since 1970: A Survey of Contemporary

Compositional Styles and Techniques”, (D.M.A. Dissertation, University of Oklahoma, 2005).
} 
recalled his favorite review of his Sonatina, about which the Edmonton Journal wrote in twentyfour point capitals: "DAVID DUKE stands out in unmemorable composers' recital."4

Information on Young's biography and background can be found in his dissertation, ${ }^{5}$ school faculty page, and personal interviews with the composer. Young has composed for various ensembles and instrumentations including: orchestra, band, choir, chamber groups, voice and piano, and a variety of solo instruments. There has been little written about his career and his solo piano works. Because of this, the author contacted some of Young's former students who currently hold positions at major musical organizations and universities in North America and Asia. Many of these people regularly publish works with major publishers such as Schirmer, Alfred, and Hal Leonard. Comments from former students are included in Chapter III reflecting the lasting impact Young made in the music world.

\footnotetext{
${ }^{4}$ Susan. C. Ross, "Music reflects Duke's current interests", The Music Scene Vol. 334 (Nov.-Dec. 1983$)$ ): 5.

${ }^{5}$ Stefan Hayden Young, "Andante and Allegro for Piano and Orchestra: An Original Composition and Analysis", (Ph.D. Thesis, Rutgers University, 1981).
} 


\section{CHAPTER II}

\section{DAVID GORDON DUKE}

Brief Biography

David Gordon Duke was born in Vancouver, British Columbia, in 1950. He received his early musical training from violinists Kenneth Yunke and Douglas Stewart from 1956-1971. After receiving a bachelor's degree from the University of British Columbia, he continued his studies in musicology at the University of North Carolina and the University of Victoria. He studied composition privately with Jean Coulthard, a female composer who dominated Western Canadian music in the twentieth century. Duke recently published a biography of Jean Coulthard with co-author William Bruneau. ${ }^{6}$

Duke taught at the University of North Carolina (1971-72), the University of British Columbia (1973-75), and Red Deer College (1975-77). He returned to Vancouver in 1978 to teach at the Vancouver Community College, where he has been an academic coordinator since 1984. Along with working in academia, Duke regularly contributes reviews and essays to The Vancouver Sun, Music Magazine, and Music Scene. He has written extensively about Canadian music and his thoughts on music have been broadcast on a number of Canadian radio stations. In addition, he is also a clinician, adjudicator, and presenter of workshops for younger composers. ${ }^{7}$

Duke is considered one of western Canada's most performed, prolific, and published composers. According to Susan C. Ross, Duke's style is best described as "crashing virtuosity

\footnotetext{
6 "David Gordon Duke," The Canadian Encyclopedia, last modified December 15, 2013, accessed January 3, 2015, http://www.thecanadianencyclopedia.ca/en/article/david-gordon-duke-emc/

${ }^{7}$ Canadian Encyclopedia, "David Gordon Duke."
} 
[with] overtones of Baroque and Renaissance...Bartókish." " Duke's music, Ross continues, is "very exciting... bright, witty passages, pleasantly tainted with English lyricism."9

Duke's compositions include a variety of genres: chamber works for a small number of instruments, orchestral works, and solo works for one instrument. His chamber music works include a variety of instrumental combinations. Notable compositions include Aria and Recitative $^{10}$ for cello and piano, Sonata da Chiesa ${ }^{11}$ for flute and organ, and Night Song ${ }^{12}$ for viola and piano. A companion piece to the piano Sonatina ${ }^{13}$ is Sonatina Semplice ${ }^{14}$ for violin and piano, which follows the classical three-movement formal structure. A piano trio called Triptych ${ }^{15}$ quotes from Chopin and borrows rhythmic ideas from west coast First Nations (i.e. aboriginal people of Canada) music. He also wrote many works for orchestra in the 1980s. Notable orchestral works include Music for Orlando ${ }^{16}$ and Concerto Grosso. ${ }^{17}$

Duke's solo piano works are included in the Music of Our Time ${ }^{18}$ by Jean Coulthard, David Duke, and Joan Hansen, which contains a total of nine graded volumes designed to introduce pianists to the musical vocabulary of the twentieth century. Another popular book Music in Many Forms, ${ }^{19}$ coauthored by Jean Coulthard, David Duke, and Sylvia Rickard, includes contemporary music based on formal designs of the past. A popular beginner book,

\footnotetext{
${ }^{8}$ Susan C. Ross, "Music reflects Duke's current interests", The Music Scene Vol. 334 (Nov.-Dec. 1983): 5

${ }^{9}$ Ibid.

${ }^{10}$ David Duke, Aria and Recitative (Canadian Music Centre, 1977).

${ }^{11}$ David Duke, Sonata da Chiesa (Canadian Music Centre, 1975).

${ }^{12}$ David Duke, Night Song (Unpublished, 1982).

${ }^{13}$ David Duke, Sonatina (Waterloo: Waterloo Music Co. Limited, 1985).

${ }^{14}$ David Duke, Sonatina Semplice (Unpublished, 1982).

${ }^{15}$ David Duke, Triptych (Canadian Music Centre, 1984).

${ }^{16}$ David Duke, Music for Orlando (Canadian Music Centre, 1986).

${ }^{17}$ David Duke, Concerto Grosso (Canadian Music Centre, 1987).

${ }^{18}$ Jean Coulthard, David Duke, and Joan Hansen, Music of Our Time, 9 vols (Waterloo: Waterloo Music Co. Limited, 1977-80).

${ }^{19}$ Jean Coulthard, David Duke, and Sylvia Rickard, Music in Many Forms (Waterloo: Waterloo Music Co. Limited, 1981).
} 
Magical Years of the Chinese,${ }^{20}$ is based on the animals of the Chinese zodiac. Other notable compositions include Special Days ${ }^{21}$ and Festival Collections. ${ }^{22}$ Sometimes Duke reuses his music from one composition to another. Barcarolle from the fourth volume of Music of Our Time is the shorter version of the second movement titled Nocturne, of his Sonatina. Barcarolle was composed a little earlier in the same year as Nocturne, 1977. The composer likes the slow and cantabile theme in the Barcarolle; therefore, he reuses it in the Nocturne.

Next, the author will examine Duke's Preludes, Postcards, and Sonatina in greater detail. In the analysis of the following pieces, the author will provide a chart containing sections, measures numbers, and tonal emphasis. The author divides the sections by roman numerals. However, if the sections are relevant and interrelated and thus can form a conventional structure such as a binary, rounded binary, ternary, rondo, or sonata allegro, the author will make additional labels. In the analysis of tonality, the author feels tonal emphasis is a better term than tonal center for two reasons. First, the absence of key signature really blurs the traditional tonality. Secondly, a specific tone may be emphasized throughout the piece and that may provide an aural sense of a tonality; however, it is often not supported by dominant to tonic harmony.

In terms of pedaling, the author will illustrate his suggestions by the use of a bracket $(\overbrace{}^{\smile}$ ). In the cases where the composer's intentions are not obviously distinguishable from the editorial suggestions, the author will mark the passage with an asterisk. In terms of the fingering, Duke and Young do not provide any fingering suggestions. The author will only provide fingering suggestions for the selected tricky passages. Finally, every piece will conclude with the discussion of the challenges to the performer of primary concern. Pedagogical

${ }^{20}$ David Duke, Magical Years of the Chinese (Waterloo: Waterloo Music Co. Limited, 1990).

${ }^{21}$ David Duke, Special Days: A Musical Year for Children (Waterloo: Waterloo Music Co. Limited, 1994).

${ }^{22}$ David Duke, Festival Collection (Palmerston, ON: Julyn Music Publications, 2002). 
and performance suggestions are subjective and are intended to provide some of several possible interpretations and ideas.

\section{Pedagogical and Performance Analysis of the Selected Piano Pieces}

\subsection{Preludes}

During the Renaissance, the prelude was a short improvisation made by lutenists checking the tuning of their instruments, keyboard players testing the touch and tone of their instruments, or church organists establishing the pitch and mode of the music to be sung during the liturgy. ${ }^{23}$

In the Baroque era, the prelude was usually played as an introduction to another larger musical piece in the same key such as Johann Sebastian Bach's Prelude and Fugues. The preludes did not stand alone musically. They could also be grouped in a suite containing a collection of dances such as Preludes, Allemandes, Courantes, Sarabandes, and Gigues. A prelude generally features a small number of rhythmic and melodic motifs that recur throughout the piece. Most music during the Baroque era had only one mood, or "affect." The idea of "affect" was that music should evoke an emotion in the listener, and that only one emotion should be evoked at a time. ${ }^{24}$

Throughout the Classical era, the prelude was not an important musical form.

Introductory material was generally presented as an integral part of a sonata or symphony rather than a separate composition. ${ }^{25}$

During the Romantic era, there was a renewed interest in older music including preludes. Mendelssohn wrote a set of six preludes and fugues. Chopin, however, treated the prelude

\footnotetext{
${ }^{23}$ David Ledbetter and Howard Ferguson. "Prelude." Grove Music Online. Oxford Music Online. Oxford University Press, accessed December 30, 2014, http://www.oxfordmusiconline.com/subscriber/article/grove/music/43302

${ }^{24}$ Ibid.

${ }^{25} \mathrm{Ibid}$.
} 
differently. Preludes were not simply an imitation of a respected past. Though some of them are short, each of Chopin's preludes can be an independent piece. ${ }^{26}$

In the twentieth century, many composers continued to write sets of preludes. Those composers include Debussy, Gershwin, Ginastera, Kabalevsky, Rachmaninoff, and Shostakovich. Unlike previous composers, Debussy's two books of piano preludes carry descriptive titles at the end of each piece. Up until the present day, preludes remain a familiar genre. As such, living composers George Crumb, Nikolai Kapustin, and Jeroen van Veen still write preludes today. ${ }^{27}$

Duke wrote seven preludes between 1980 and 1985. The longest is No. 6 while No. 4 is the shortest having only 14 measures. Duke presents a variety of writing: contemporary techniques combined with traditional approaches. His preludes can be played individually or as a whole set. In these preludes, one specific motive or theme is usually presented and recurs throughout. The structure is similar to the preludes in the Baroque era, except the harmonic language is more typical of the twentieth century.

\section{Prelude No. 1}

Prelude No. 1 contains three (ABA) sections. A brief analysis of this piece is presented in the table below:

\begin{tabular}{|c|c|c|}
\hline Section & Measures & Tonal Emphasis \\
\hline $\mathrm{I}(\mathrm{A})$ & $1-4$ & A \\
\hline II (B) & $5-12$ & $\mathrm{D}, \mathrm{E} b, \mathrm{E}$ \\
\hline III (A) & $13-16$ & A \\
\hline
\end{tabular}

\footnotetext{
${ }^{26}$ David Ledbetter and Howard Ferguson. "Prelude." Grove Music Online. Oxford Music Online. Oxford University Press, accessed December 30, 2014, http://www.oxfordmusiconline.com/subscriber/article/grove/music/43302 ${ }^{27}$ Ibid.
} 
Prelude No. 1 consists of a three-voice texture: soprano, tenor, and bass. The right hand plays flowing sixteenth notes. The left hand presents two voices: sustaining bass notes on downbeats and tenor voice off-beats (Example 2.1a).

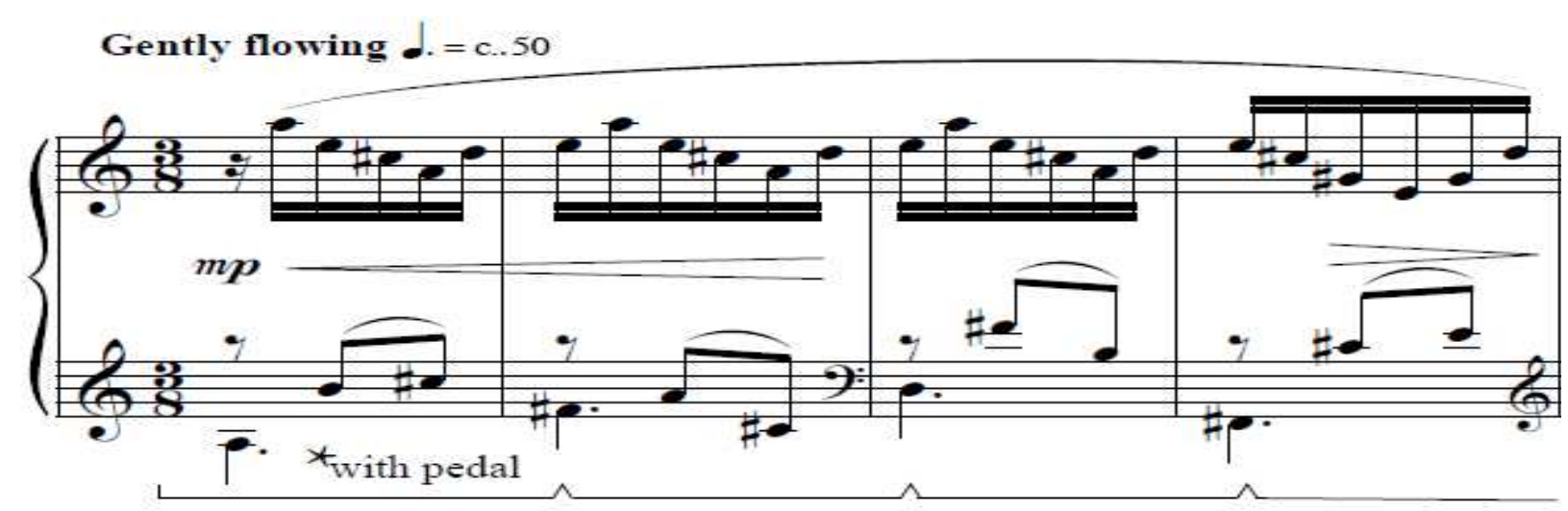

Example 2.1 a Prelude No. 1, mm. 1-4

In this prelude, there are three sections. The first section is four measures long. An A major tonality is established with A major arpeggios in the right hand. The second section is eight measures long. It incorporates not only the arpeggios, but also scalar passages. This section reaches the forte dynamic by combining the bass and tenor in measures 11-12. Here, Duke indicates molto rit, which helps to stress the climax of the phrase. Harmonically, the interplay between D major and $\mathrm{E} b$ major creates more tension until resting on the $\mathrm{E} 7$ fermata (Example 2.1b). This anticipation establishes a dominant-tonic relationship in A major, which leads into the last section. This is similar to the first section, but one octave higher and at the softest ( $p p$ ) dynamic level. The piece ends quietly in A major. 


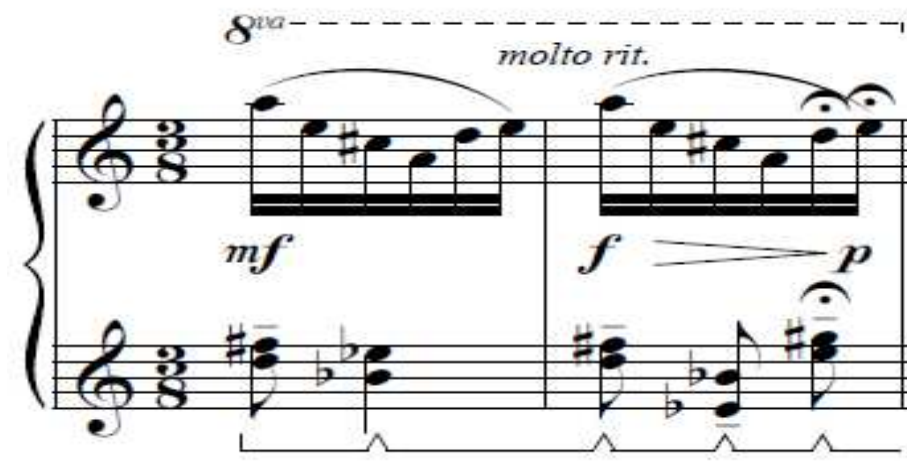

Example 2.1b Prelude No. 1, mm. 11-12

In terms of pedaling, Duke only marks with pedal. ${ }^{28}$ The author recommends pedaling on every downbeat so the dotted quarter notes can be sustained (Example 2.1a). Performers should play the inner voice tenor as lightly as possible to easily distinguish between the two voices in the left hand. At measures 11-12, the harmonic progression changes frequently. It is recommended to change the pedal according to the left-hand harmonic progressions (Example 2.1b).

The author feels there is one challenge to the performer of primary concern in Prelude No. 1. Though this prelude is simple and short, the ability to create a gently flowing melodic line requires a complete relaxation of the wrist and arm. It should not sound mechanical and certainly not like an etude or a finger technique exercise. To avoid rhythmic inconsistency in the right-hand sixteenth notes, the performer should imagine caressing the keyboard rather than playing to the bottom of the keys.

\footnotetext{
${ }^{28}$ All pedal markings are those of the author of this paper, except those noted by an asterisk, which are the composer's.
} 


\section{Prelude No. 2}

Prelude No. 2 contains three sections. A brief analysis of this piece is presented in the table below:

\begin{tabular}{|c|c|c|}
\hline Section & Measures & Tonal Emphasis \\
\hline I (Theme A) & $1-8$ & $\mathrm{D}$ \\
\hline II (Theme B) & $9-16$ & D \\
\hline III (Theme A+B) & $17-23$ & $\mathrm{D}$ \\
\hline
\end{tabular}

Each formal division is clearly marked by double bar lines. In the first section, Duke varies the rhythmic grouping of the $7 / 8$ meter as $3+2+2$ or $2+2+3$. The tonal emphasis is on $\mathrm{D}$ major triad with the left hand playing the root and the third while the right hand is playing the fifth. The right-hand melody serves as Theme A in measures 1-3 (Example 2.1c). This section is clearly in two voices. Duke includes many hairpin crescendi and decrescendi, but the performer should maintain Cantabile, senza rigore (in a singing style, without strictness) as notated at the beginning. This section ends on an A7 half cadence.

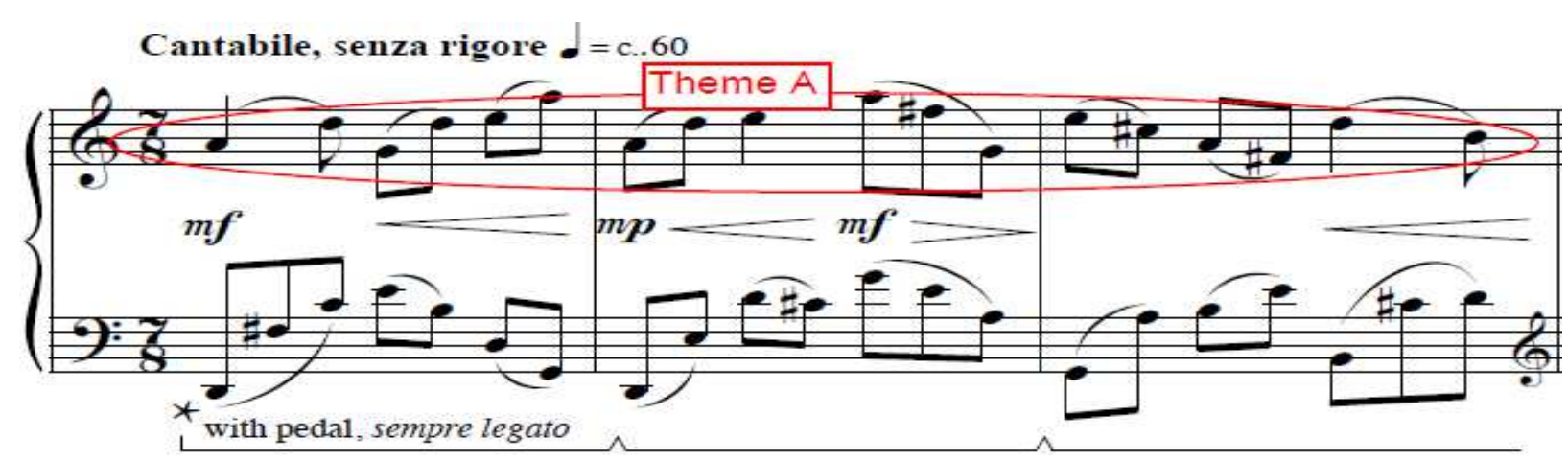

Example 2.1c Prelude No. 2, mm. 1-3

The second section starts with a meter change to 5/8. Duke varies the rhythmic grouping as $2+3$ or $3+2$. This section indicates a little slower. Not only does the tempo change, but the texture becomes thicker moving to three voices and more. The accented inner voice serves as 
Theme B in measure 9 to 10 (Example 2.1d). Like the first section, there are many crescendi and decrescendi. This section also ends on an $\mathrm{A} 7$ half cadence.

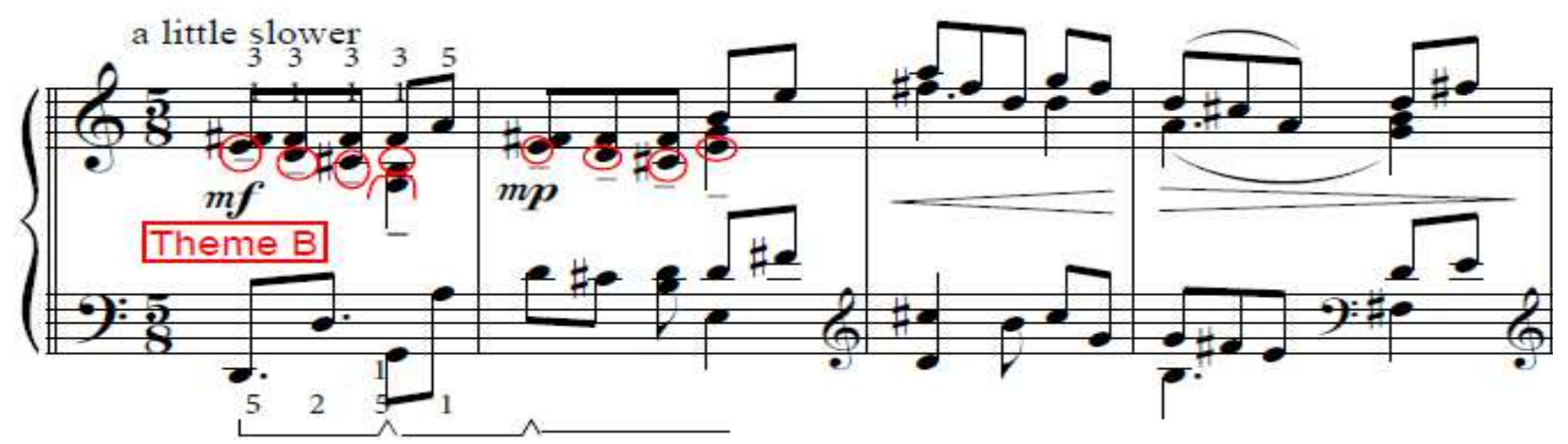

Example 2.1d Prelude No. 2, mm. 9-12

The last section starts with a combination of both Themes A and B in measure 17.

Theme $\mathrm{A}$ is in the upper stave. Theme $\mathrm{B}$ is in the lowest and inner voices marked by tenutos which stress the melody (Example 2.1e). With consistent crescendo markings in each measure, this section builds in intensity. The doubling of Theme A at the octave, the wide spaced chords in the left hand, and the poco allargando sign help this passage reach the dynamic climax (ff) at measure 20. After the climactic build up, the piece gradually dies away. The half cadences presented at the close of the previous two sections finally resolve to a D major tonality at the end.

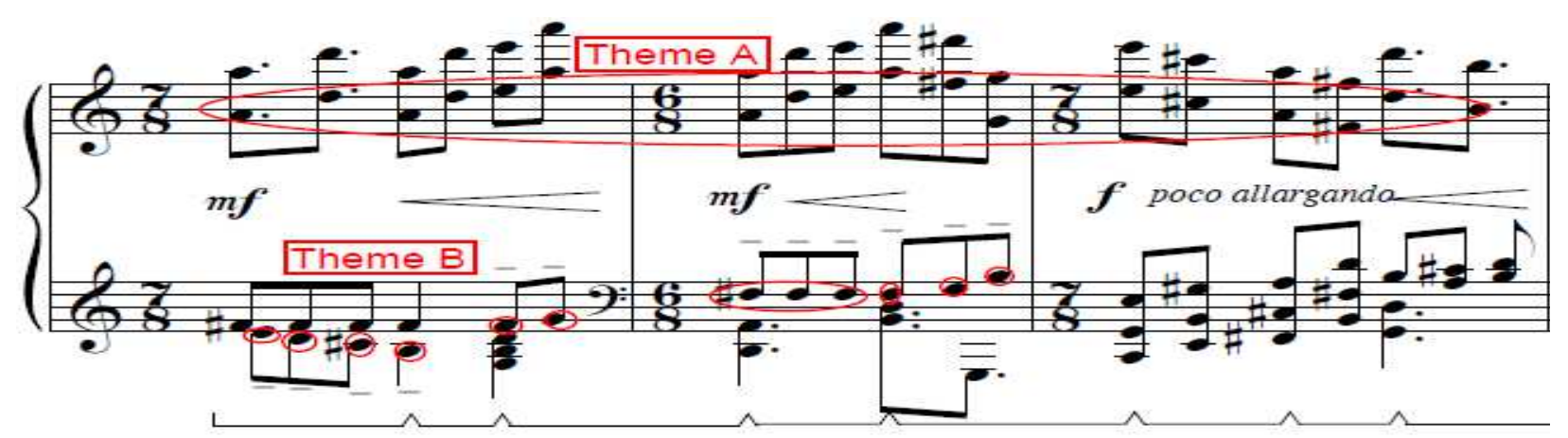

Example 2.1e Prelude No. 2, mm. 17-19

In terms of pedaling, Duke only marks with pedal, sempre legato. In the first section, a wide range of accompaniment figures are presented in the left hand. The author suggests 
changing the pedal at the beginning of each measure (Example 2.1c). For the second section, since the texture is thicker, it is important to decide the most effective pedaling without blurring too much of the phrase. Most of the time, dotted quarter note followed by a quarter note pedal is recommended as the harmonic progression changes (Example 2.1d). The pedaling in the final section is similar to the second section.

The author feels there are three challenges to the performer of primary concern in Prelude No. 2. The first challenge lies in the ability to bring out the inner melody line in measure 9. The performer can pronate to the right hand thumb with the support of the wrist and try the fingering suggestion marked in Example 2.1d. The second challenge involves the big left-hand chords in measure 19 (Example 2.1e). This might be a challenge for people with smaller hands; though not marked to roll the chords, many cannot reach the interval of a tenth. Therefore, rolling the chord is the solution. It is necessary to keep a flexible wrist when rolling the chords. The third challenge is the rhythmic complexity. It can be hard to feel the bigger pulse. Keeping the eighth note steady is the best solution to this issue. In other words, the performer may find it easier to pay attention to the grouping of notes rather than the changing meters, especially because the eighth note remains constant.

\section{Prelude No. 3}

Prelude No. 3 contains three sections. A brief analysis of this piece is presented in the table below:

\begin{tabular}{|c|c|c|}
\hline Section & Measures & Tonal Emphasis \\
\hline \hline I & $1-4$ & $\mathrm{~A}$ \\
\hline II & $5-12$ & $\mathrm{~A}$ \\
\hline III & $13-16$ & $\mathrm{~A}$ \\
\hline
\end{tabular}


Prelude No. 3 is presented in two voices. The clash of semitones between A and G\# occurs every two measures. If the eight pitches in the first two measures are considered together, they might be seen as a serial pitch cell outlining a chromatic scale from $\mathrm{E} b$ to $\mathrm{B} b$. The intervals of seconds seem to be important. The mixtures of minor seconds and augmented seconds together create a unique dissonance (Example 2.1f).

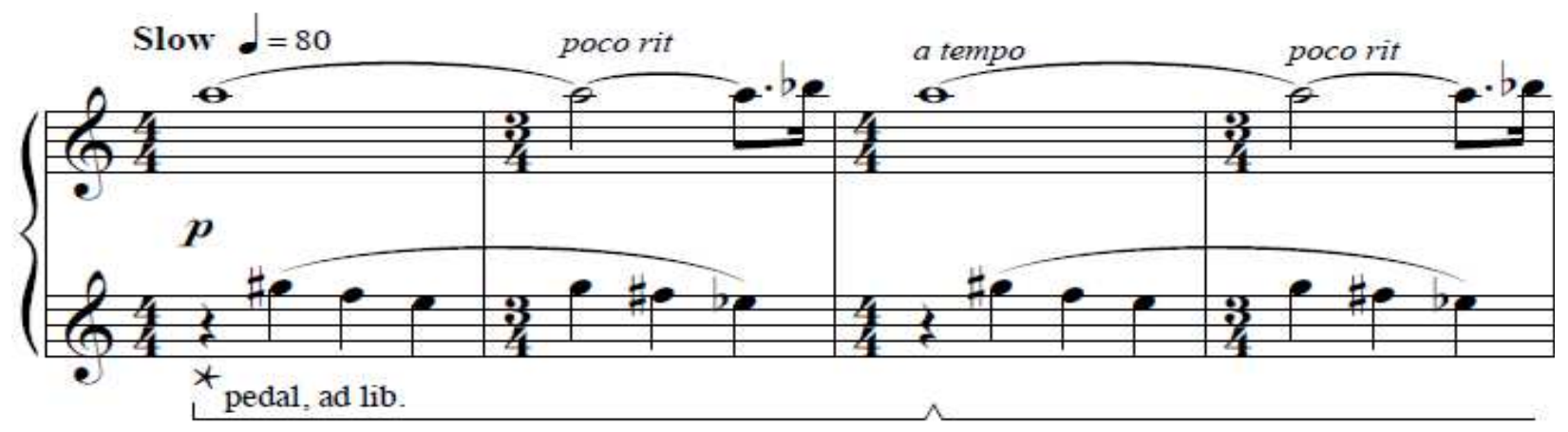

Example 2.1f Prelude No. 3, $\mathrm{mm} .1$-4

The meter changes frequently between $4 / 4$ and $3 / 4$. Instead of counting measure by measure, it is helpful to think in larger units such as $7 / 4$. This way, the musical phrase will be easily heard. In terms of pedaling, Duke only marks pedal, ad lib. The author recommends pedaling every two measures to support the larger unit of $7 / 4$ and give a slightly blurred effect (Example 2.1f). It would be fine to try without pedaling as an alternative solution considering the thin texture.

The author feels there are two challenges to the performer of primary concern in Prelude No. 3. The first challenge deals with the pacing. Though it is a technically simple and short piece, Duke includes very specific tempo markings. It is important to differentiate poco rit vs. rit and poco rit vs. a little slower. In an interview with the composer, he stated that poco rit and rit are more of an end-phrase gesture whereas $A$ little slower (Example 2.1g) means slower than 
the previous two. ${ }^{29}$ The second challenge deals with dynamic. Within sixteen measures, the music presents many different dynamics including: $p, m p, m f, f$, and $f f$. The variety of dynamic contrasts makes it an effective exercise in tone production.

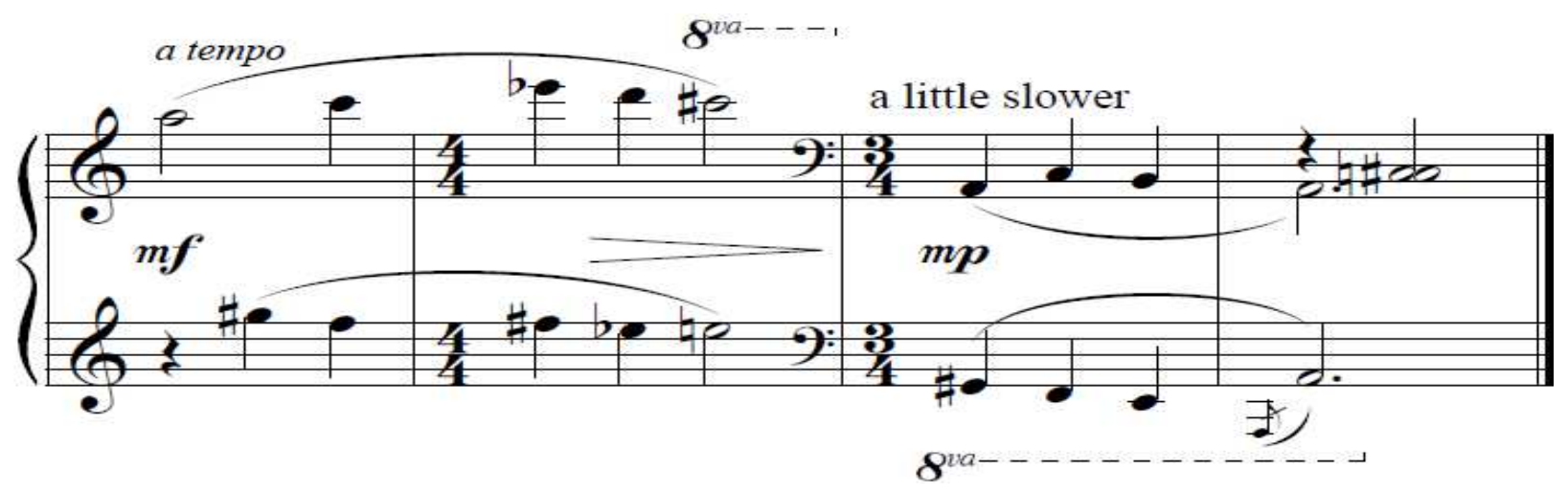

Example 2.1g Prelude No. 3, mm. 13-16

Prelude No. 4

Prelude No. 4 contains three sections. A brief analysis of this piece is presented in the table below:

\begin{tabular}{|c||c||c||}
\hline Section & Measures & Tonal Emphasis \\
\hline \hline I & $1-5$ & B $b$ with F pedal point \\
\hline II & $6-9$ & B $b$ with D pedal point \\
\hline III & $10-14$ & Ambiguous, F \\
\hline
\end{tabular}

The first section starts with a motif in the bass voice that consists of two sixteenth notes and a quarter note. The right-hand melody presents a $\mathrm{B} b$ tonality by outlining the $\mathrm{B} b$ triad. This is accompanied by the hypnotic rhythmic pattern in the left hand that sets up a pedal point on $\mathrm{F}$ (Example 2.1h).

29 David Duke. Interviewed by Wei Chen Lin. Vancouver, December 29, 2014. 


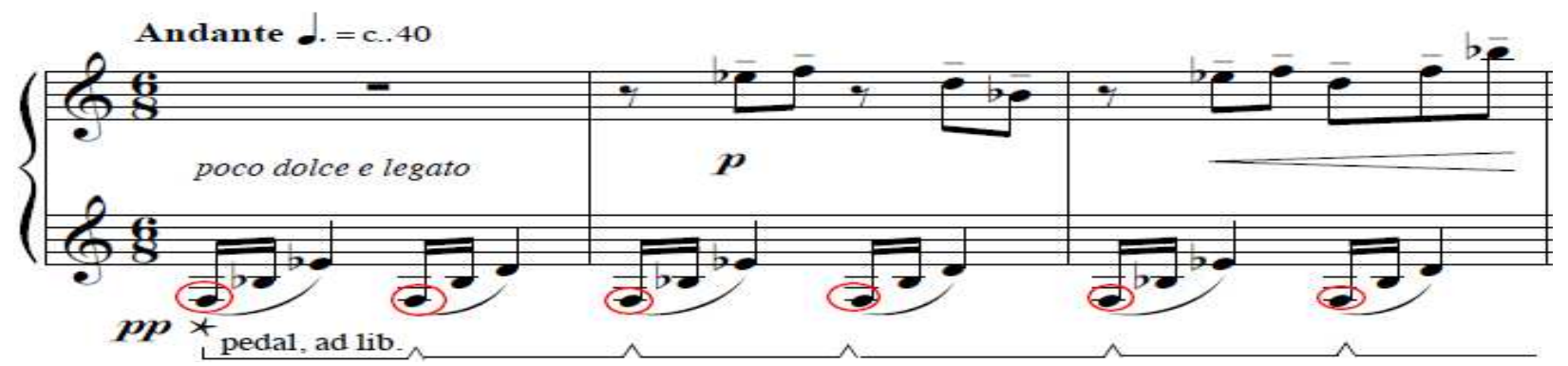

Example 2.1h Prelude No. 4, mm. 1-3

In the second section, the right hand plays the same melody that outlined the $\mathrm{B} b$ triad.

The left hand changes the pedal point to D (Example 2.1i).

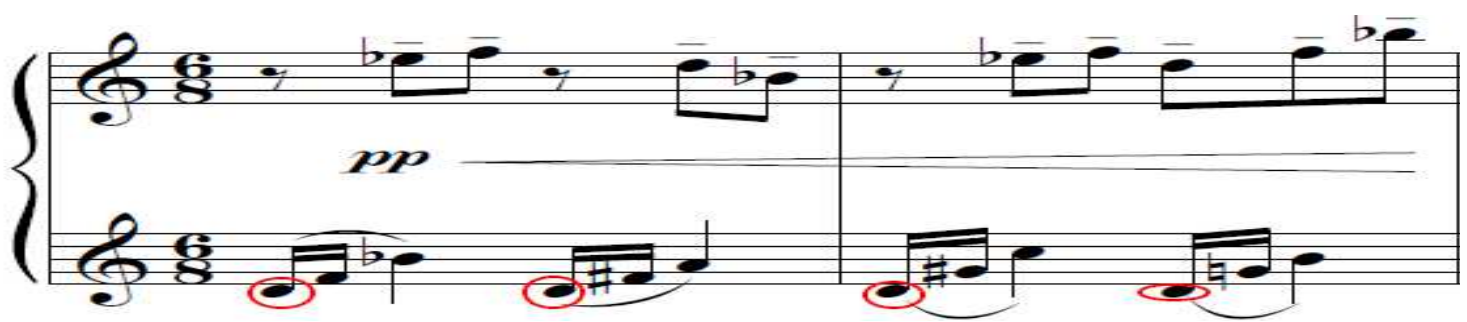

Example 2.1i Prelude No. 4, mm. 6-7

The last section is harmonically unstable because the left hand no longer emphasizes one pedal point. The right-hand melody is ornamented with added seventh and ninth intervals (Example 2.1j), which creates more dissonance.
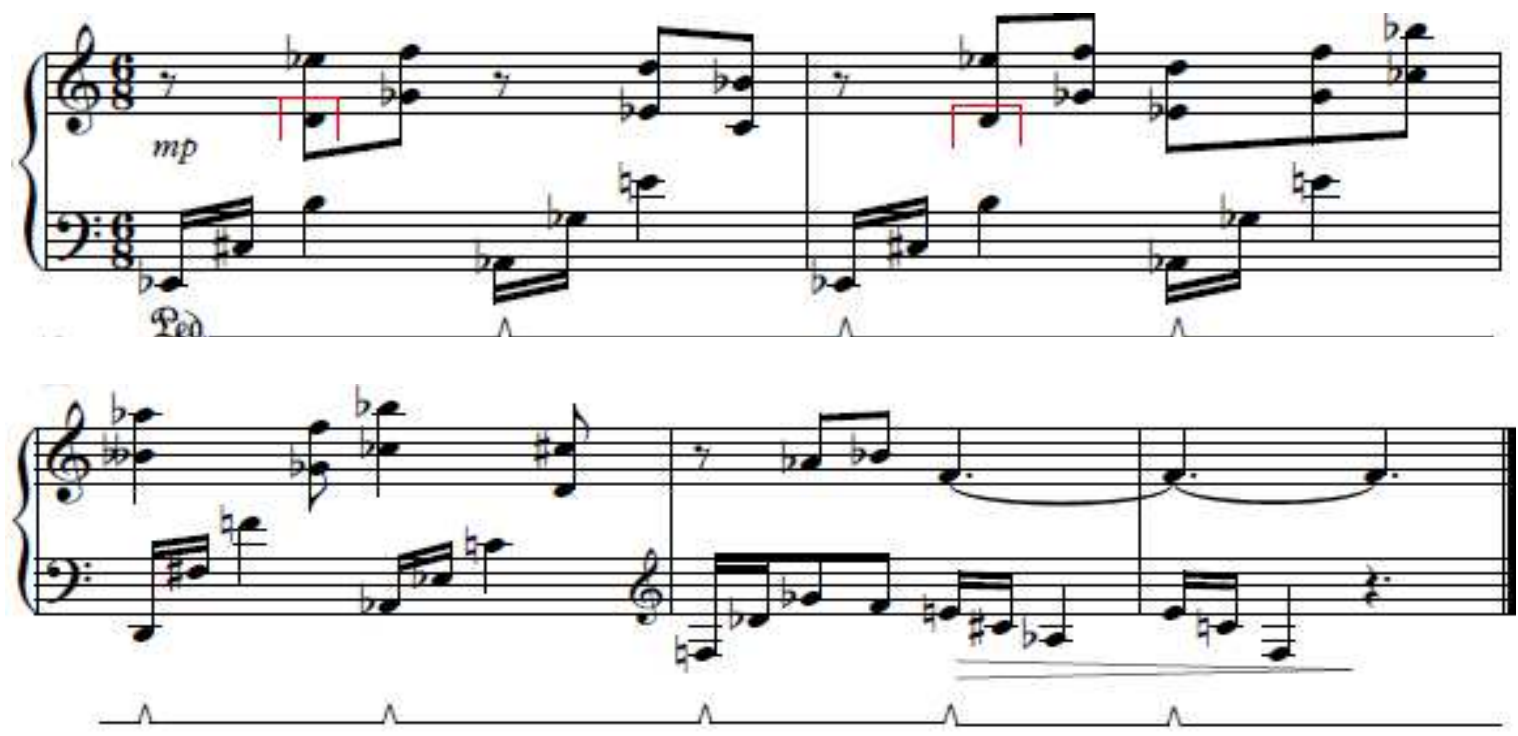

Example 2.1j Prelude No. 4, mm. 10-14 
This piece is an effective study in phrasing. The meter, 6/8, creates two pulses per measure. Each phrase is supported by a crescendo to the middle and decrescendo to the end. In terms of pedaling, Duke only marks pedal, ad lib. It is recommended to pedal on every downbeat and the fourth beat (Example 2.1h). Not only will this maintain the two pulses per measure, but this will also sustain the pedal point.

The author feels there is one challenge to the performer of primary concern in Prelude No. 4. The challenge is the last phrase in which the left hand arpeggiates the wide intervals and the right hand presents sevenths and ninths. If the student's hand is too small, they can consider distributing some of the lower notes of the right hand to the left hand (Example 2.1j). This will aid in projecting the soprano melody. This compositional style is similar to that of Bartók in which he takes a simple melody and harmonizes it in different ways. Each subsequent time, the affect changes.

\section{Prelude No. 5}

Prelude No. 5 contains three sections. A brief analysis of this piece is presented in the table below:

\begin{tabular}{|c||c|c|}
\hline Section & Measures & Tonal Emphasis \\
\hline \hline I & $1-8$ & Ambiguous \\
\hline II & $9-17$ & Ambiguous \\
\hline III & $18-28$ & Ambiguous \\
\hline
\end{tabular}

Each section starts with the same melodic motif (disregarding octave displacements): F\#-

D-E. The melodic motifs that begin each section share the same rhythm: dotted half note followed by a quarter note and a whole note (Example $2.1 \mathrm{k}$ ). 


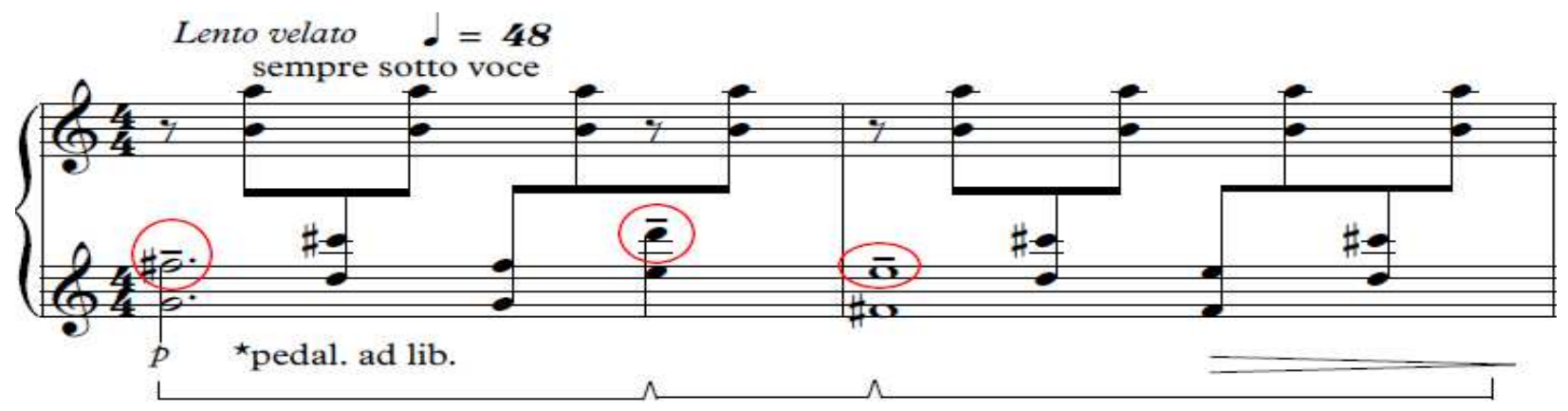

Example 2.1k Prelude No. 5, $\mathrm{mm}$. 1-2

The first section starts with the melody in the left hand thumb. The intervals of seventh are prominent throughout this section. The score specifies sempre sotto voce to differentiate the melody from the accompaniment. One shoud play the tenuto markings on the melodic notes slightly heavier than the accompaniment (Example 2.1k).

The second section starts in measure 9. It begins the same way as the first section; both hands play on alternating eighth notes. The octave register might be different, but the melodic line and rhythmic motifs are the same. A three-measure-long crescendo helps to reach forte at measure 16. In this section, the accompaniment is no longer at the seventh. It includes various interval sizes from seconds to ninths.

The final section starts in measure 18. Unlike the previous two sections where both hands play on alternating eighth notes, here, the left hand plays the melody and the right hand plays a continuous eighth-note accompaniment that contains primarily the intervals of sevenths and ninths (Example. 2.1l).

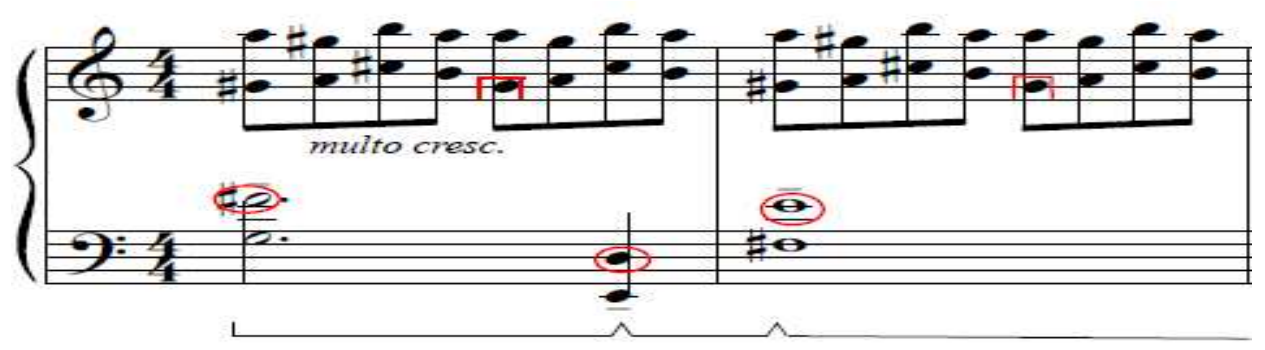

Example 2.1l Prelude No. 5, mm. 18-19 
Although Duke marks pedal, ad lib, the author recommends pedaling according to the melody for clarity (Example 2.1k). Though it can be dissonant when pedaling multiple instances of sevenths, the result is ultimately an expression of timbre rather than harmony.

The author feels there are two challenges to the performer of primary concern in Prelude No. 5. The first challenge lies in the balance between the melodic line and the accompaniment. Since the melody is in the left hand with tenuto markings, the performer can pronate to the left hand thumbs with the support of the wrist and arm weight. Whenever possible, keep the accompaniment veiled as Duke states velato in the beginning. This will help distinguish the melody from the accompaniment. The second challenge deals with large intervals, such as the ninths. This can be difficult for students with smaller hands. With discretion, it is possible to distribute some of the inner notes to the other hand, as long as it does not disrupt the execution of the steady eighth notes (Example 2.1l).

\section{Prelude No. 6}

Prelude No. 6 is the longest of the set. This prelude has no meter indication. Musical ideas are divided by double bar lines; however, the number of beats in each measure is inconsistent. Duke states that the absence of a time signature is for the performer not to lock into a tempo, but keeps the music flowing. ${ }^{30}$ Despite the lack of a time signature, Duke provides a tempo indication, Moderato mistico. The author divides this piece into eight sections demarcated by a three-note descending pattern that appears throughout. A brief analysis of this piece is presented in the table below:

${ }^{30}$ David Duke. Interviewed by Wei Chen Lin. Vancouver, December 29, 2014. 


\begin{tabular}{|c|c|c|}
\hline Section & Measures & Tonal Emphasis \\
\hline Introduction & $1-4$ & \\
\hline I & $5-11$ & \multirow{2}{*}{ Ambiguous } \\
\hline II & $12-16$ & \\
\hline III & $17-23$ & \\
\hline IV & $24-25$ & \\
\hline V & $26-37$ \\
\hline VI & $38-45$ \\
\hline VII & $46-48$ \\
\hline
\end{tabular}

In the introduction, there are two distinctive ideas, $\mathrm{A}$ and $\mathrm{B}$. Idea $\mathrm{A}$ is characterized by descending motion, while idea B is characterized by ascending motion (Example 2.1m).

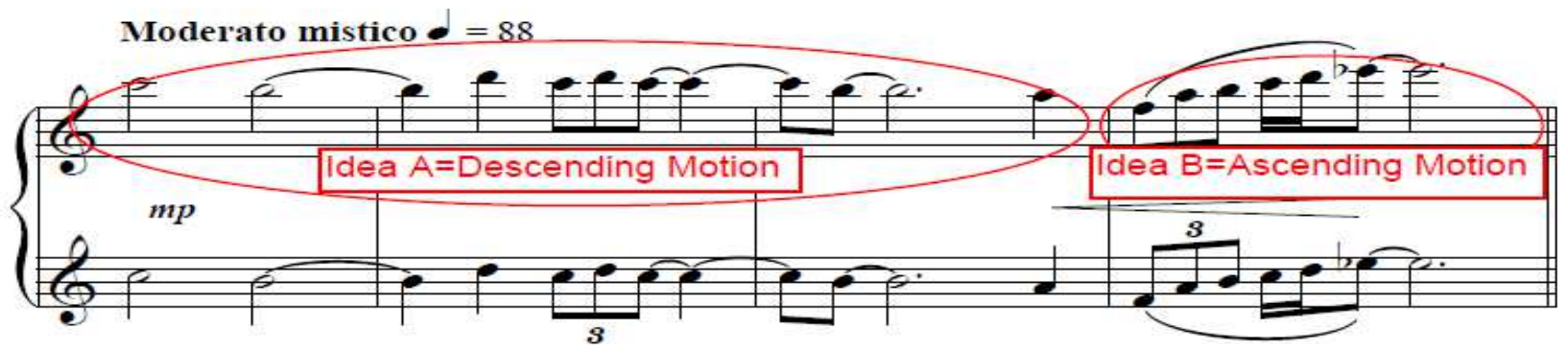

Example 2.1m Prelude No. 6, $\mathrm{mm} .1-4$

After the introduction, the following seven sections all start with the idea A which is reduced to three descending notes. These three notes have slur marking that indicates the pitches are to continue resonating after their attack like bell-tones. The length of time between each half note should be somewhat equal. The score specifies that the performer is to keep the pedal depressed for the three bell-tones. From measures 6 to 11, upward motion of idea B alternates between hands for a total of four iterations. At the measure 10, idea $\mathrm{A}$ is presented in the right hand in a momentary elision (Example 2.1n). 


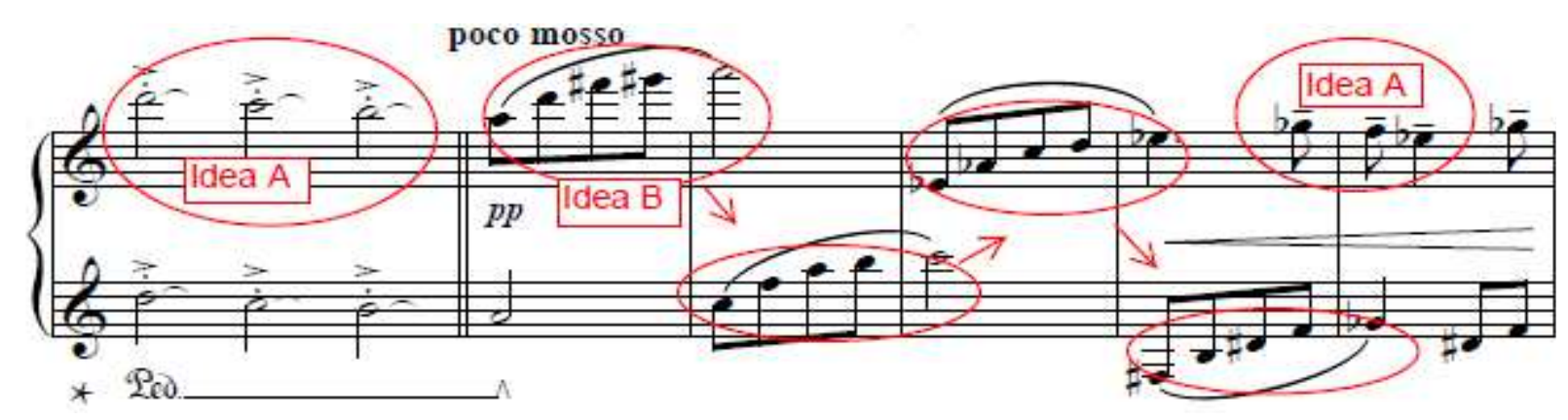

Example 2.1n Prelude No. 6, $\mathrm{mm} .5-10$

The second and third sections follow the same pattern as the first section. It starts with idea $\mathrm{A}$ and concludes with idea $\mathrm{B}$. The fourth section starts with idea $\mathrm{A}$ at measure 24 . In measure 25, idea $\mathrm{B}$ is introduced as the $\mathrm{B}$ b overtone series (Example 2.1o). This passage should be played freely, and the sound should not decay entirely before the next pitch is sounded. Duke claimed that the inspiration comes from Rameau's unmeasured work. ${ }^{31}$

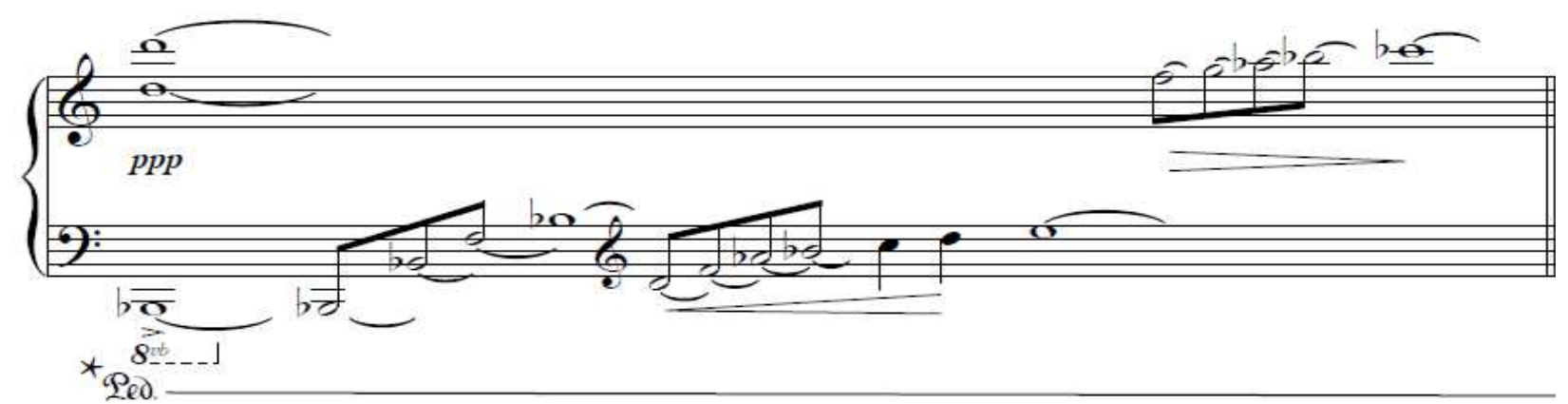

Example 2.1o Prelude No. 6, m.25

After the overtone series, the fifth section starts with idea A in measure 26, while idea B continues in measure 27 . It starts with both hands separated by a distance of six octaves and continues with eight iterations of idea B. At measure 34, idea A in the right hand joins the idea $\mathrm{B}$, which continues with a long crescendo until it reaches a dynamic of ff.

${ }^{31}$ David Duke. Interviewed by Wei Chen Lin. Vancouver, December 29, 2014. 
The sixth section starts in measure 38 , where the three bell-tone gesture returns. While the right hand presents the idea $\mathrm{A}$, the left hand presents idea $\mathrm{B}$. This marks the loudest point of the piece at a dynamic of fff. Immediately after, Duke adds another free measure to allow the sound of the bell-tones to decay (Example 2.1p).

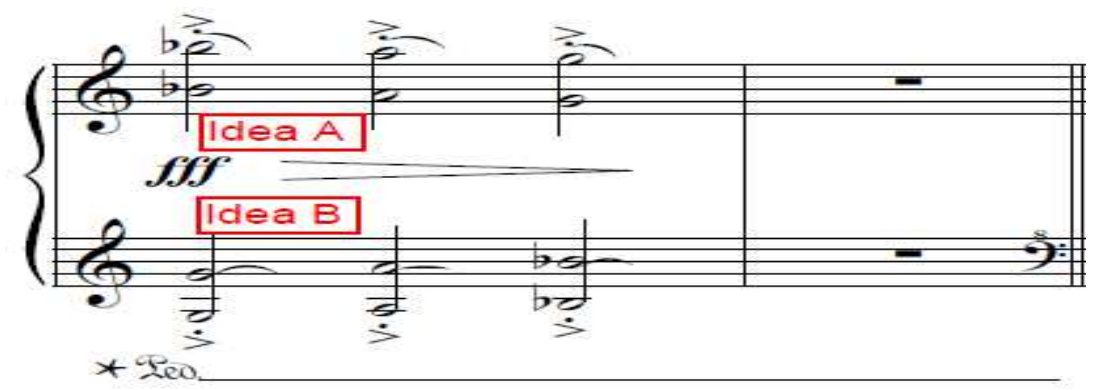

Example 2.1p Prelude No. 6, $\mathrm{mm}$. 38-39

The final section starts with idea A that is presented at a ppp dynamic in measure 46.

Misled by the free measure, the listener may assume it is finished. Only with the statement of the last single note, an A, can the performer finally rest (Example 2.1q).

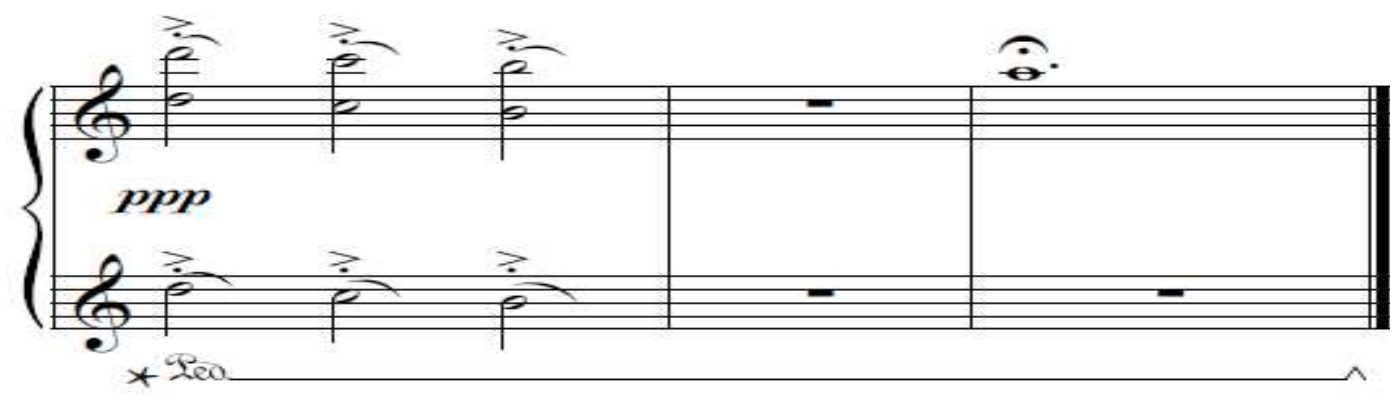

Example 2.1q Prelude No. 6, $\mathrm{mm} .46-48$

In terms of pedaling, Duke indicates consistently for the three bell-tones (Examples 2.1n, $p, q)$. Another place is measure 25 where the $\mathrm{B} b$ overtone series is introduced. He intends for this passage to be mysterious; to achieve this, the score denotes a sudden change in dynamic from $m f$ to $p p p$ (Example 2.1o). Here the author suggests using una corda (soft pedal) along with the damper pedal. This will help to produce a thinner timbre. The una corda pedal in this 
case is not only used as a coloring device, but also to create contrasting moods from ideas A and B. A performer can explore different pedal techniques to play with the timbre.

The author feels there are two challenges to the performer of primary concern in Prelude No. 6. The first challenge is the control of tone in delicate passages. One can explore playing with different parts of the finger to create different color. The second challenge is the tempo and pacing. Duke only states moderato mistico, the performer should feel the phrase line rather than counting beat by beat. Careful use of rubato will enhance the flow of the music. Even though the notes are not difficult from a technical perspective, the expressive interpretation requires intense concentration.

\section{Prelude No. 7}

Prelude No. 7 contains three (ABA) sections. A brief analysis of this piece is presented in the table below:

\begin{tabular}{|c|c|c|}
\hline Section & Measures & Tonal Emphasis \\
\hline $\mathrm{I}(\mathrm{A})$ & $1-8$ & $\mathrm{E}$ \\
\hline II (B) & $9-19$ & $\mathrm{C}, \mathrm{F} \#, \mathrm{~A} b, \mathrm{~F}, \mathrm{~B}$ \\
\hline III (A) & $20-27$ & $\mathrm{E}$ \\
\hline
\end{tabular}

The first section begins with a descending pentachord motif. This section goes though meter changes in this order: $5 / 8,4 / 8,3 / 8,5 / 8$, and $7 / 8$. Though the score denotes a tempo suggestion of quarter note $=104$, it is recommended that the performer keeps the eighth-note

pulse internally as a metric reference. This method is easier as not all the odd numbered meters $(3 / 8,5 / 8,7 / 8)$ can be subdivided evenly into quarter notes (Example $2.1 r)$. 


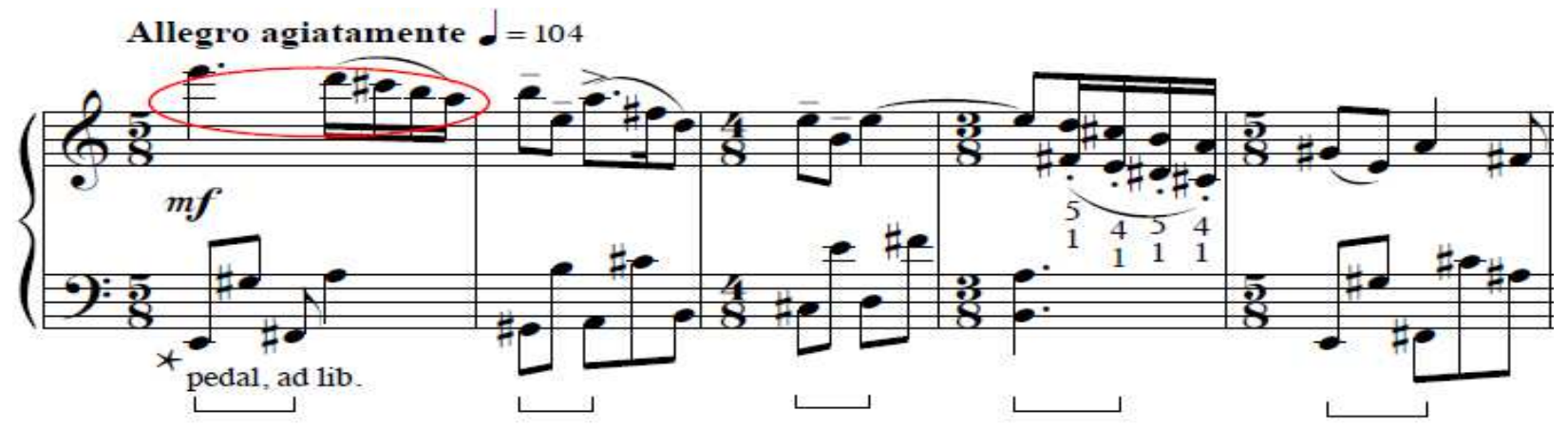

Example 2.1r Prelude No. 7, mm. 1-5

The second section begins in measure 9 . Metrically, this section stays in $6 / 8$ without any changes. The right hand presents continuous eighth notes and is grouped into two pulses per measure. The left hand presents syncopated rhythms against the right hand. According to the dynamic markings, the left hand is the melody and the right hand is the accompaniment (Example 2.1s). Harmonically, the tonal emphasis changes every two measures progressing from: $\mathrm{C}$ major, $\mathrm{F} \#$ major, $\mathrm{C}$ major, $\mathrm{A} b$ major, $\mathrm{F}$ major, and $\mathrm{B}$ major.

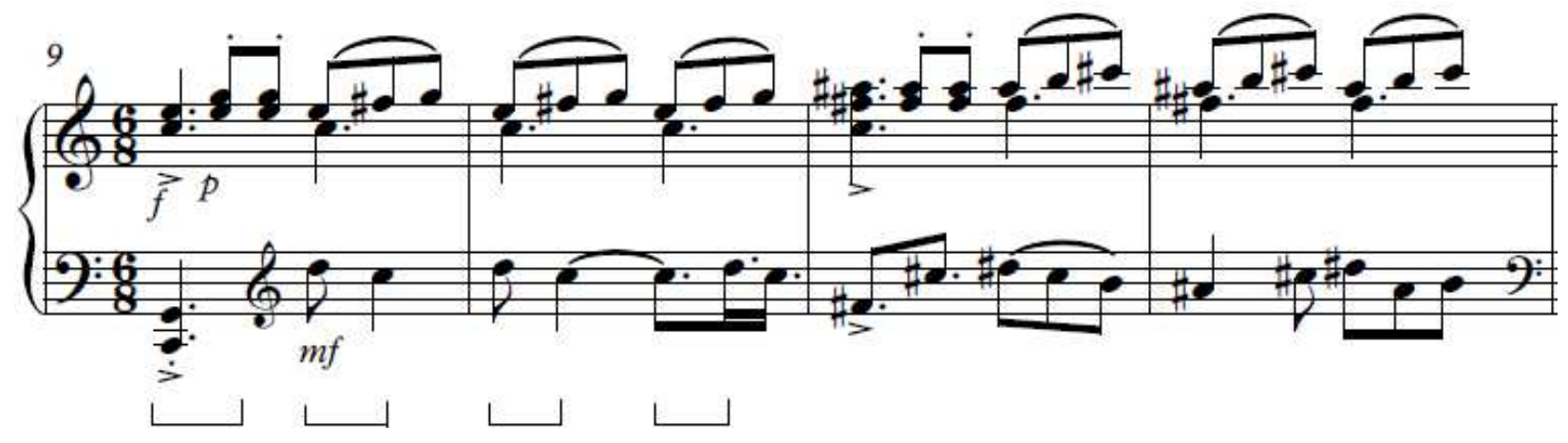

Example 2.1s Prelude No. 7, mm. 9-12

The final section begins with the descending pentachord motif in the left hand in measure 20. This is similar to the first section except the motif is doubled in octave (Example 2.1t). As this section has more complex rhythms, such as four against three, it is wise to keep the righthand eighth note steady. 


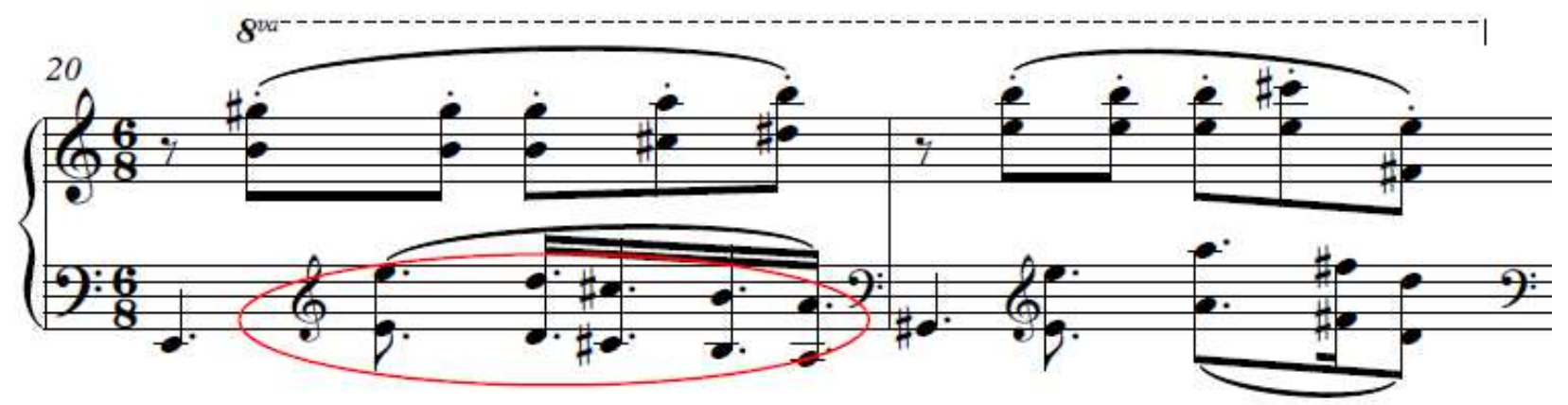

Example 2.1t Prelude No. 7, mm. 20-21

In terms of pedaling, Duke only marks pedal, ad lib. In the first section, since the meter changes frequently, the author recommends pedaling on beat one and releasing on beat three (Example 2.1r). In the second section, a waltz character is shown in 6/8 meter. The author suggests pedaling on beats one and four but releasing on beats two and five (Example 2.1s).

The author feels there are two challenges to the performer of primary concern in Prelude No. 7. The score indicates allegro agiatamente with quarter note $=104$. If the performer keeps the eighth note as 208 , it is indeed fast. Therefore, the first challenge presented by this piece is to practice duplets against triplets and triplets against quadruplets fluently to avoid rhythmic inconsistencies. Using the exercise below by tapping the rhythms without pitches will help the player master this skill (Example 2.1u). For two against three, the common denominator is six; by counting six, one can see where each beat falls. For three against four, the common denominator is 12 ; by counting twelve, one can see where each beat falls. Slow practice is highly recommended. The second challenge is the parallels sixths in measure 4 . The portato should be moderately detached. The performer can try the fingering suggested in the Example 2.1r. It requires the thumb to move consecutively four times, but keeping it light and gliding through the keys will help. 

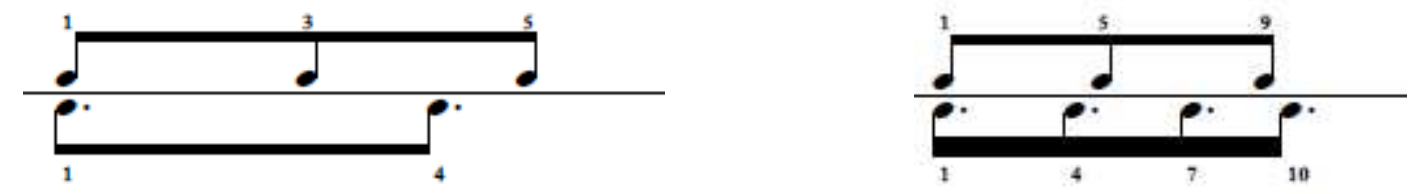

Example 2.1u Prelude No. 7

\section{$\underline{2.2 \text { Postcards }}$}

Postcards were written during Duke's travels to Europe and the United States in the 1980s. There are six in total. Each postcard is dedicated to someone important in his life. In each piece, Duke annotated his greetings by writing a paragraph about the place or a scene he observed. A postcard is intended to consolidate the essence of a place in a single $3 \mathrm{X} 5$ visual snap shot. Each piece concludes with the title, an approach similar to the titling of Debussy's Preludes. Duke intends to have the performer experience each individual sound world with fresh ears, without the prescriptive influences by the titles. ${ }^{32}$ Each one is like a character piece, showing a variety of compositional techniques. Quotations of familiar melodies are common in many of these works.

Duke goes beyond traditional harmony, synthesizing it with the twentieth century contemporary technique to create new sound palettes. All of them are written without key signatures. However, that does not mean there is no tonal emphasis.

In terms of meter, Numbers 1 and 4 are metrical pieces. Numbers 2 and 3 have dotted bar lines that show smaller divisions within the pieces; however, not all the bars are metrically equal. Numbers 5 and 6 contain no bar lines.

\footnotetext{
${ }^{32}$ David Duke. Interviews by Wei Chen Lin. Vancouver, December 29, 2014.
} 


\section{Postcard No. 1}

No. 1 is about the Places des la Bastille in Paris. It consists of two sections. A brief analysis of this piece is presented in the table below:

\begin{tabular}{|c||c|c|}
\hline Section & Measures & Tonal Emphasis \\
\hline \hline I & $1-6$ & $\mathrm{D}$ \\
\hline II & $7-13$ & $\mathrm{D}$ \\
\hline
\end{tabular}

The score indicates a tempo of slow: clear and calm; this is to be played peacefully without agitation. In the first section, the presentation of a minor ninth introduces the ear to dissonance in measure 1. Duke wants the notes to sustain and vibrate by indicating slur lines after the whole notes. This is supported by the pedal marking indicated by the composer in the score. Even though the right hand sustains with long whole notes, the left hand should be treated as a melodic line despite the large disjunct leap (Example 2.2a). In the second section, the melody switches to the right hand in measure 7. This is supported by a crescendo that leads to $m f$, which is the loudest point of the piece. In this postcard, there are several crescendi and decrescendi hairpin markings, but nothing higher in volume than $m f$.

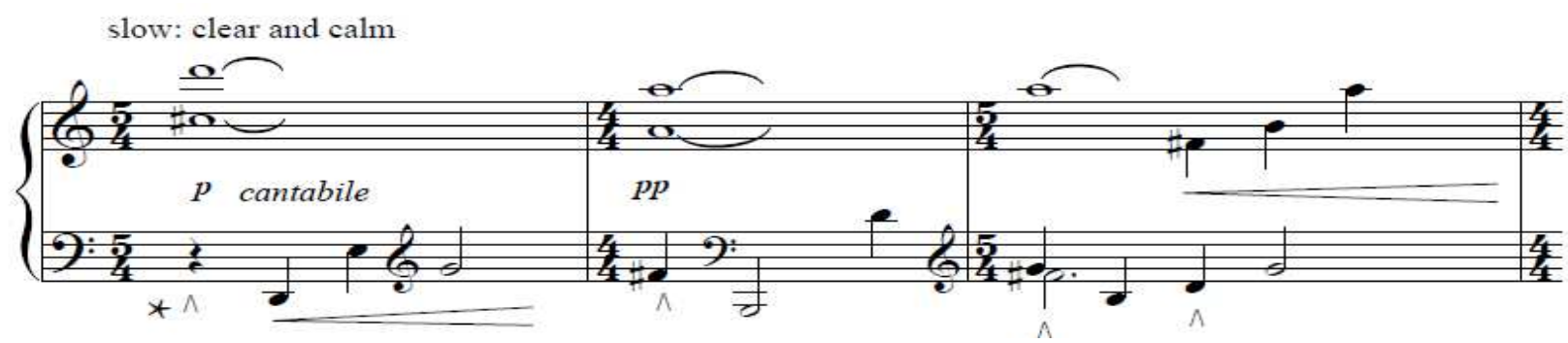

Example 2.2a Postcard No. 1, mm. 1-3

The right hand in the last system presents a melodic fragment from the French national anthem, La Marseillaise (Example 2.2b). 


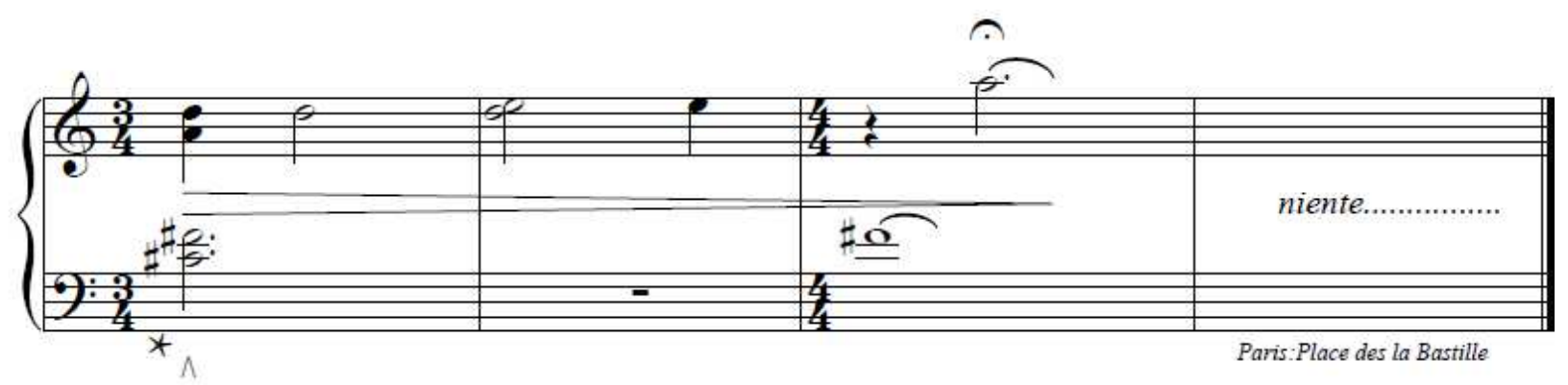

Example 2.2b Postcard No. 1, mm. 10-13

The author feels there are two challenges to the performer of primary concern in Postcard No. 1. The first challenge is to evoke the appropriate mood. Performers should experiment with different touches. Slowing down the pressure on the keys will control the speed and attack of the hammer which will provide a subdued color. The second challenge deals with the meters that change frequently between $5 / 4,4 / 4$, and $3 / 4$. It is recommended to keep the quarter note steady.

\section{Postcard No. 2}

No. 2 is about a winter night in Rye, Sussex. There is no meter indication. The dotted bar lines and commas serve as indications for each smaller division or musical thought. The author divides this piece into three sections for two specific reasons. First, each section starts with a low Eb pedal note. Second, Duke indicates a new pedal marking at the onset of those $\mathrm{E} b$ notes. A brief analysis of this piece is presented in the table below:

\begin{tabular}{|c||c|c|}
\hline Section & Measures & Tonal Emphasis \\
\hline \hline I & $1-3$ & $\mathrm{E} b$ \\
\hline II & 4 & $\mathrm{E} b$ \\
\hline III & $5-7$ & $\mathrm{E} b$ \\
\hline
\end{tabular}

As Duke states in the annotation for No. 2, "After a surprisingly good dinner, we went for a walk: cold but so clear you could see the lights of France off in the distance and cold, bright stars." The musical imagery is the star that twinkles from far away, like each note that rings and 
vibrates. There is an embedded nursery rhyme, Ah! Vous Dirais-Je Maman, known as Twinkle, Twinkle, Little Star in English (Example 2.2c). Duke admits his fascination with the bells as he was growing up. In his home, the clock struck the Westminster chime every fifteen minutes. The character of bell-like sounds in his compositions is inspired by this experience. ${ }^{33}$ The tonal emphasis is on $\mathrm{E}$, the same key as the embedded nursery rhyme.

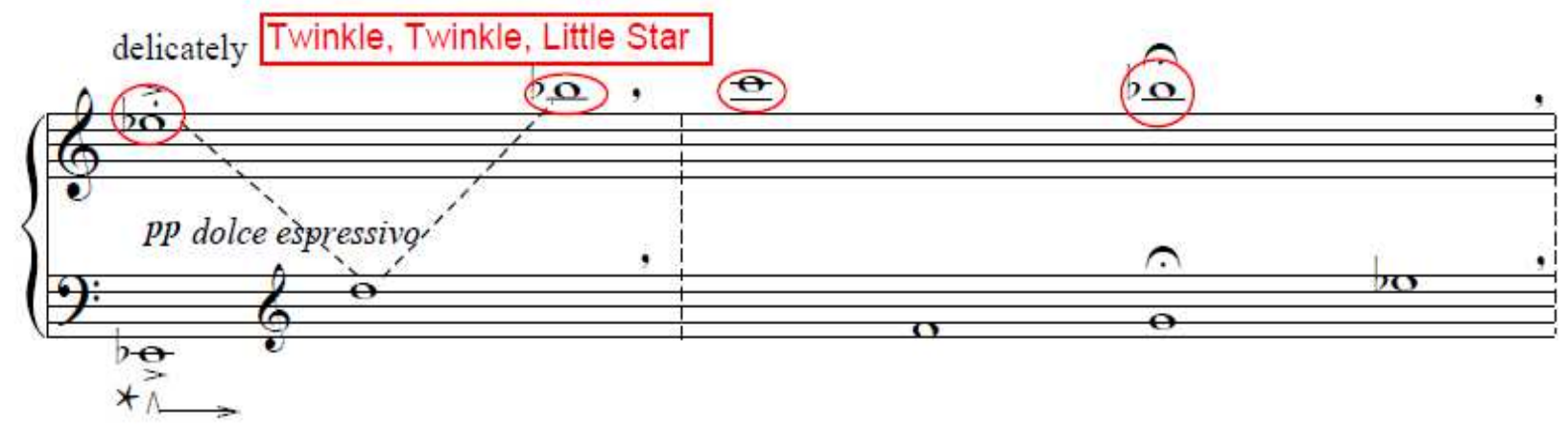

Example 2.2c Postcards No. 2, mm. 1-2

In terms of pedaling, Duke indicates three places to press down the pedal; however, he does not show where to release. Assuming each pedal is supposed to be depressed until the next indication, the author suggests shallow pedaling so the resonance does not accumulate to disrupt the mood of this piece.

The author feels there are two challenges to the performer of primary concern in Postcard No. 2. The first challenge is for the performer to evoke the right affect. Duke specifically marks delicately, dolce expressivo. Whole notes are used extensively throughout this piece, sometimes labeled with fermati. It is important to distinguish the whole notes with fermati from the regular whole notes. The performer must listen constantly to the decay of one note and blend into the beginning of the next note. The second challenge is to create three different dynamics in three

\footnotetext{
${ }^{33}$ David Duke. Interviewed by Wei Chen Lin. Vancouver, December 29, 2014.
} 
consecutive whole notes (Example 2.2d). The performer should keep the arm very loose and sink into the key with very light energy.

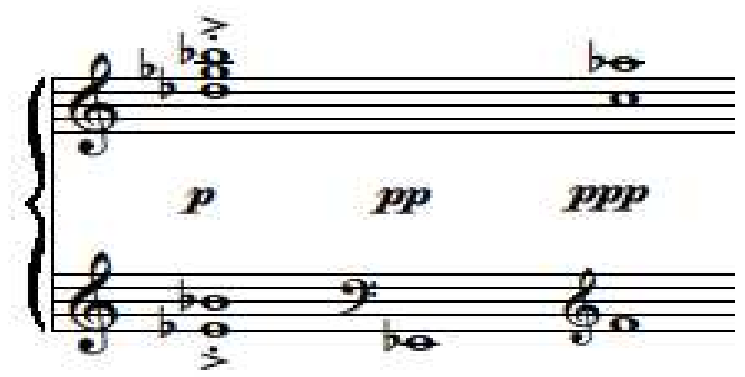

Example 2.2d Postcards, No. 2, m. 4

Postcard No. 3

No. 3 is about the Place des Vosges in Paris. There is no key signature, but it begins and ends on $\mathrm{B} b$ with an added perfect fifth (F). Additionally, there is no meter indication. Phrases or musical thoughts are divided by dotted bar lines; however, the number of beats in each measure is inconsistent. The author divides this piece into four sections based on the tonal emphasis. A brief analysis of this piece is presented in the table below:

\begin{tabular}{|c|c|c|}
\hline Section & Measures & Tonal Emphasis \\
\hline \hline I & $1-2$ & $\mathrm{~B} b$ \\
\hline II & $3-5$ & $\mathrm{D} b$ \\
\hline III & $6-7$ & Ambiguous \\
\hline IV & $8-9$ & $\mathrm{E} b, \mathrm{~B} b$ \\
\hline
\end{tabular}

Duke marks with energy in the beginning. The piece begins with a ff chord. After the initial fermata, the eighth notes spin through the first system ceaselessly until they arrive at the second fermata. The right-hand melody is from the French nursery rhyme, Le Carillon de Vendôme, a children's song that is often sung in a round. Elements of imitation are presented in 
which the left hand imitates the right hand an octave below. It does not last long as the chain breaks in measure 2 (Example 2.2e).

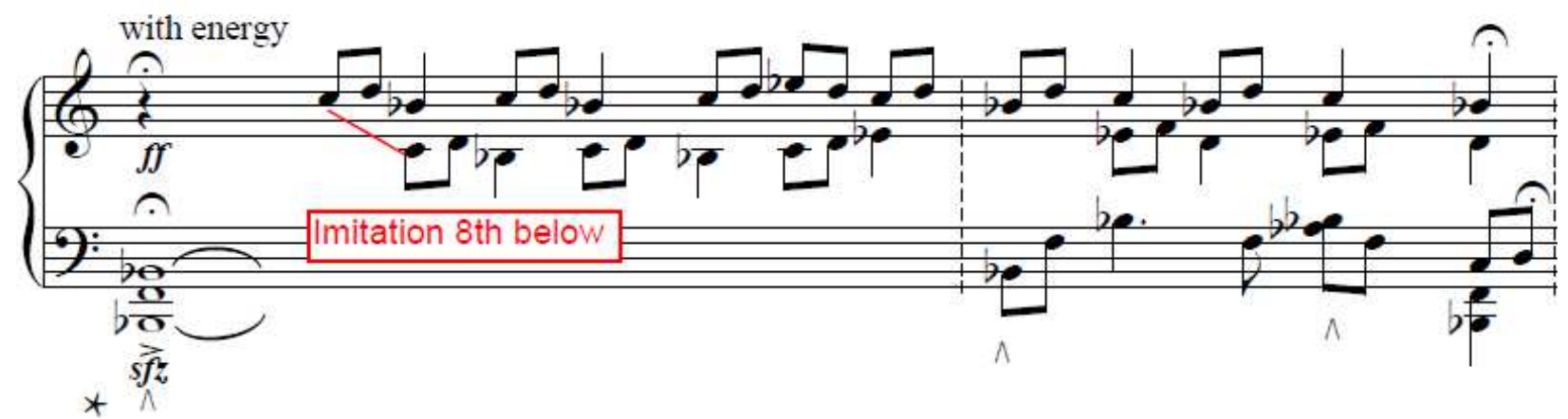

Example 2.2e Postcards No. 3, mm. 1-2

In the second system, the right-hand theme is transposed up a minor third in comparison to the beginning. The continuous eighth notes are interrupted by a fermata in measures 6 and 7 . In measure 8 , a series of sevenths appear marked by an accent. It is an augmented version of the primary theme and is transposed up a fifth. The piece ends with the tail of the primary theme starting in the left hand and imitated a fifth above by the right hand (Example 2.2f).

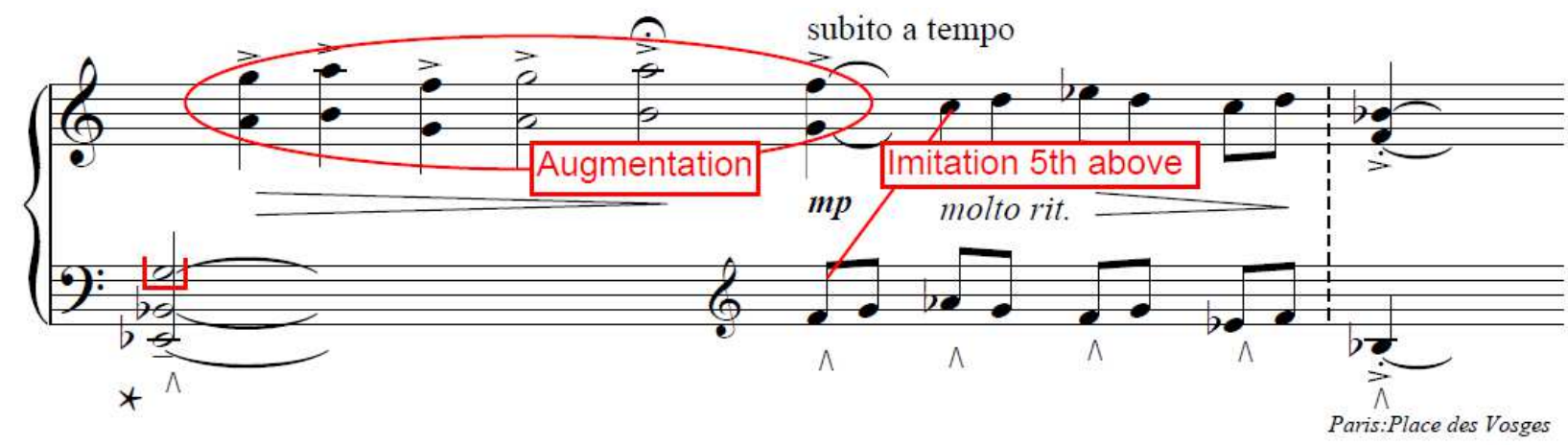

Example 2.2f Postcards No. 3, mm. 8-9

In terms of pedaling, the author feels that the composer has thoroughly marked the places where to change the pedal. By following it carefully, the performer will find the authenticity the composer intended.

The author feels there are three challenges to the performer of primary concern in Postcards No. 3. The first challenge lies in the contrapuntal techniques of the round. 
Independence between hands is required. Performers should master each hand separately before putting both hands together. The second challenge is the tempo and pacing. Duke does not indicate any tempo markings except three rit. signs as well as four fermati. Thinking of the rit. as an end-phrase gesture will help the performer avoid dragging. A typical tempo for this folk song is moderato, the author suggests a metronome marking of quarter note $=80-100$. The last challenge deals with the left-hand chords expanding over an octave. Redistributing one note to the right hand when possible or rolling the chord is recommended (Example 2.2f).

\section{Postcard No. 4}

No. 4 is about the Victoria and Albert Museum in South Kensington, England. A brief analysis of this piece is presented in the table below:

\begin{tabular}{|c||c|c|}
\hline Section & Measures & Tonal Emphasis \\
\hline \hline I & $1-3$ & $\mathrm{D}$ \\
\hline II & $4-7$ & $\mathrm{C}, \mathrm{B}$ \\
\hline III & $8-16$ & $\mathrm{E}, \mathrm{B}$ \\
\hline IV & $17-20$ & $\mathrm{~B}$ \\
\hline
\end{tabular}

The piece opens with a 6/8 time signature. There are two pulses per measure. The right hand presents eighth notes without the occurrence of a note on the strong beat, while the left hand applies the duplet rhythm, denoted here by dotted eighth notes. The tempo indication is gently flowing at the beginning (Example 2.2g).

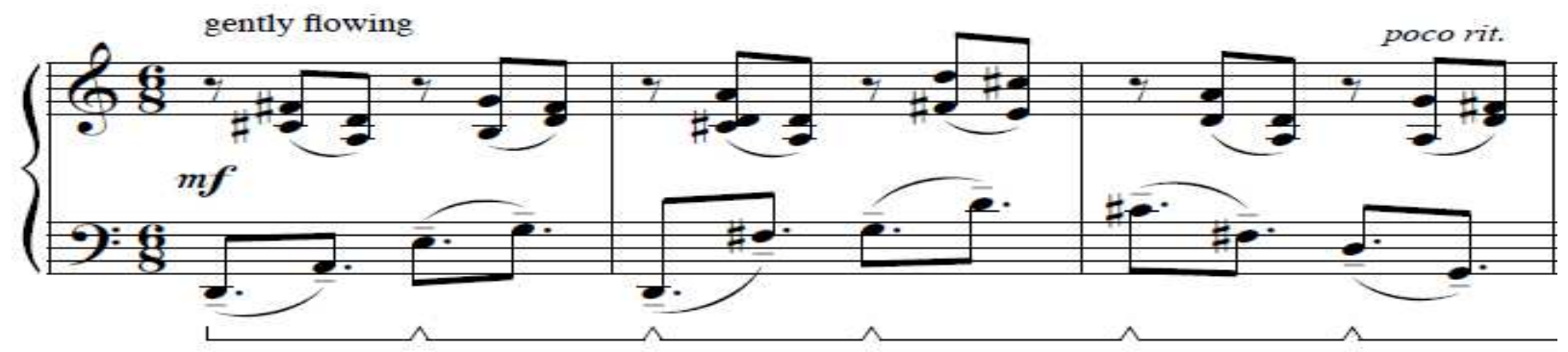


From measures 4-8, each bar contains a crescendo sign. Even though the dynamic is reduced to $p$ at measure 6 , it builds to $f f$ over the course of the next two measures. The righthand melody is taken from Elgar's Enigma Variation (Example 2.2h).

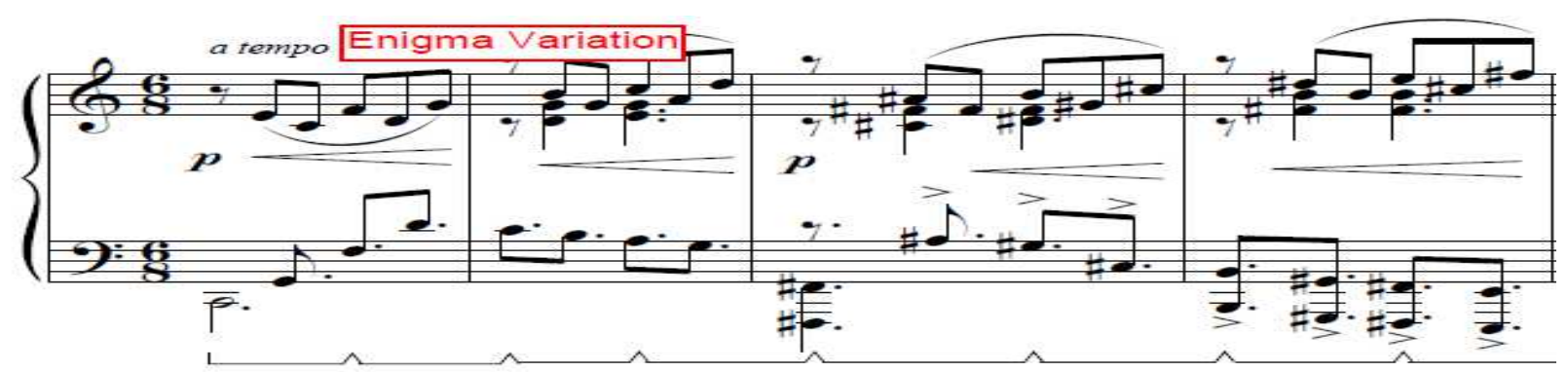

Example 2.2h Postcards No. 4, mm. 4-7

From measures 8-11, the duplets and triplets switch hands until the fermata. Even though this build-up is accompanied by a crescendo sign, the fermata occurs simultaneously with the dynamic marking subito $p p$. This sudden decrease of dynamic requires a slight hesitation before placing the chord. It will make the $p p$ more effective. While the right hand plays the Enigma variation theme, the Westminster chime melody is presented in the left hand (Example 2.2i). This again demonstrates the composer's fascination with bells.

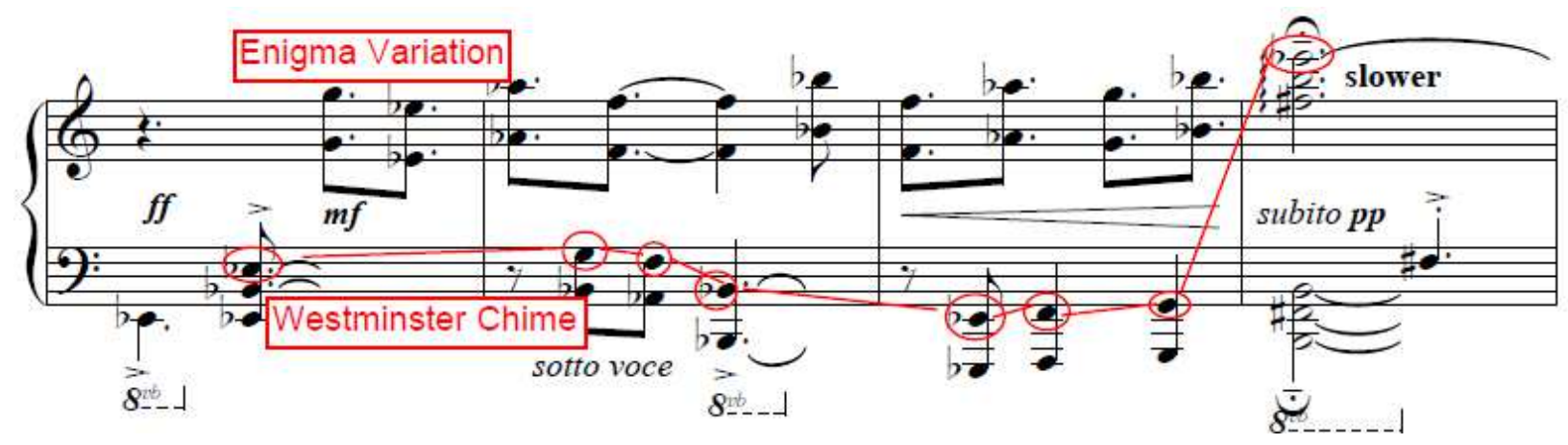

Example 2.2i Postcards No. 4, mm. 8-11 
From measures 12-16, triplets are no longer present, as both hands play duplets. It is notable to see duplets dominating for such long time as the piece is still in a compound duple meter of $6 / 8$ (Example $2.2 j$ ).

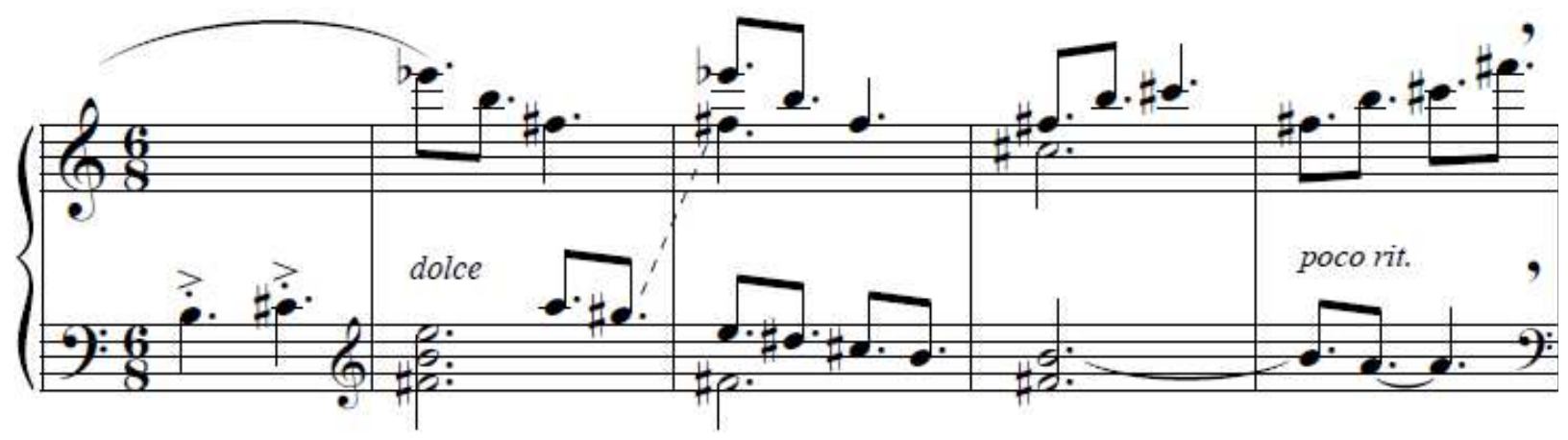

Example 2.2j Postcards No. 4, mm. 12-16

From measures $17-20$, the time signature changes to $3 / 4$. What seems to be awkward duplets in $6 / 8$ time has now become the norm in $3 / 4$. Before the meter changes, there is a breath mark, to prepare the next section: nobilimente (Example 2.2k). The piece ends with Elgar's Enigma Variation melody in the right hand.

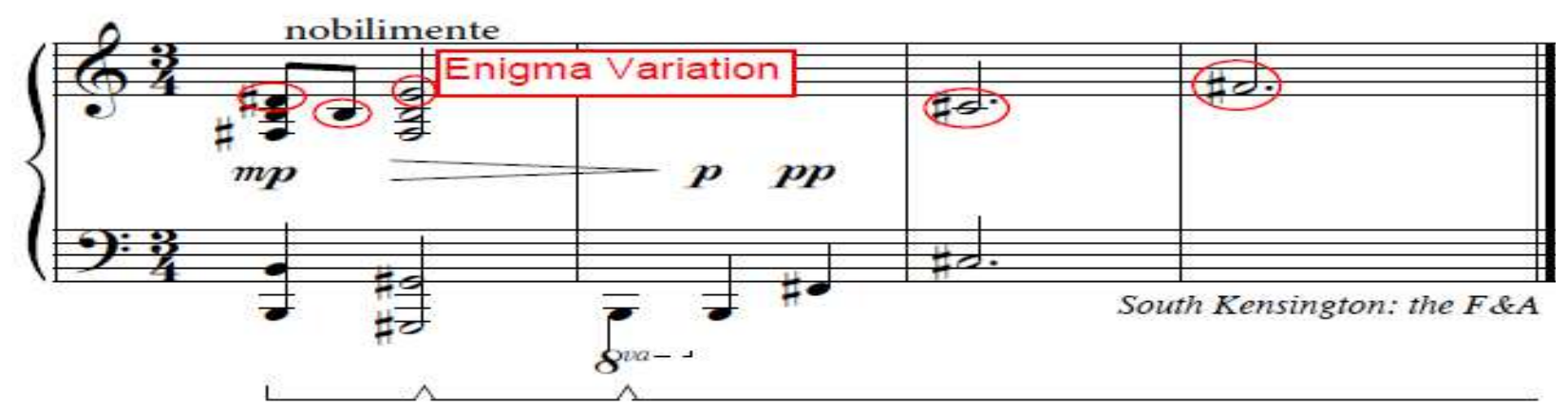

Example 2.2k Postcards No. 4, mm. 17-20

In terms of pedaling, Duke does not provide any indication. The author recommends pedaling on every downbeat and the fourth beat in $6 / 8$. This will maintain two pulses per measure. As in 3/4 time, a pedal suggestion is provided in Example 2.2k. Duke indicates gently 
flowing at the beginning but he does not provide a metronome marking. The author suggests dotted quarter note $=60-69$, which creates a nice, flowing quality.

The author feels there is one challenge to the performer of primary concern in Postcards No. 4. The challenge is the three against two rhythms that needs to be worked out smoothly. The performer should feel two pulses per measure regardless of which hand plays duplets or triplets. It is recommended that the performer tap out the rhythm with their hands first. The performer must practice simultaneously tapping the right-hand triplets and the left-hand duplets. Count verbally 1, 2, \& 3 while tapping the rhythm (Example $2.2 l$ on the left). Once this feels comfortable, the performer should then remove the downbeat from the right hand (Example 2.2l on the right). They will still be able to count $1,2, \& 3$ simultaneously. Once this is mastered, switch the duple and triple roles with the hands.
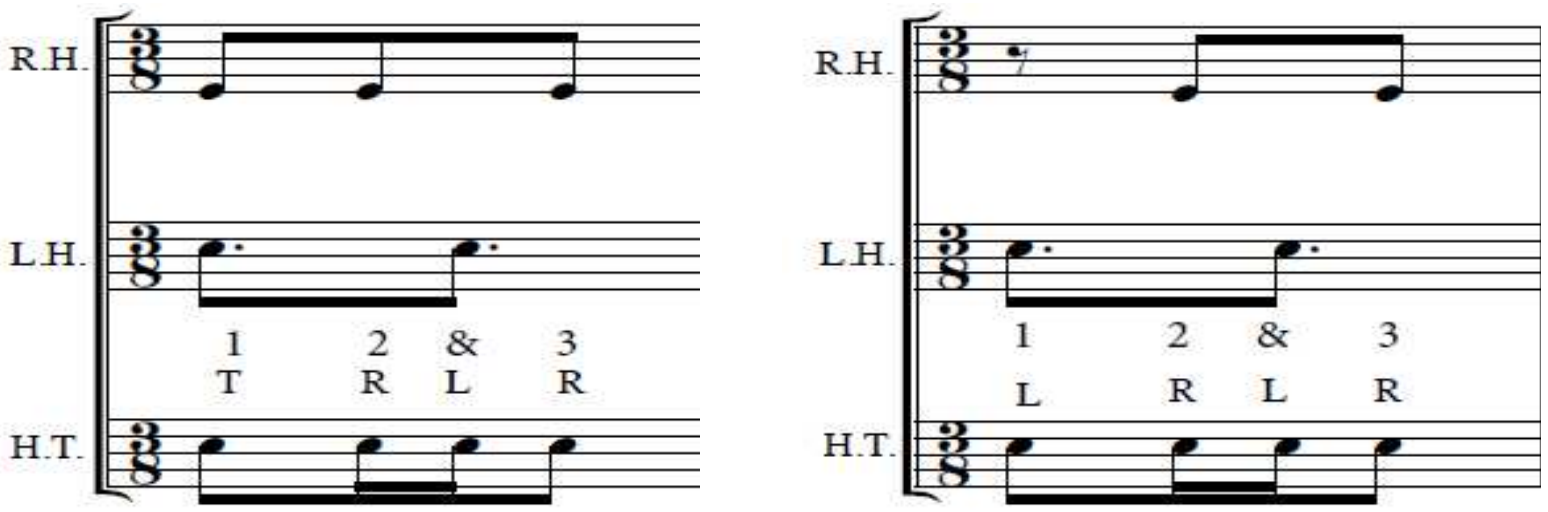

Example 2.2l

\section{Postcard No. 5}

No. 5 is about Vienna where Duke visited the Zentral-friedhoff (Central cemetery). This piece is composed without bar lines and with no tempo marking; it should sound free. The tonal emphasis is on E. The author divides this piece into three sections based on the entries of the theme and the expressive marking provided by the composer. A brief analysis is presented in the table below: 


\begin{tabular}{|c|c|c|}
\hline Section & Unmeasured & Tonal Emphasis \\
\hline I (Declaimed) & Unmeasured & E \\
\hline II (Shadowy) & Unmeasured & E \\
\hline III (pp. Clear) & Unmeasured & E \\
\hline
\end{tabular}

As Duke writes this postcard paragraph, "I just had a performance of my little choir piece (with Hebrew texts) at the Votifkirche." The melodic content is evocative of chant. It is a selfquote from his choral work, 3 Blessings and A Benediction. ${ }^{34}$

The first section starts with a clear, robust melody marked declaimed. The echo immediately follows with a $p$ dynamic. It is extended by adding the tail of the theme and ends on the dominant note, B (Example 2.2m).
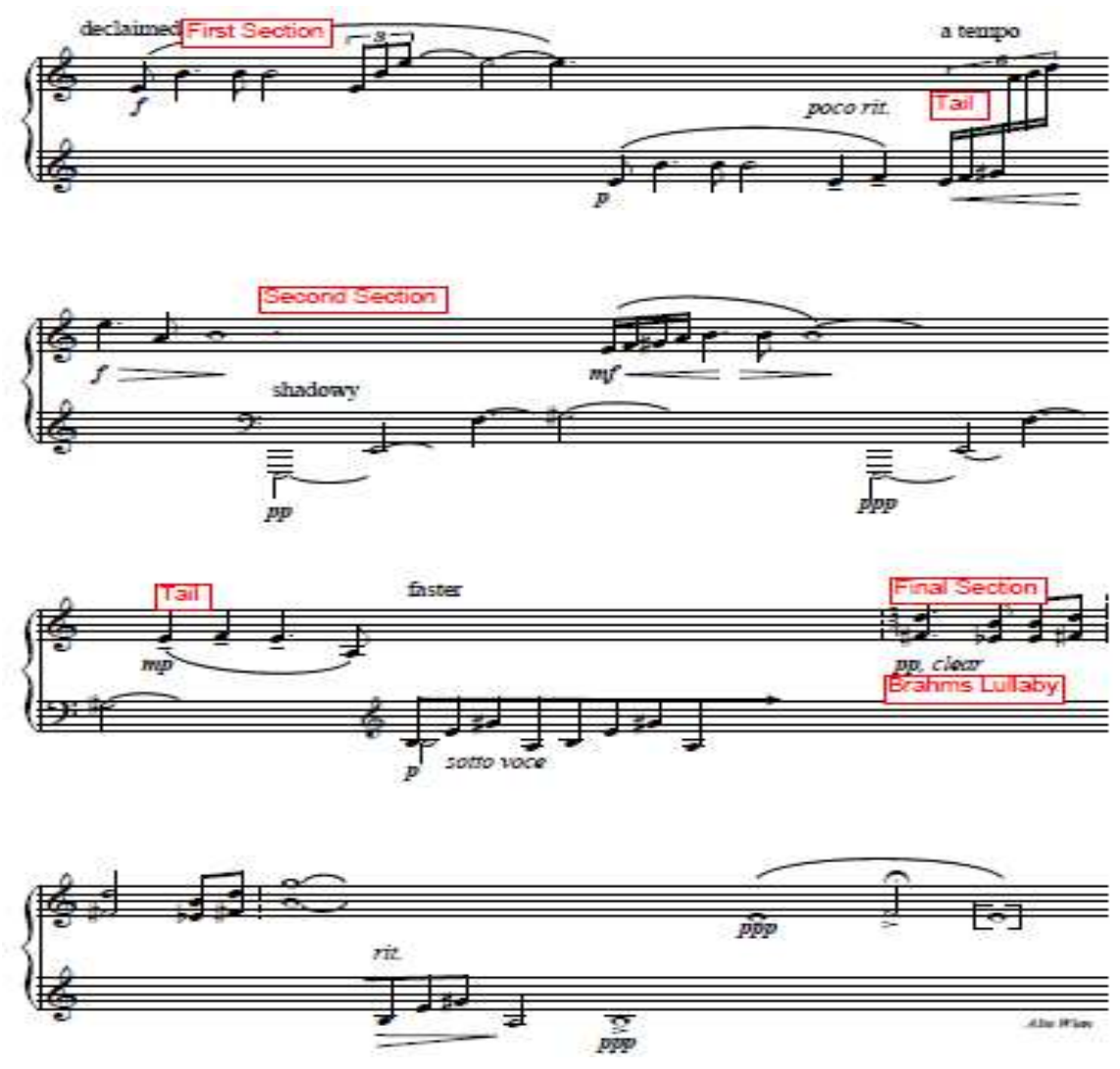

Example 2.2m Postcards No. 5

\footnotetext{
${ }^{34}$ David Duke, 3 Blessings and a Benediction, (Unpublished, 1994).
} 
The second section begins on the low bass note E and gradually rises. Duke marks shadowy ( $p p)$ and intends this to be somewhat mysterious. As soon as the sixteenth notes enter, the opening theme returns. It is interrupted by another low bass note $\mathrm{E}$ that is marked softer than the previous one ( $p p p)$. We hear the tail of the theme at a $m p$ dynamic. This section ends on a series of eighth notes in the left hand, which is to be played faster and with a sotto voce sound (Example 2.2m).

Duke does not write out how long he wants the performer to play this group of notes. In the midst of this free passage, the final section emerges. It is introduced by the interval of a sixth in the right hand. Even though this piece lacks a time signature, Duke indicates 3/4 time only for two measures. Those two bars contain a quote from Brahms' Lullaby (Example 2.2m). As the left-hand passage slows down, it arrives at the dominant note (B). It resolves to $\mathrm{E}$ in the right hand with an upper neighbor note interruption (Example 2.2n).

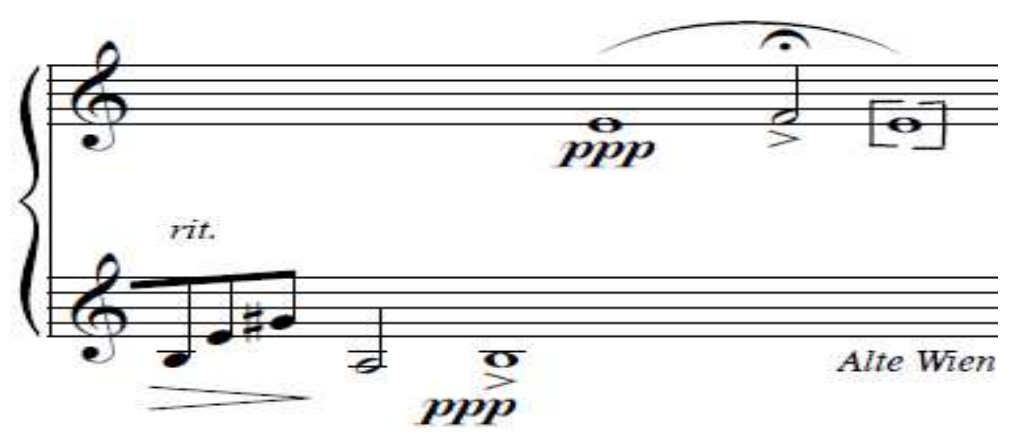

Example 2.2n Postcards No. 5

In terms of pedaling, Duke does not specify any pedal marking. It is recommended to pedal with discretion. The author suggests one long pedal per section. Pressing down the damper pedal one quarter of the way will be enough to create the exact effect of slight coloration and a subtle amount of extra resonance. 
The author feels there are two challenges to the performer of primary concern in Postcards No. 5. The first challenge deals with the pacing. Duke does not indicate any tempo or metronome markings. The performer can experiment with rubato at different places. For the triplets and sextuplets, perhaps they can start slower then speed up. The second challenge deals with the hand placement on the keyboard in the third system (Example $2.2 \mathrm{~m}$ ). It is necessary to keep the left hand low and the right hand closer to the fall board so both hands avoid bumping into each other.

\section{Postcard No. 6}

No. 6 is about Hillsboro, North Carolina. This piece is composed without bar lines and with no tempo marking; it should sound like an improvisation. The author divides this piece into three sections based on the fermata. A brief analysis of this piece is presented in the table below:

\begin{tabular}{|c||c||c|}
\hline Section & Measure & Tonal Emphasis \\
\hline \hline I & To Fermata 1 & $\mathrm{C}$ \\
\hline II & To Fermata 2, $\mathrm{C \#}$ \\
\hline III & To the end & $\mathrm{E}, \mathrm{B} b, \mathrm{e}, \mathrm{c}, \mathrm{D}$ \\
\hline
\end{tabular}

There are very few expression or phrase markings. The score denotes relaxed at the beginning. The piece opens with a strong bass note $\mathrm{C}$, followed by a tertian harmony built on $\mathrm{B}$. There are many groups of beamed eighth notes. Each group has different numbers of eighth notes. The score marks these eighth notes to be played in a cantabile style. Varying the rubato will help this sound less predictable. The first section ends on a $\mathrm{C}$ major chord with an added ninth at the first fermata (Example 2.2o). 


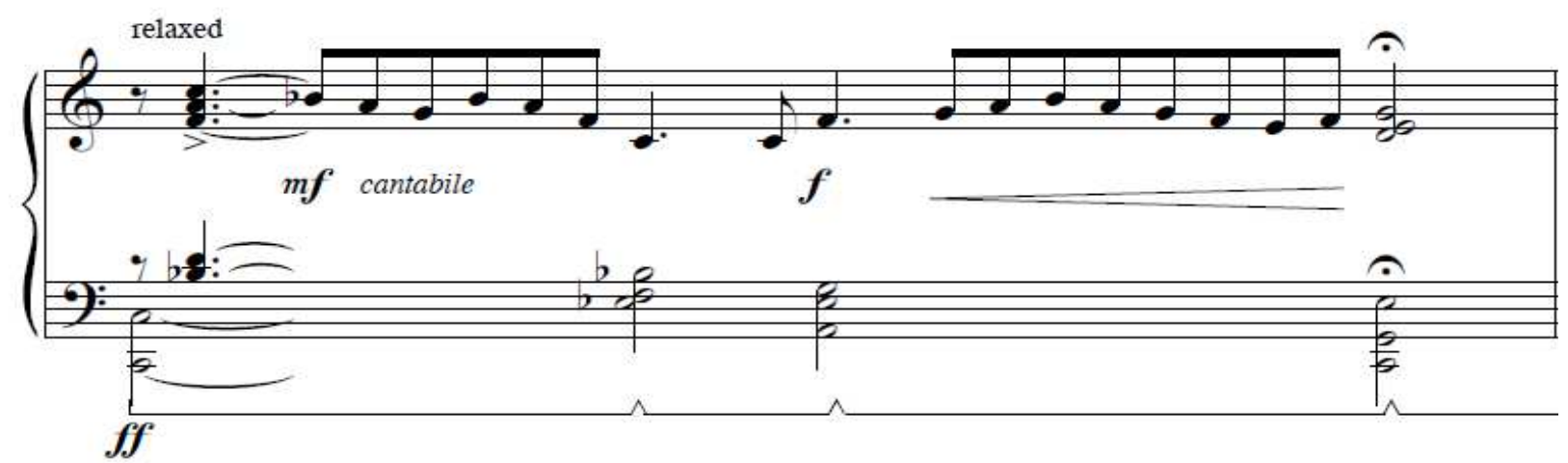

Example 2.2o Postcards No. 6

The second section starts the same way as the first phrase. It is interrupted by polychord in the middle. The second phrase ends on the second fermata, $\mathrm{C} \#$ with a suspension (Example $2.2 p)$

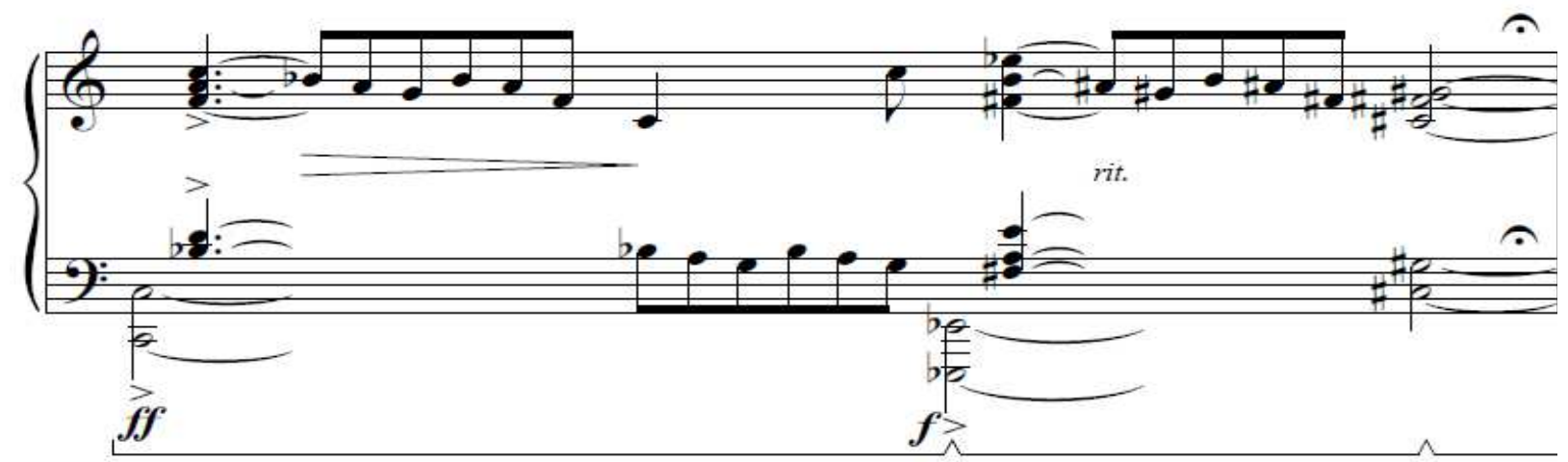

Example 2.2p Postcards No. 6

The final section starts with the implications of E major and goes through brief tonal emphasis of $\mathrm{E}$ major, $\mathrm{B} b$ major, $\mathrm{E}$ minor, $\mathrm{C}$ minor, finally ending on $\mathrm{D}$ major. The added nonchord tones always lend a sense of dissonance (Example2.2q). 

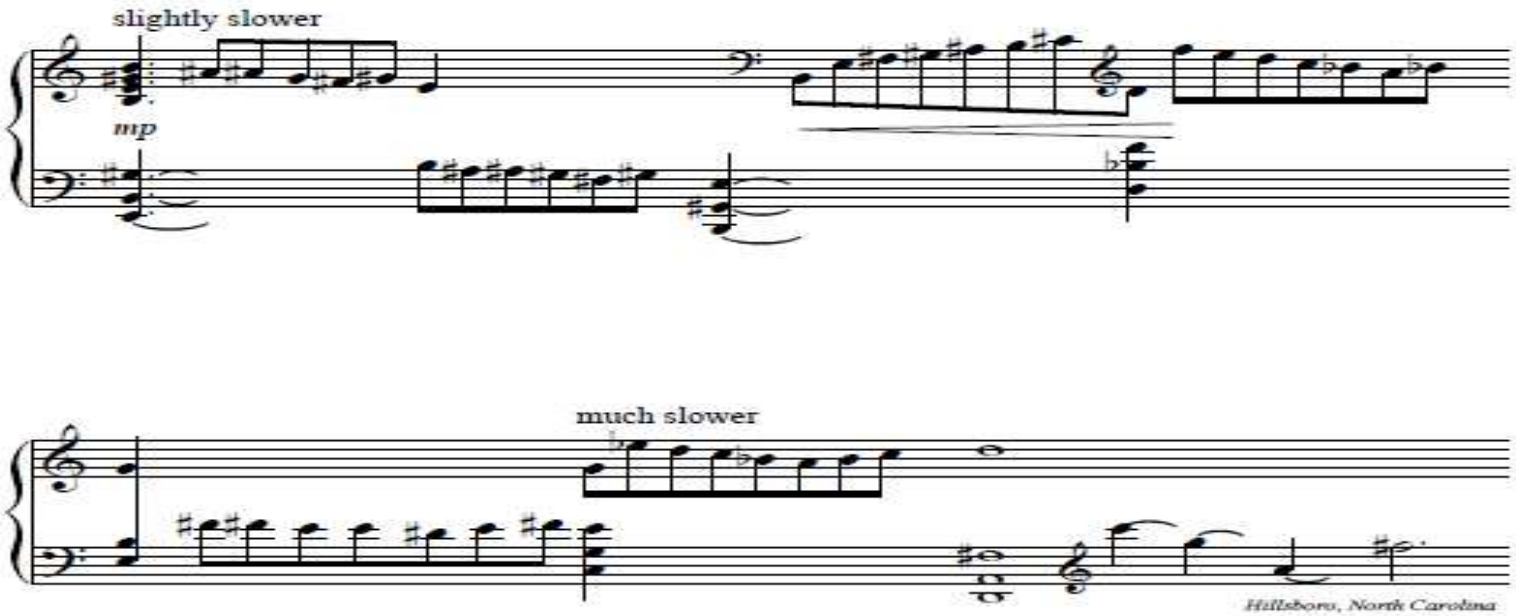

Example2.2q Postcards No. 6

In terms of pedaling, Duke again does not provide any instructions. The author suggests that a new pedal is needed whenever a new harmony is presented through the low bass notes (Examples 2.20 and $p$ ).

The author feels there is one challenge to the performer of primary concern in Postcards No. 6. The challenge is the interpretation of pacing. Duke wrote in this postcard paragraph, “...I love the old magnolias, Not too far to the Appalachians either." The musical imagery is about the landscape. The performer can experiment taking rubato at different places. It will have a different effect. Like an artist paints a landscape on a canvas, a pianist explores different timbre and color on a piano.

\section{$\underline{2.3 \text { Sonatina }}$}

A sonatina is a short and 'light' sonata. In the Classical period, they were written for didactic purposes, and many are still in use as teaching materials today. A sonatina follows the generic conventions of the sonata but on a smaller scale. It usually contains three movements. The first movement is often in sonata-allegro form with a short or no development section. The second movement is usually slow. The third movement is usually in rondo form with a light- 
hearted character. Sonatinas by Clementi, Kuhlau, Dussek, and Diabelli are the most representative works in piano repertoire. ${ }^{35}$

Duke began working on his sonatina in 1976 when he was teaching at the Red Deer College. The attempt at writing a sonatina was popular among the students of Jean Coulthard at that time. The piece was commissioned by his friend, Dr. Vivienne Rowley, who gave the premier performance in 1977. It was later dedicated to Jon Kimura Parker. Throughout this work, Duke combined traditional processes with polytonal harmony. The mixtures of several compositional techniques make this a "postmodernist" work (thematic transformation, cyclic technique, 12-bar blues, 12-tone technique, parallelism, polytonal, mixed-rhythm). It is called a sonatina because it is short, not because it is easy.

35 "Sonatina." Grove Music Online. Oxford Music Online. Oxford University Press, accessed February 15, 2015, http://www.oxfordmusiconline.com/subscriber/article/grove/music/26198. 


\section{First Movement}

This movement is in sonata-allegro form. A brief analysis of the movement is presented in the table below:

\begin{tabular}{|c|c|c|c|}
\hline Label & Measures & Section & Tonal Emphasis \\
\hline \multirow[t]{5}{*}{ Exposition } & $1-4$ & Theme A1 & $\mathrm{A}$ \\
\hline & $5-11$ & Theme A2 & A \\
\hline & $11-20$ & Bridge & Ambiguous \\
\hline & $21-30$ & Theme B & $\mathrm{E}$ \\
\hline & $31-36$ & Codetta (Transformed A2) & Ambiguous \\
\hline Development & $37-50$ & $\begin{array}{l}\text { Theme } \mathrm{C}+\text { Fragmentation } \\
\text { and Variation of the previous themes }\end{array}$ & Ambiguous \\
\hline \multirow[t]{6}{*}{ Recapitulation } & $51-55$ & Theme B & $\mathrm{C}$ \\
\hline & $56-58$ & Bridge & Ambiguous \\
\hline & $59-60$ & Theme A1 & A \\
\hline & $61-66$ & Theme A2 & A \\
\hline & $67-74$ & Theme C (Transformed) & $\mathrm{F} \#$ \\
\hline & $75-85$ & Coda (Themes A1+A2) & A \\
\hline
\end{tabular}

In the exposition, the theme $\mathrm{A}$ has two parts: $\mathrm{A} 1$ and $\mathrm{A} 2$. In the beginning, theme $\mathrm{A} 1$ opens with a light, lyrical passage in the upper register that sweeps down the keyboard in a crescendo to the lowest register (Example 2.3a). The tempo indication is quickly (eighth note $=$ 184). After a brief silence, theme A2 immediately follows. The score indicates a new marking, aggressively, molto cres. This time, the music is presented at an even softer dynamic of ppp, at first in the lowest register and then moving towards the higher register in a crescendo to a louder dynamic level of $f$ (Example 2.3b). The tonal emphasis of theme A1 and A2 is on A. This section stays in compound and complex meter $(3 / 8,4 / 8,5 / 8,6 / 8)$. 


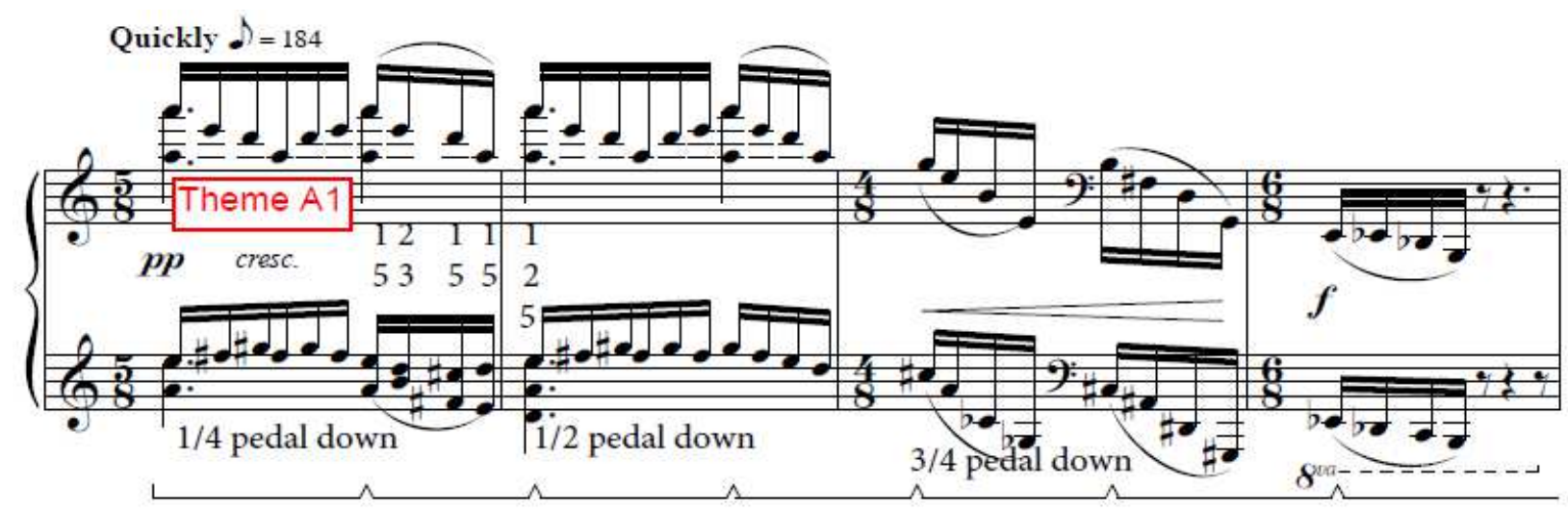

Example 2.3a Sonatina $1^{\text {st }}$ movement, $\mathrm{mm} .1$-4
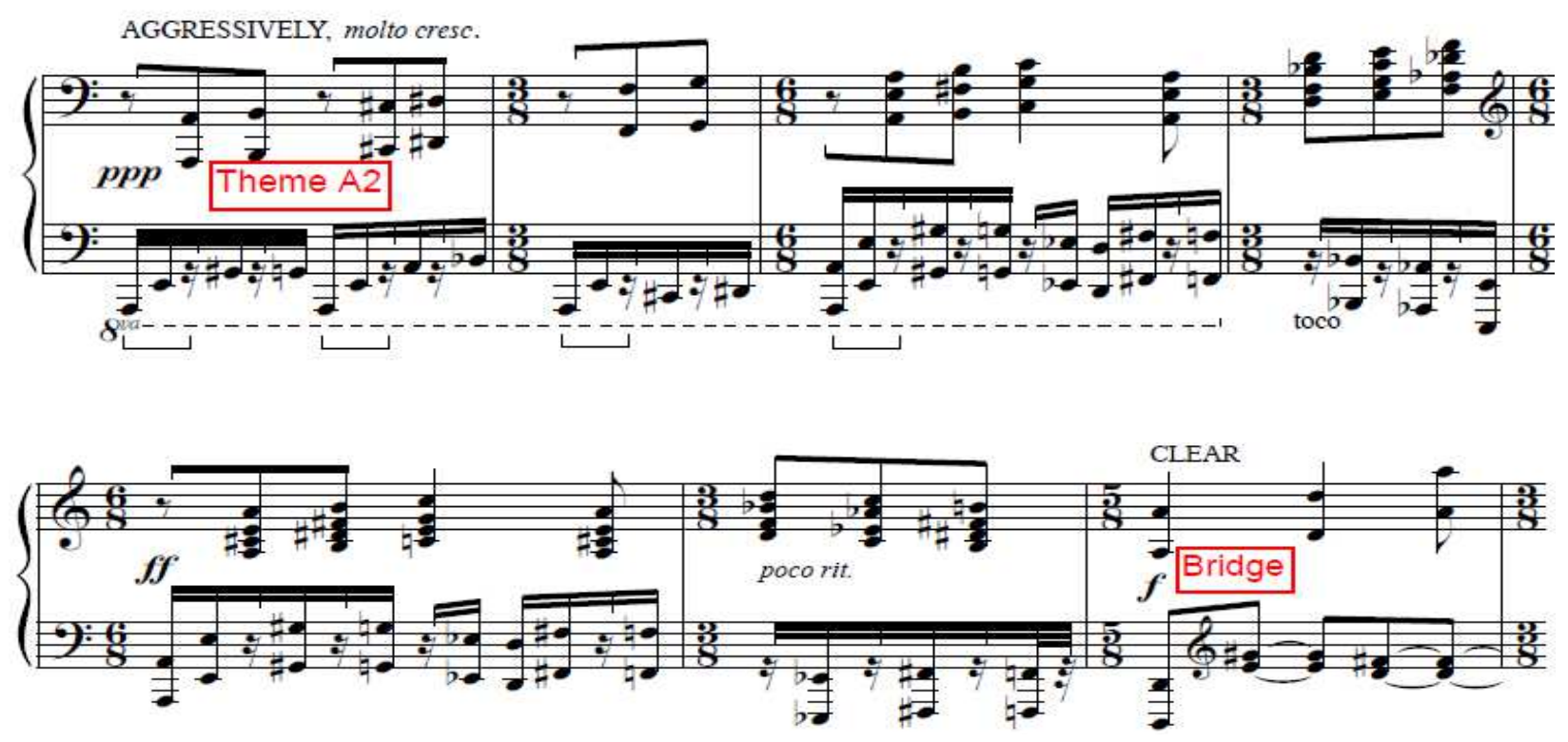

Example 2.3b Sonatina $1^{\text {st }}$ movement, mm. 5-11

At measure 11, a new marking, clear, starts the bridge section. In this section, the meter is still either compound or complex $(3 / 8,5 / 8,7 / 8,9 / 8)$, but also marks the first appearance of simple time (3/4) in measure 16. A dotted quarter rest with a fermata concludes this section.

Like most classical sonatas, theme B provides a contrasting idea to theme A in character and in key. This is, in part, achieved by giving a new tempo indication, "slower, rubato." At measure 21, the left hand presents this lyrical theme accompanied by a pedal point on $\mathrm{E}$ (Example 2.3c). At measure 31, a codetta begins. The score denotes $A$ Tempo I to indicate that 
this needs to return to the tempo of theme A. The right-hand inner voice carries the same melodic contour as in measures 7 and 9. It is in fact the transformation of theme A2 (Example 2.3d). A series of parallel $5^{\text {ths }}$ conclude this section. Instead of a repeat sign at the end of the exposition, there is a fermata over the double bar line to indicate the conclusion of this section.

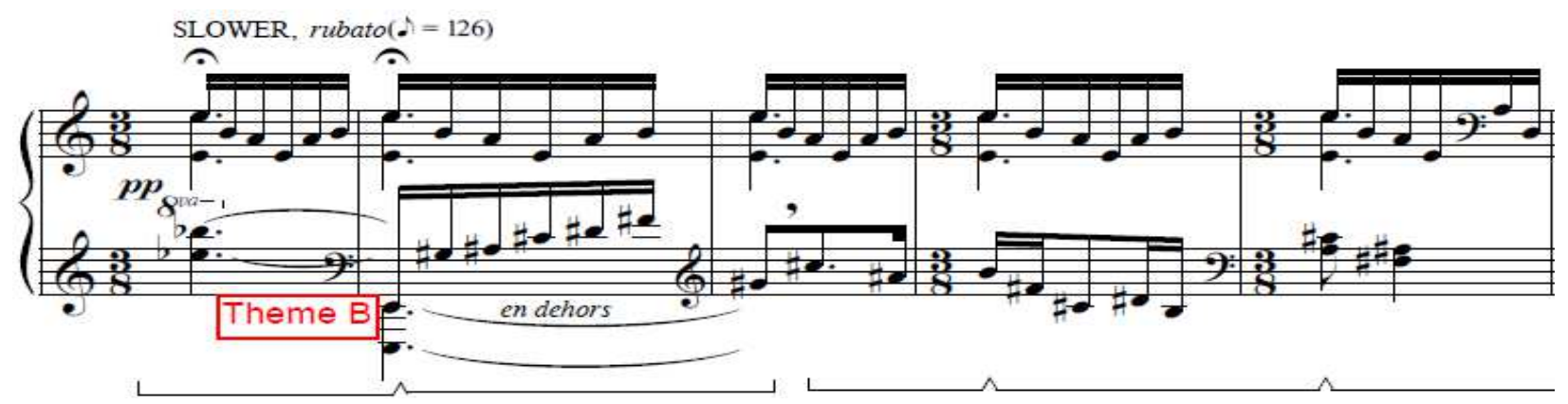

Example 2.3c Sonatina $1^{\text {st }}$ movement, $\mathrm{mm}$. 21-25

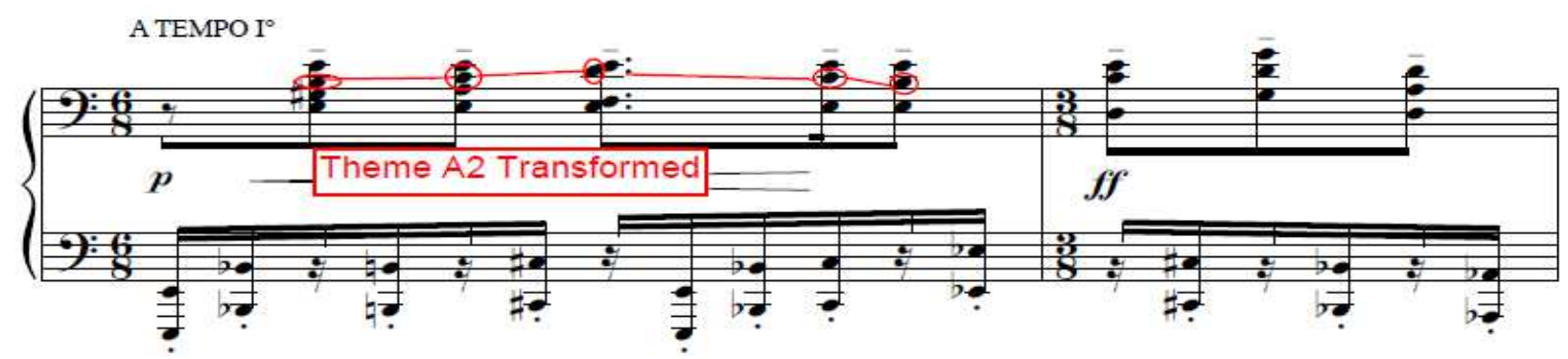

Example 2.3d Sonatina $1^{\text {st }}$ movement, $\mathrm{mm} .31-32$

At measure 37, the development starts with a series of parallel chords in the right hand. Theme $\mathrm{C}$ is introduced with a new expressive marking, misterioso, poco a poco cres (Example 2.3e). The left hand incorporates many of the broken octaves which present instability of the tonal center. This section mostly remains at a softer dynamic level until the very end, at which point there is a crescendo to $f f$. Again, to conclude this section, there is a fermata over the double bar line just like at the end of the exposition. 


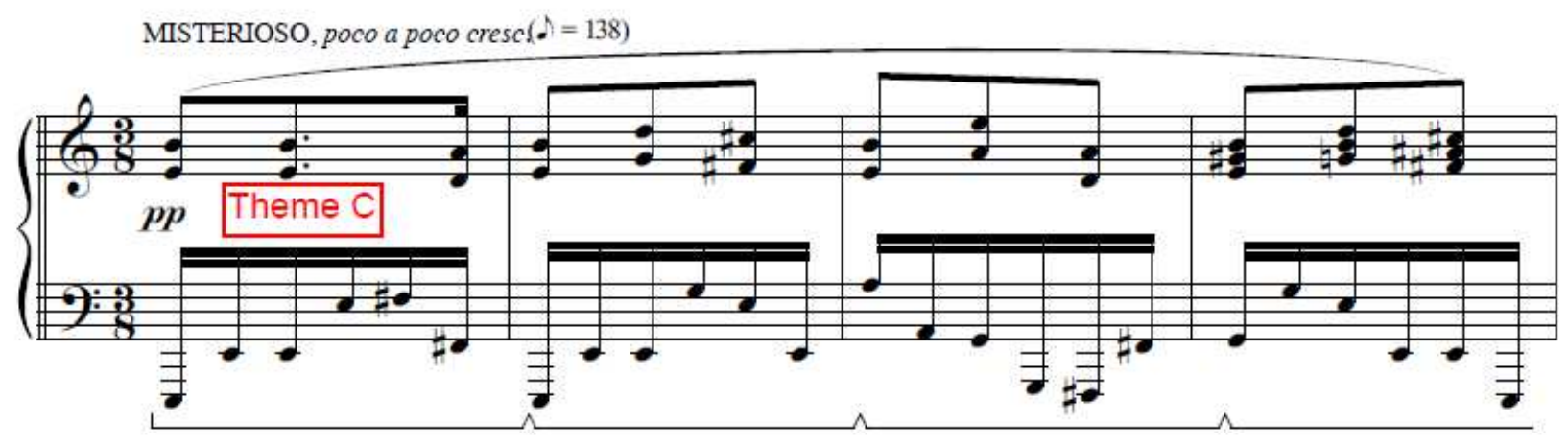

Example 2.3e Sonatina $1^{\text {st }}$ movement, $\mathrm{mm}$. 37-40

At measure 51, the recapitulation begins with theme B instead of theme A. The dynamic level of theme B presented here is $f f f$, unlike theme $\mathrm{B}$ in the exposition at a dynamic of $p p$ (Example 2.3c). Instead of staying in the tonic key (A), it emphasizes on $\mathrm{C}$ which is a third away. This reverse entry of the theme was used in the Classical era, notably in Mozart's Piano Sonata No. 9 in D major, K. 311/284c. A series of parallel fifths acts as a bridge to the return of theme A1. It starts slow and proceeds to accelerate to theme A2 where Tempo 1 is indicated. Duke brings back the misterioso theme $\mathrm{C}$ that was presented in the development. It occurs twice in the right hand; the first time in parallel fifths and the second time in many second inversion chords. Here, Duke indicates solid, sonorous rather than misterioso (Example 2.3f).

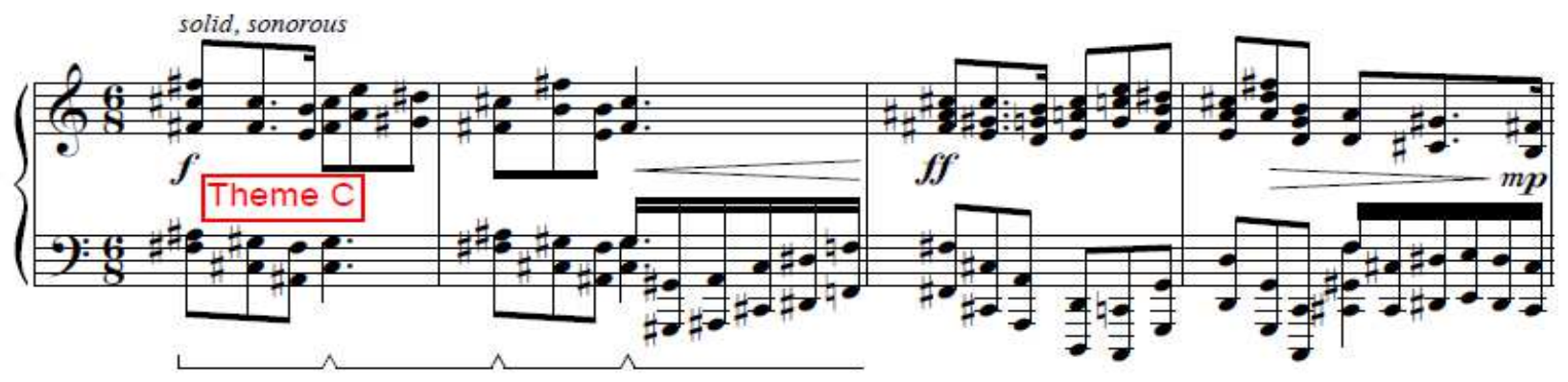

Example 2.3f Sonatina $1^{\text {st }}$ movement, mm. 67-70

At measure 75, the coda begins. It starts with the right hand playing theme A1 (Example 2.3g). The tonal emphasis on A is stressed on every strong beat because of the pedal point. At 
measure 83 , theme A2 is presented in right hand. The texture thickens and the intensity increases to an octave glissando that ends this movement (Example 2.3h).

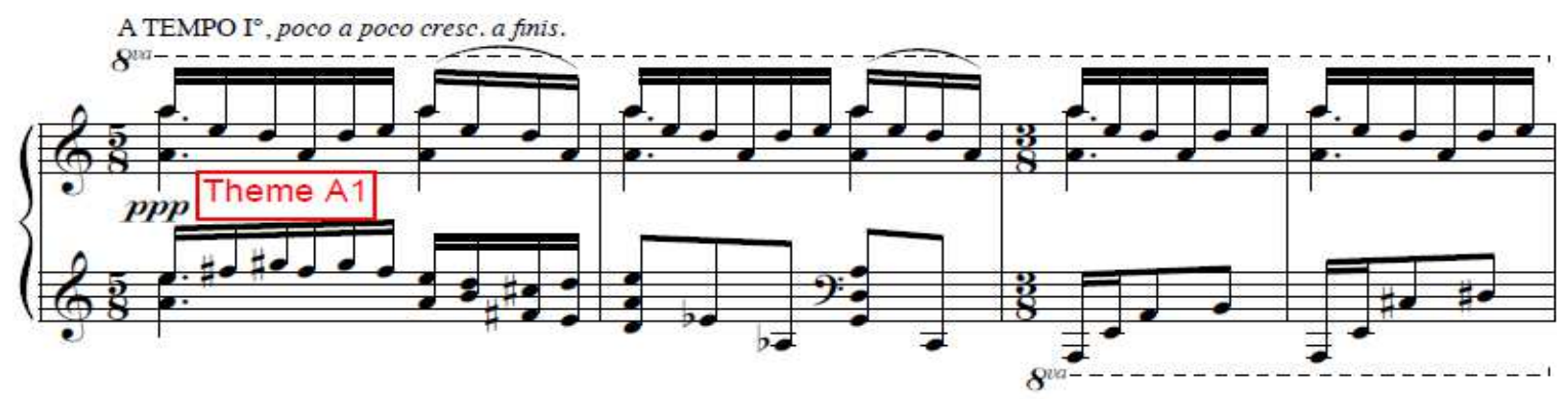

Example $2.3 \mathrm{~g}$ Sonatina $1^{s t}$ movement, $\mathrm{mm} .75-78$

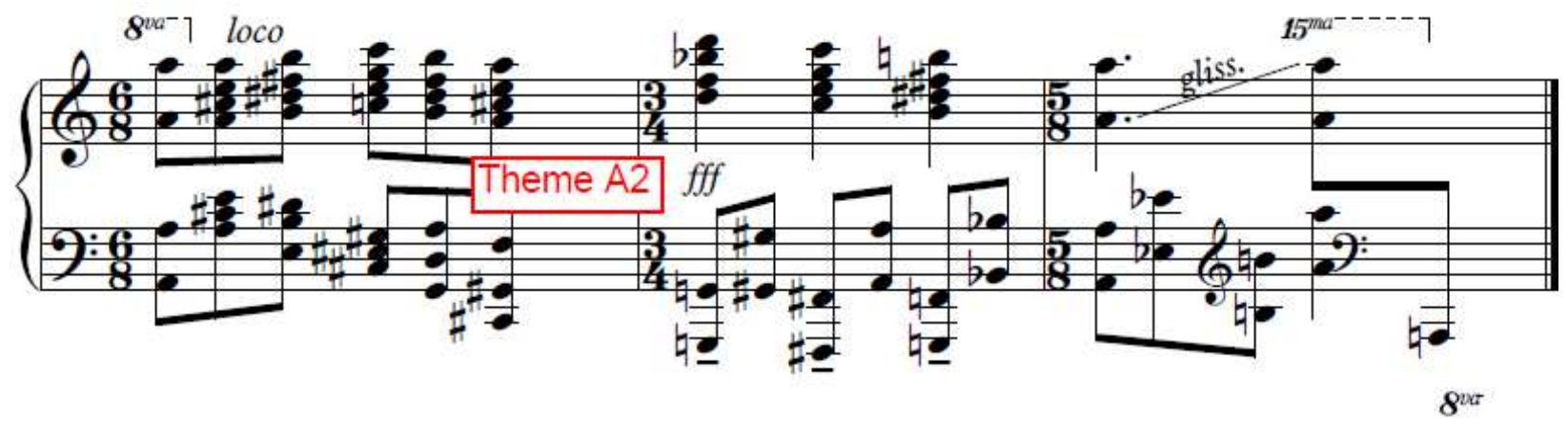

Example 2.3h Sonatina $1^{s t}$ movement, $\mathrm{mm} .83-85$

In terms of pedaling, Duke does not indicate anything for the performer. In theme A1, the author recommends pedaling one quarter way down and gradually deepens so the resonance and volume can be accumulated (Example 2.3a). In theme A2, it is recommended to use a rhythmic pedal. A touch of pedal on every first and fourth beat will enhance the clarity of the 6/8 meter (Example 2.3b). In themes $\mathrm{B}$ and $\mathrm{C}$, since there are low bass notes that support the harmony, a longer pedal is recommended to enrich the sonority. The author provides pedal suggestions in the Examples 2.3c, $e$ and $f$.

The author feels there are four challenges to the performer of primary concern in the first movement. The first challenge is navigating the extremities of the keyboard. The performer needs to make sure the torso is flexible and can easily lean to the right or left. The second 
challenge is dynamic contrast. Within many passages spanning a short amount of time, the dynamic changes from very soft to very loud or vice versa. There should be eight different dynamic levels in this movement, $p p p, p p, p, m p, m f, f, f f$, and $f f f$. The third challenge is the interpretation of the fermati. One can find fermati over a rest (measure 20), over a sixteenth note (measure 21), over double barlines (measure 37), over a quarter note (measure 54), and over an eighth note (measure 56). The performer should interpret them with discretion. The author suggests that fermata over a note is more like an end-phrase gesture whether it is a sixteenth note, eighth note, or quarter note. Fermata over a rest or double barlines is more like an end of a section; hence, a breath is needed for the change of character or tempo. The fourth challenge is the non-idiomatic left-hand writing in measure 1. It is technically difficult to play the double notes as smoothly and as quickly as possible. The performer can try the fingering indicated in Example 2.3a. It requires the thumb to move consecutively three times, but keeping it light and gliding through the keys will help.

\section{$\underline{\text { Second Movement }}$}

The second movement is titled Nocturne. This is a longer version of his anther miniature, Barcarolle, taken from the fourth volume of Music of Our Time. It is in a rondo form. A brief analysis of the movement is presented in the table below: 


\begin{tabular}{|c|c|c|c|}
\hline Section & Measures & Tonal Emphasis & Technique \\
\hline Introduction & $1-4$ & $\mathrm{C}$ & Ostinato pattern \\
\hline $\mathrm{A}$ & $5-17$ & $\mathrm{C}$ & Textural inversion \\
\hline $\mathrm{B}$ & $18-29$ & $\mathrm{C}$ & 12-tone technique over 12-bar blues \\
\hline $\mathrm{A}$ & $30-33$ & $\mathrm{C}$ & Two measures ostinato pattern \\
\hline $\mathrm{C}$ & $34-49$ & $\mathrm{E} b$ & 12-tone technique \\
\hline $\mathrm{A}$ & $50-57$ & $\mathrm{C}$ & Ostinato pattern \\
\hline Coda & $58-62$ & $\mathrm{C}$ & Ostinato pattern, Hemiola \\
\hline \hline
\end{tabular}

Unlike the frequent metric changes in the first movement, this movement stays in compound duple $6 / 8$ most of the time. The introduction section starts with a very calm twomeasure ostinato pattern (Example 2.3i). The A section contains three phrases. The first phrase starts with the melody in the right hand while the left hand continues the ostinato pattern at measure 5 (Example 2.3j). The second phrase starts with textural inversion, the melody in the left hand and the right hand takes over the ostinato. The melody returns to the right hand and the left hand continues the ostinato pattern in the third phrase. This section is marked slow, cantabile, therefore the melody should always project and sing.

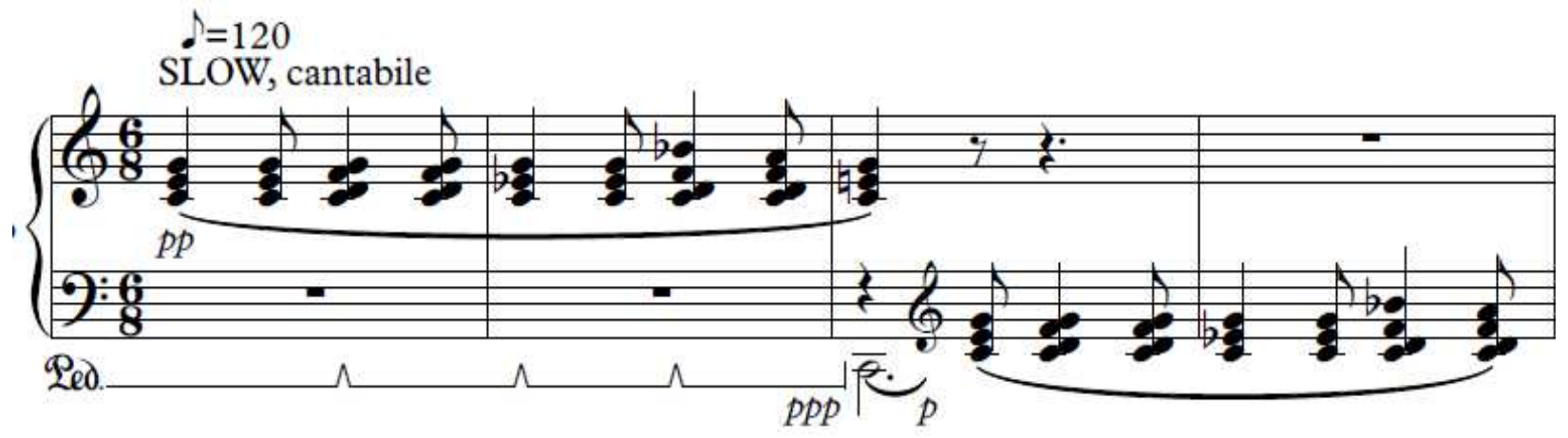

Example 2.3i Sonatina $2^{\text {nd }}$ movement, mm. 1-4 


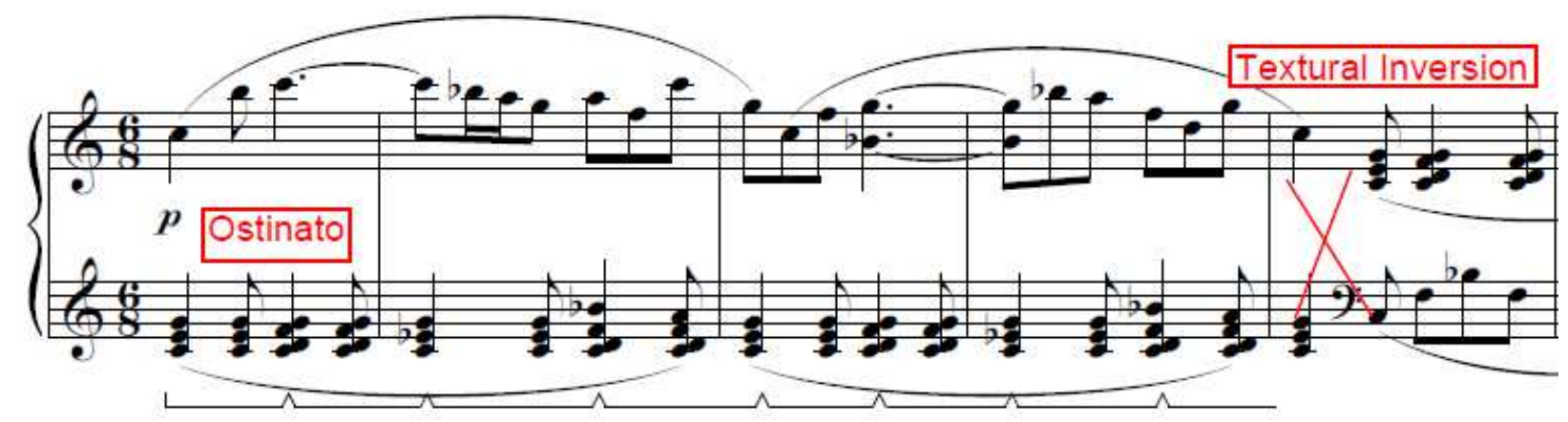

Example 2.3j Sonatina $2^{\text {nd }}$ movement, mm. 5-9

At the end of A section, a rit. sign is indicated. The B section starts in measure 18. A new tempo marking, slower, very relaxed is presented (Example 2.3k). Instead of a sudden change of tempo, the performer can ease in without interruption. The underlying harmony is a 12-bar blues progression. There are three phrases. Each one of them is four measures long. Within each phrase, 12 independent pitches are presented (dodecaphonic 0-11).

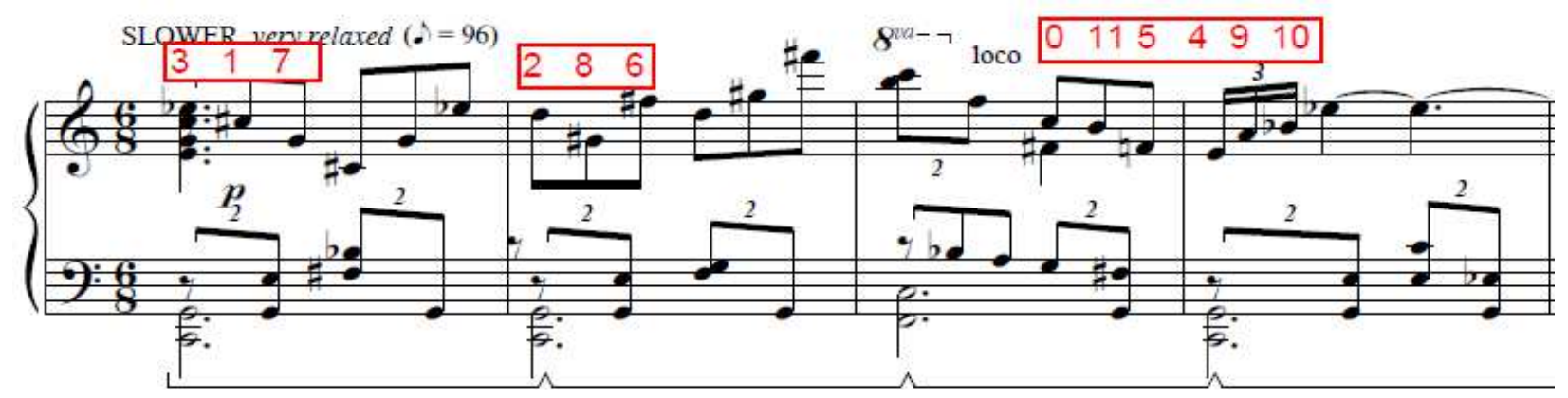

Example 2.3k Sonatina $2^{\text {nd }}$ movement, $\mathrm{mm} .18-21$

The A section returns at measure 30. Unlike the previous A section that was 17 measures long, this one is only 4 measures long. The melody does not just stay in one hand; instead, it jumps from the left hand to the right hand and back to the left hand (Example 2.3l). 


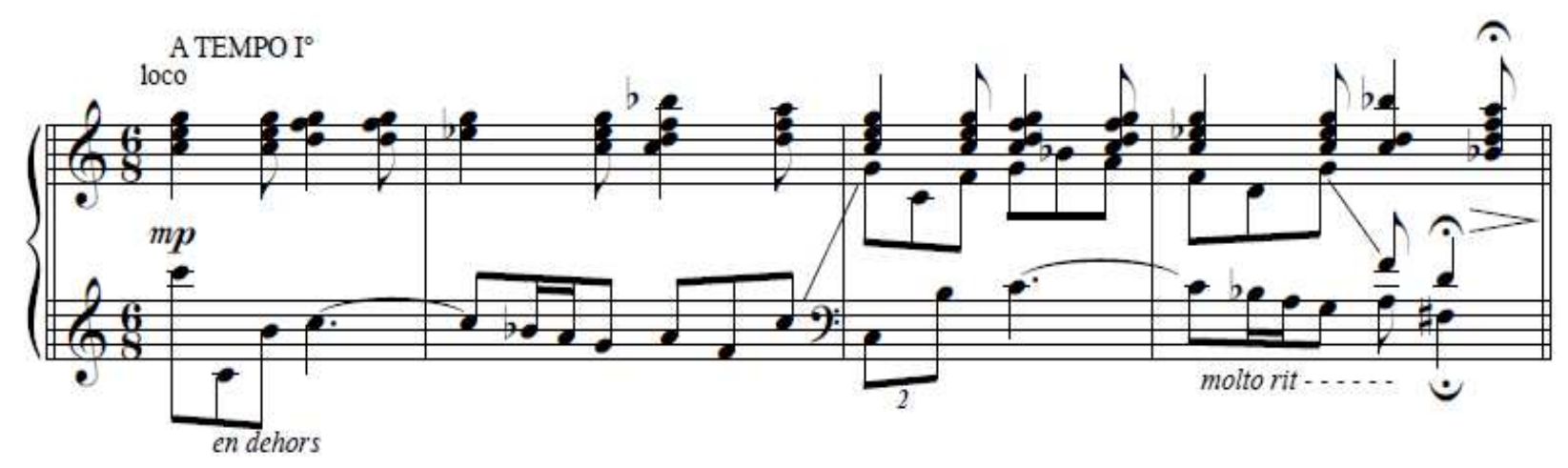

Example 2.3l Sonatina $2^{\text {nd }}$ movement, mm. 30-33

The $\mathrm{C}$ section starts with an $\mathrm{E} b$ octave in a low register in the left hand with a mixture of different intervals such as fifths, sixths, sevenths, and ninths as an accompaniment in the right hand. This dissonance should be subdued, indicated in the score as distantly. In measures 36 to 39, a 12-tone (dodecaphonic 0-11) melody is presented in the left hand (Example 2.3m). At measure 40, another 12-tone melody is presented in octaves (Example 2.3n). Comparing from the fourth beat of measures 37 to 39 with the fourth beat of measures 41 to 43, these two 12-tone melodies are an inversion to each other because the intervals are the same (See arrows in the Examples $2.3 m$ and $n)$.

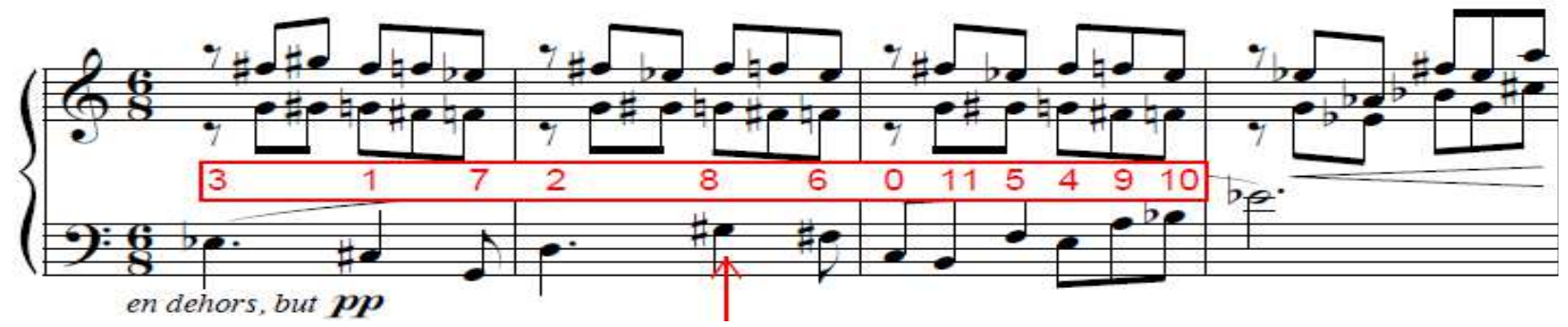

Example 2.3m Sonatina $2^{\text {nd }}$ movement, mm. 36-39 


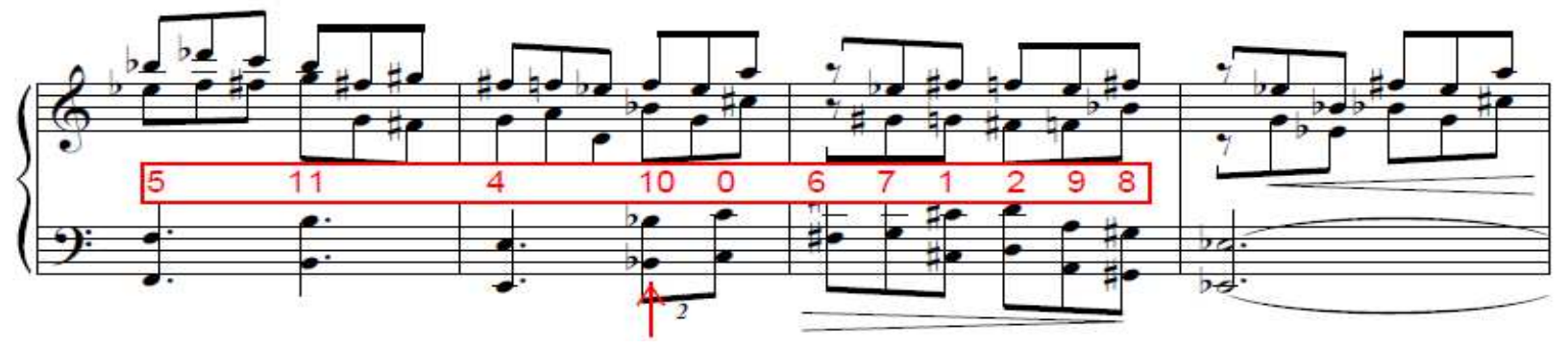

Example 2.3n Sonatina $2^{\text {nd }}$ movement, mm. 40-43

The A section returns at measure 50. The melody is doubled at the octave. It starts in the left hand and moves to the right hand. A cadential extension concludes this section. It is recommended to use one pedal from measures 54 to 57 . As the hands ascend in register, the performer may lift the foot gradually so the dynamic can drop to ppp (Example 2.3o).

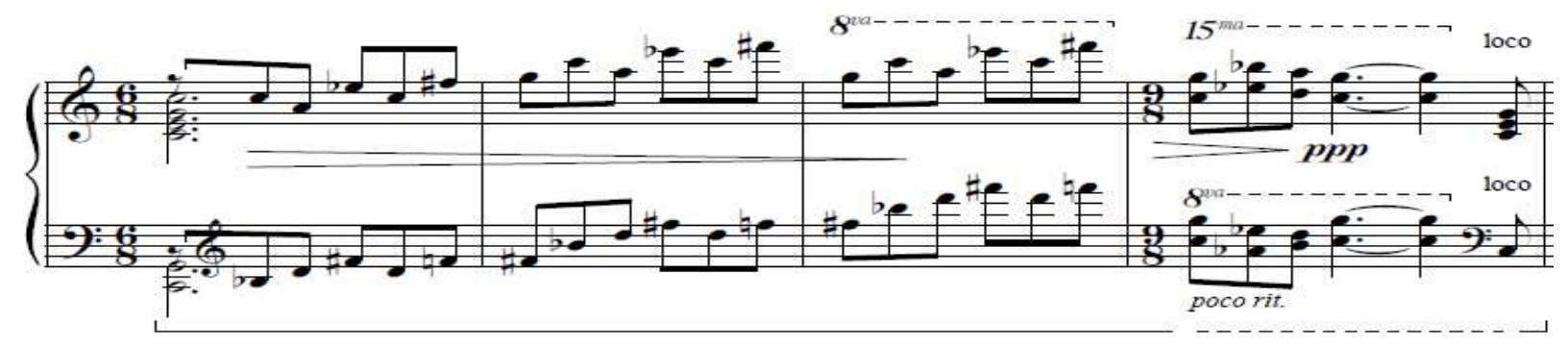

Example 2.3o Sonatina $2^{\text {nd }}$ movement, mm. 54-57

The score denotes the marking darkly for the coda section. Rather than two pulses, there are three equal quarter notes within the $6 / 8$ meter. This dark mood comes from the surprise of the hemiola rhythm. The two-measure ostinato pattern returns to recall the beginning and bookend the movement (Example 2.3p).

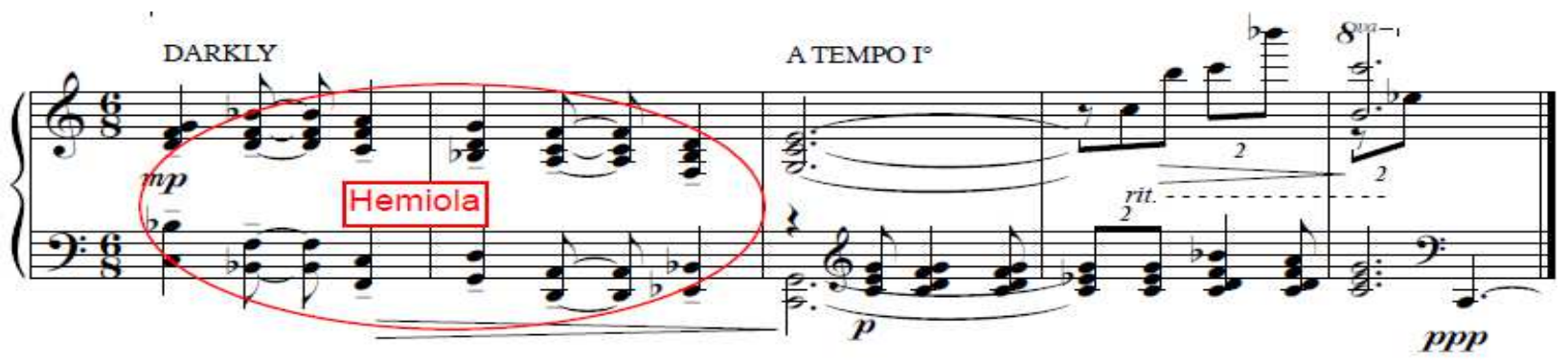

Example 2.3p Sonatina $2^{\text {nd }}$ movement, $\mathrm{mm} .58-62$ 
In terms of pedaling, Duke does not indicate pedal marking for the performer. In the A section, the author recommends pedaling on the first and fourth beat so two pulses can be felt per measure (Example 2.3i). In the B section, it is recommended to pedal on every downbeat so the 12-bar blues progression can be emphasized (Example 2.3k). In the $\mathrm{C}$ section, frequent change of pedal is recommended so the 12-tone melody can be clearly presented without too much blurring.

The author feels there are three challenges to the performer of primary concern in the second movement. The first challenge is the rhythm. Regardless which hand plays duplet or triplet the performer should always count " $1,2, \& 3$ ” verbally so this becomes comfortable (Example 2.2l). The second challenge is the melody versus the accompaniment. The melody should always project even if it is presented in only one voice. Melody moving from one hand to another should be smoothly transferred (Example 2.3l). The third challenge lies in the pianist's ability to evoke the nocturnal atmosphere. This movement should be played with a gently rocking rhythm, at times, sounding like a delicate lullaby.

\section{Third Movement}

This Third movement is rondo. A brief analysis of the movement is presented in the table below: 


\begin{tabular}{|c|c|c|c|}
\hline Section & Measures & Tonal Emphasis & Observations \\
\hline \hline A & $1-6$ & D Whole-tone & Interplay between 6/8 and 5/8 \\
\hline B & $7-14$ & Polytonal & Leap between registers \\
\hline C & $15-38$ & $\mathrm{~A}, \mathrm{E} b, \mathrm{C}$ & Recalling materials from A section and previous two movements \\
\hline A & $39-44$ & $\mathrm{C}$ & Interplay between duplets and triplets in 6/8 \\
\hline B & $45-51$ & Polytonal & Leap between registers \\
\hline A & $52-58$ & C Whole-tone & Interplay between 6/8 and 5/8 \\
\hline Coda & $59-62$ & C & Recalling previous material \\
\hline
\end{tabular}

The A section starts in 6/8 time. In measure 1, two pulses per measure are clear. The left hand presents material based on a whole tone scale. In measure 2, the meter is temporarily $3 / 4$ in the right hand but it is the hemiola effect that disrupts the expectation of $6 / 8$. This intrusion of irregular pulse is further emphasized in the $5 / 8$ time in measure 3 . It is best to feel the pulse as 3 beats +2 beats rather than $1 \frac{1}{2}+1 \frac{1}{1 / 2}+1+1$ (Example 2.3q).

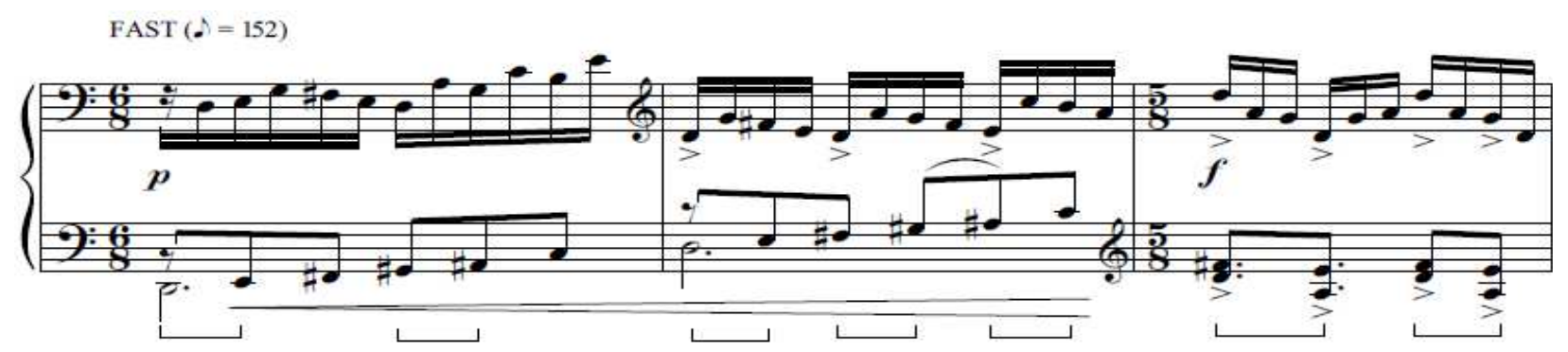

Example 2.3q Sonatina $3^{\text {rd }}$ movement, mm. 1-3

The entire A section is a long crescendo that culminates in the arrival of the B section. At this point, the primary focus is the melody in the bass that is accompanied by upper-register chords. The score indicates that this section should be played boisterously (Example 2.3r). The texture suddenly becomes three staves. The tempo changes from eighth note $=152$ to 192 . This tests the pianist's ability to leap around. In the B sections, polychords are presented (Example 
2.3u). At times, this section feels like a waltz because of the low bass notes on the strong beats provides a clear triple meter. This B section builds up intensity to a brief pause.

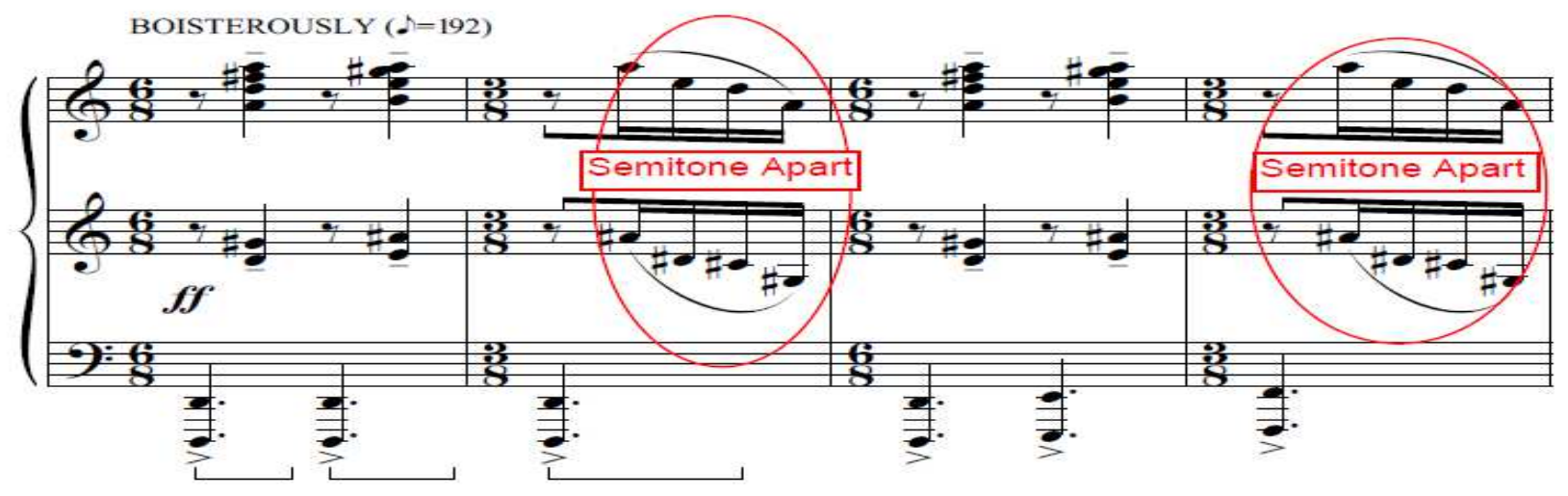

Example 2.3r Sonatina $3^{\text {rd }}$ movement, $\mathrm{mm}$. 7-10

The $\mathrm{C}$ section starts with the new marking poco pesante (eighth note $=144)$. This section is primarily a recall of material presented in the previous two movements. Several instances of former thematic material are reintroduced. Theme $\mathrm{C}$ of the first movement (Example 2.3e) is presented at measure 15. From measures 15-22, there are four phrases. Each phrase is two measures long (Example 2.3s). While the right hand recalls theme $\mathrm{C}$ from the first movement, the left hand is taken from the right hand A section material of the third movement (Example 2.3q). With each subsequent phrase, the texture gets thicker by adding more voices and the dynamic gets louder until it arrives at the lowest Eb octave at measure 23. At this point, the score indicates slower, $($ eighth note $=88)$. A fermata immediately follows to prepare for the next phrase.

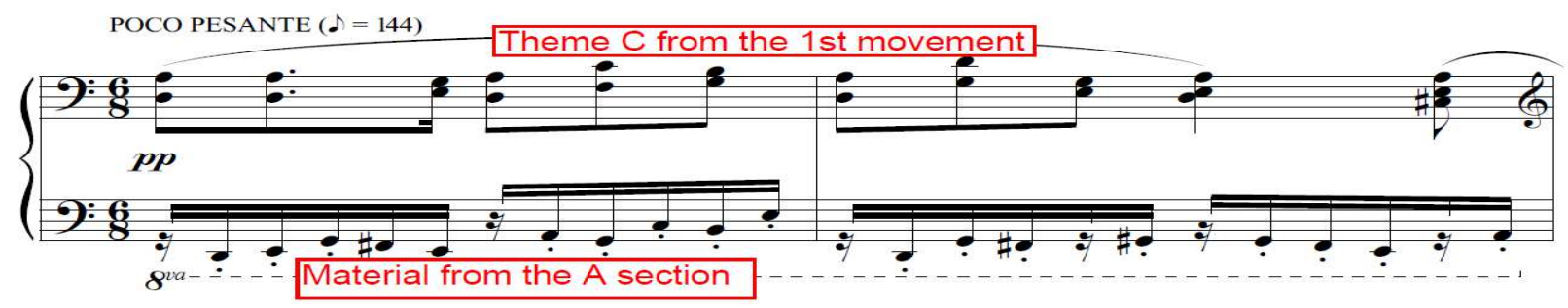

Example 2.3s Sonatina $3^{\text {rd }}$ movement, $\mathrm{mm} .15-16$ 
From measures 24 to 35 , recalled material from the $\mathrm{C}$ section of the second movement is presented (Examples $2.3 m$ and $n$ ). One hand plays a 12-tone melody while the other hand accompanies with a mixture of fifths, sixths, sevenths, and ninths. Unlike its presentation in the second movement, this instance features hand-crossing technique and a displacement of register (Example 2.3t). This $\mathrm{C}$ section ends as it rests on a D major triad.

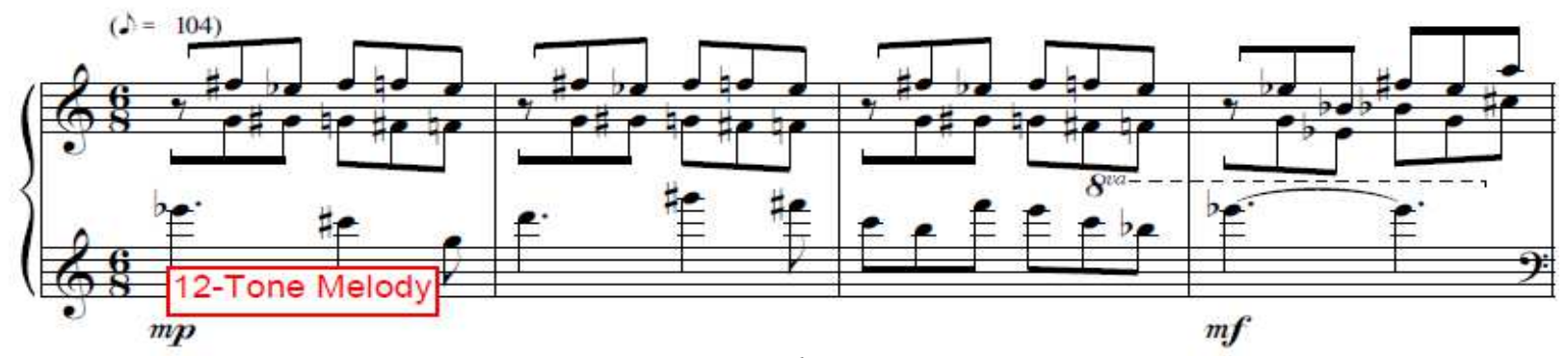

Example 2.3t Sonatina $3^{\text {rd }}$ movement, mm. 24-27

A breath is marked in preparation for the return of the A section. The score indicates poco a poco accel. It starts with $p p$ and gradually crescendo to the return of the $\mathrm{B}$ section at measure 45. This increase of dynamics is supported by the doubling of the octaves and incorporation of the low register notes.

From measures 45 to 51 , the writing becomes 3 staves again. Just like the previous B section, there are many instances of juxtaposed polychords. A recall of the 12-tone melody from the second movement is presented in the bass voice from measures 48 to 51 . The row is exactly the same as the example 2.3n, except played one octave lower (Example 2.3u).

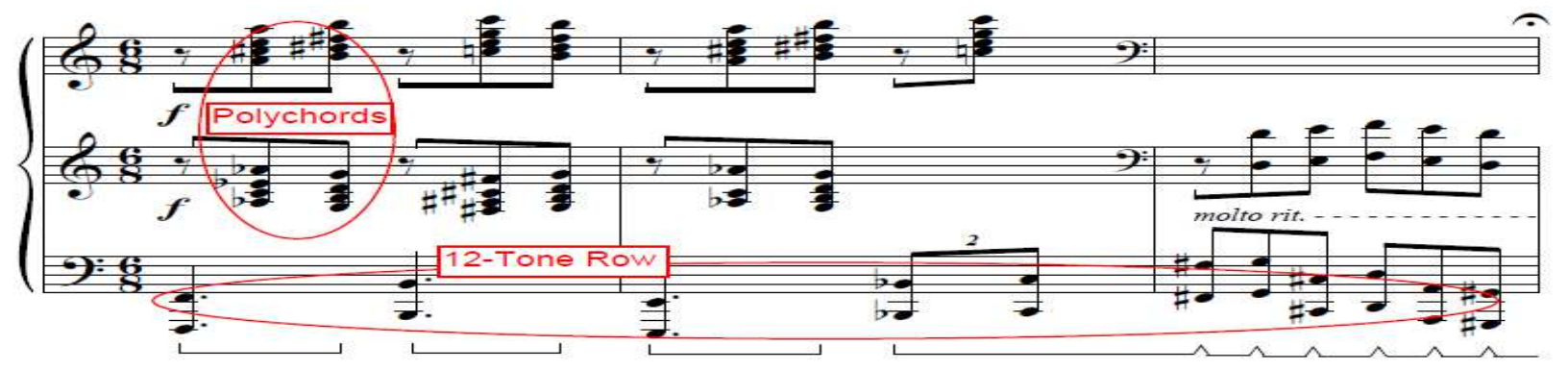

Example 2.3u Sonatina $3^{\text {rd }}$ movement, mm. 49-51 
The final $6 / 8$ of the A section is heard when there are two pulses that alternate with three pulses every other measure. The left hand also incorporates the whole tone scale in broken octaves and in dotted rhythms (Example 2.3v). Not only does this create a sense of urgency, it reinforces the momentum that drives the piece to its end. As the pianist sweeps up then down the keyboard, the intensity builds.

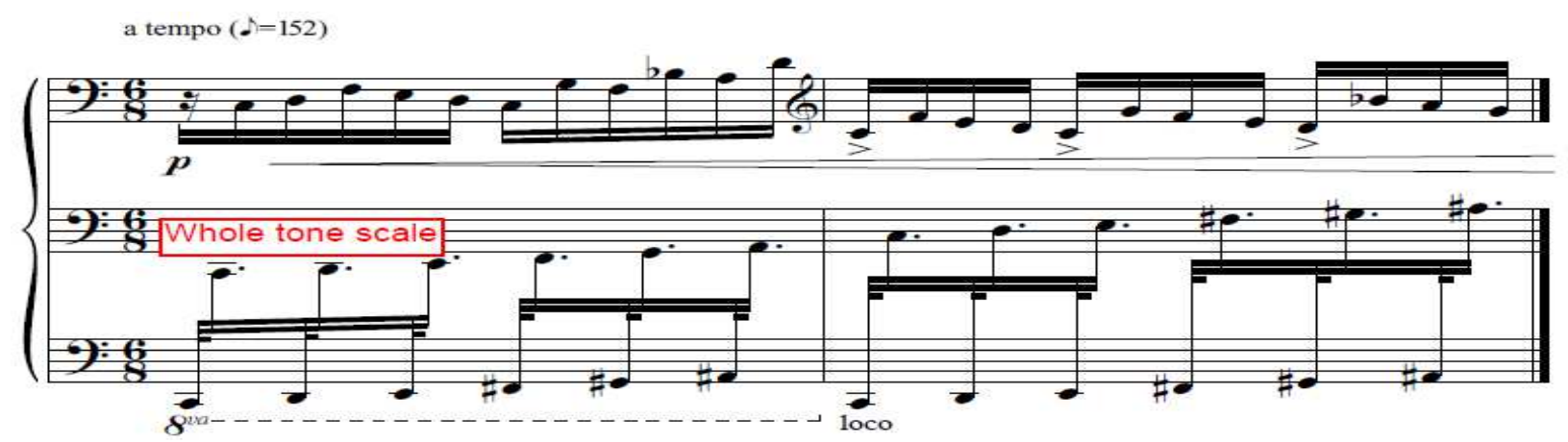

Example 2.3v Sonatina $3^{\text {rd }}$ movement, mm. 52-53

In the coda section (Example 2.3w), an augmentation of theme A2 from the first movement (Examples 2.3d) is presented at the loudest dynamic of this movement, fff. The piece ends triumphantly in $\mathrm{C}$ major.

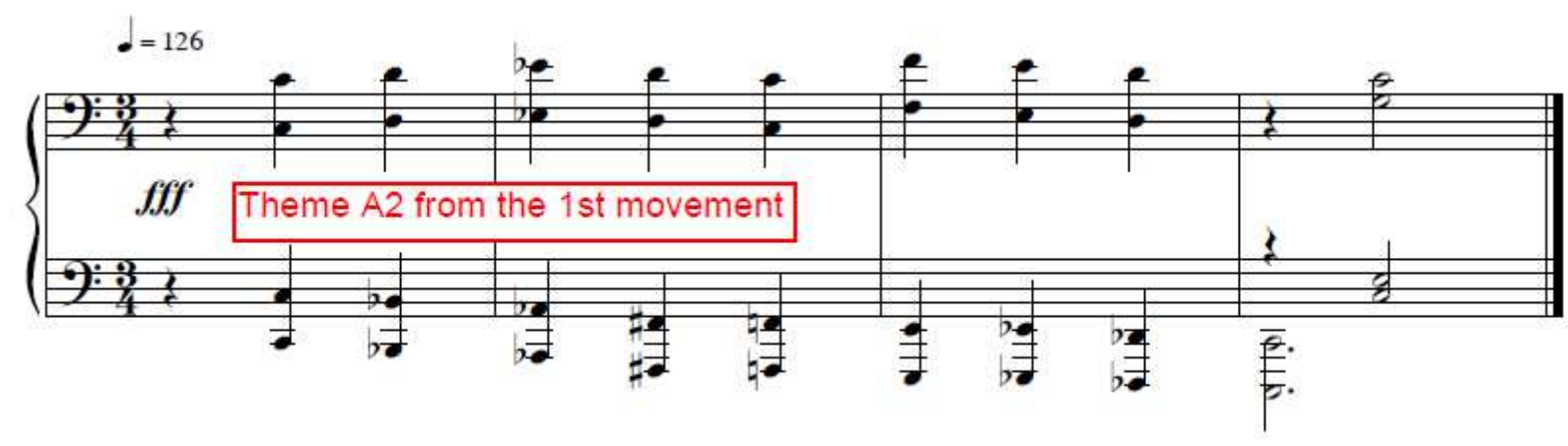

Example 2.3w Sonatina $3^{\text {rd }}$ movement, mm. 59-62

In terms of the pedaling, Duke does not indicate any marking. The author offers a pedal suggestion in the Example $2.3 q$ to further illustrate the mixture of pulses in the A section. 
In the compound time of the B sections, the author recommends pedaling on the first and fourth beat and releasing on the third and sixth beat. This will enhance the clarity of the waltz rhythm (Example 2.3r).

The author feels there are three challenges to the performer of primary concern in the third movement. The first challenge deals with the rhythm. The performer should be able to feel the pulse regardless of the time signature $(6 / 8$ or $5 / 8)$. The second challenge is the $\mathrm{B}$ section that requires the pianist to be able to leap around the keyboard. Making sure the arm is loose when traveling between registers will help the accuracy. Often it is important and easier to focus on the melodic line rather than the hectic accompaniment. Despite the dense texture of the accompaniment, the balance between melody and accompaniment should be well planned. It is important to practice slowly so the muscle and aural memory can be retained. The third challenge deals with the pacing. There are many different tempo markings (eighth note $=152$, 192, 144, 88, 104, 112, and 126). Each section is indicated with a new tempo marking. This sudden change of tempo can create a dramatic change of mood. However, at times the performer can experiment with gradual ritardando or accelerando into the new tempo. This will help the movement not sound episodic, fragmented, or predictable.

To summarize, Duke's Preludes, Postcards, and Sonatina contain a variety of writing. In his seven Preludes, one specific motive or idea is usually presented and recurs throughout. In terms of formal structure, Preludes numbers 1 and 7 are in ABA form and the rest are throughcomposed. All of them are written without key signatures but tonal emphasis can be found in numbers $1,2,3,4$, and 7 through the use of perfect cadence and the constant stress of a particular pitch. In terms of meter, No. 6 is the only one without time signature. Additionally, the numbers of the beat in each measure is inconsistent. Duke supplies a tempo marking and a metronome 
marking in each of these Preludes. They range from quarter note $=48$ (No.5) to quarter note $=$ 104 (No.7). Lastly, Duke leaves the pedal decision for the performer to experiment with because he only indicates with pedal or pedal, ad lib.

The six Postcards are small character pieces like Debussy's Preludes. In terms of formal structure, they are all through-composed. Numbers 1 and 4 have meter indication. Numbers 2 and 3 have dotted bar lines that show smaller divisions within the piece; however, not all the bars are metrically equal. Numbers 5 and 6 contain no bar lines. In terms of key, they are all written without key signatures. Tonal emphasis is established through the use of the same accidentals or the same pitch at the beginning and end of the score. Duke does not offer a tempo marking, rather, expressive indications such as clear, calm, delicately, gently flowing, and relaxed. In the first three Postcards, he gives specific pedal markings but there is no pedal indication in the latter three. Finally, all of them have a quotation embedded except No. 6.

The last work of Duke's compositions discussed here is his Sonatina. This is a "postmodernist" work because it contains different compositional techniques such as thematic transformation, cyclic technique, 12-bar blues, 12-tone technique, parallelism, polytonal, and mixed-rhythm. This work follows the generic conventions of the sonata but on a smaller scale. It contains three movements: fast-slow-fast. The first movement is in sonata-allegro form. The second and the third movements are both in rondo form. In terms of the tonal emphasis, some sections are very ambiguous because of the atonal writing. Nevertheless, the first movement starts and ends in A while the second and the third movements are in C. For the tempo, Duke is very specific and provides metronome marking in every new section. This is helpful to the performer especially because meter changes frequently occur in the outer movements. For the pedaling, Duke does not provide any pedal suggestion. In an interview with Duke, he states that 
this is his most advanced work in his solo piano compositions. He believes the performer should make the pedal decision based on his/her interpretation. ${ }^{36}$

${ }^{36}$ David Duke. Interviewed by Wei Chen Lin. Vancouver, December 29, 2014. 


\section{CHAPTER III \\ STEFAN YOUNG}

\section{Brief Biography}

Stefan Young was born in Newark, New Jersey in 1946. His musical studies began with his parents, Raymond and Ruth Young. After receiving a bachelor's degree from Rollins College in Winter Park, Florida, he obtained certificates in piano, harmony, and solfège from the American Conservatory of Music, Fontainebleau, France. In 1969-1970, he continued his music studies privately with Nadia Boulanger, Annette Dieudonné, and Robert Casadesus in Paris. Upon returning to the United States, he was drafted, but served as a conscientious objector at Morristown Memorial Hospital in New Jersey. In 1974, he received a master's degree in piano under Mieczyslaw Munz's guidance from the Juilliard School of Music and started teaching at Montclair State College where he remained until 1977. He received his Ph.D. in composition from Rutgers University in 1981 during which time he began teaching at Westminster Choir College of Rider University, ${ }^{37}$ (WCC) where he has remained since $1979 .{ }^{38}$

Young has maintained a busy career as a performer, conductor, composer, and teacher. His performance of Beethoven's Choral Fantasy with the Summit Chorale was listed among the best performances in New Jersey by the Newark Star-Ledger in 1993. Other more recent performances include a recital for the Greater Princeton Steinway Society and Martha's Vineyard Camp Meeting Association in Oak Bluffs, MA. ${ }^{39}$ In addition to being a pianist, he is an equally talented organist. For many years, he was asked to write organ pieces for the opening convocation played at the Princeton University Chapel.

\footnotetext{
${ }^{37}$ In 1992, Westminster Choir College merged with Rider University.

${ }^{38}$ Stefan Hayden Young, "Andante and Allegro for Piano and Orchestra: An Original Composition and Analysis", (Ph.D. Thesis, Rutgers University, 1981).

39 "Stefan Young," Faculty Page Rider University, accessed on January 30, 2015, http://www.rider.edu/faculty/stefan-young.
} 
Every summer, Young organizes the Westminster High School Composers Week where young composers from all over the nation come to study with him. He has served as a coordinator of the Westminster Composers Ensemble and as Westminster's International Student Advisor. He has also been a judge for state-wide music organizations, both in piano and composition. He has received many honors and awards including the Greater Miami Symphony First Prize winner, New Jersey Music Teachers' Association (NJMTA) composer of the year, a Presser Foundation Scholarship, and John Philip Sousa Awards. Most recently, in 2011, he received the Rider University Distinguished Teaching Award. ${ }^{40}$ Young's former compositional students hold major positions in the musical organizations and universities in North America and Asia. Many of them regularly publish works for major publishers such as Schirmer, Alfred, and Hal Leonard. His former student, Rebecca Oswald, an award-winning composer states:

In my composition lessons with Dr. Young, he consistently encouraged me to push forward and develop any musical elements and ideas that seemed to stretch my own boundaries of compositional comfort. His excitement about my early creations supported my growing confidence in the validity of my compositional voice and my eagerness to continue exploring new ground throughout my career as a composer. I am still riding that wave of encouragement and I think I always will. ${ }^{41}$

Ryan Brechmacher, who is currently on piano faculty at the Princeton Day School, fondly remembers how Dr. Young taught him the value of counterpoint and states:

I hated those exercises and my work was often the victim of his red pen. Despite my inability to be "correct" in my contrapuntal writing, by causing me to be aware of counterpoint and helping me to use it as a tool in my own writing, my compositions suddenly took a dramatic turn in complexity and maturity. Whenever I write, no matter if it is for choir, band, or solo piano, I am now keenly aware of the texture and the moving lines. ${ }^{42}$

Another of Young's projects is his recording, Anthology of Art Songs, which is available on Arabesque Recordings, released in 2000. Singers on the album are from WCC's voice faculty

\footnotetext{
${ }^{40}$ Stefan Young. Interviewed by Wei Chen Lin. Princeton, October 29, 2014

${ }^{41}$ Rebecca Oswald, e-mail message to author, August 25, 2015. www.rebeccaoswald.com

${ }^{42}$ Ryan Brechmacher, e-mail message to author, August 25, 2015. www.ryanbrechmacher.com
} 
and include Lindsey Christianson, Margaret Cusack, Elem Eley, Thomas Faracco, and Marvin Keenze, among others. The Anthology of Art Songs consists of Young's original compositions. This is considered a major contribution to the literature of modern vocal music. Young has been described as "a remarkable craftsman who plunges deeply into the meaning of his chosen poetry and proceeds to paint the pictures and plumb the moods with great skill and appositeness."43

Young has composed for various genres including a variety of solo instruments, voice and piano, chamber ensembles, band, choir, and orchestra. He has been commissioned by organizations including the Haverford singers, NJMTA, and WCC. His chamber music includes a variety of combinations of instruments. Notable compositions include Variations on the Theme of Paganini ${ }^{44}$ for string quartet, Song of Solomon ${ }^{45}$ for piano trio and soprano, and Piano Quintet $^{46}$ that uses some modern techniques such as playing inside of the piano and clusters. For choral music, a commissioned work, Oh! Vengeance, was written for Westminster Kantorai singers, viola, and piano. This music includes vocal sound effects such as glissandos, groans, moans, stamping, clapping, and whispering. Besides chamber and choral music, he wrote a number of traditional marches for band. He orchestrated and conducted his high school band for its premier performance. ${ }^{47}$

In terms of solo piano compositions, Young wrote the pedagogical pieces Prelude ${ }^{48}$ and From the Dark Woods $^{49}$, both commissioned by NJMTA in 1991. Two others, Meditation ${ }^{50}$ and

\footnotetext{
${ }^{43}$ Stefan Young, Liner Notes, Anthology of Art Songs, Stefan Young (piano), Arabesque Recordings, 2000, compact disc.

${ }^{44}$ Stefan Young, Variation on the Theme of Paganini (Unpublished, 2003).

${ }^{45}$ Stefan Young, Song of Solomon (Unpublished, 2003).

${ }^{46}$ Stefan Young, Piano Quartet (Unpublished, 2000).

${ }^{47}$ Stefan Young. Interviewed by Wei Chen Lin. Princeton, October 29, 2014.

${ }^{48}$ Stefan Young, Prelude (Unpublished, commissioned by NJMTA in 1991)

${ }^{49}$ Stefan Young, From the Dark Woods (Unpublished, commissioned by NJMTA in 1991)

${ }^{50}$ Stefan Young, Meditation (Unpublished, 2002).
} 
La Guitarra ${ }^{51}$, were written for Fang Ting Liu and Andrea Fang respectively. He often writes pieces for his students based on their individual needs for advancement. It is unfortunate that many of his original piano compositions were given away to his students at the time of the lesson, and there are no copies to be found. Though many of his piano pieces have not been published, the author feels Young's compositions are well written pianistically for students. The following section examines Prelude, From the Dark Woods, Meditation, and La Guitarra in greater detail.

\section{Pedagogical and Performance Analysis of the Selected Piano Pieces}

\subsection{Prelude}

The composer was commissioned to write a piece for NJMTA in 1991. (For background information on prelude, please see Chapter II, page 8) This prelude is in three sections. A brief analysis of this piece is presented in the table below:

\begin{tabular}{||c||c||c|c|}
\hline Section & Tempo & Measures & Tonal Emphasis \\
\hline \hline $\mathrm{A}$ & Allegro & $1-24$ & Octatonic Scale Centered on C (Version 1) \\
\hline $\mathrm{B}$ & Adagio & $25-36$ & Octatonic Scale Centered on C\# (Version 2) \\
\hline $\mathrm{A}^{1}$ & Allegro & $37-58$ & Octatonic Scale Centered on C (Version 1) \\
\hline
\end{tabular}

There are three versions of octatonic scales (Example 3.1a). The A section is built on the octatonic scale centered on $\mathrm{C}$ (Version 1). The pattern starts with a semitone. The row is $\mathrm{C}, \mathrm{D} b$, $\mathrm{E} b, \mathrm{E}, \mathrm{F} \#, \mathrm{G}, \mathrm{A}, \mathrm{B}$. Enharmonic spellings are presented but the pattern remains the same (Example 3.1b).

\footnotetext{
${ }^{51}$ Stefan Young, La Guitarra (Unpublished, 1993).
} 
1.

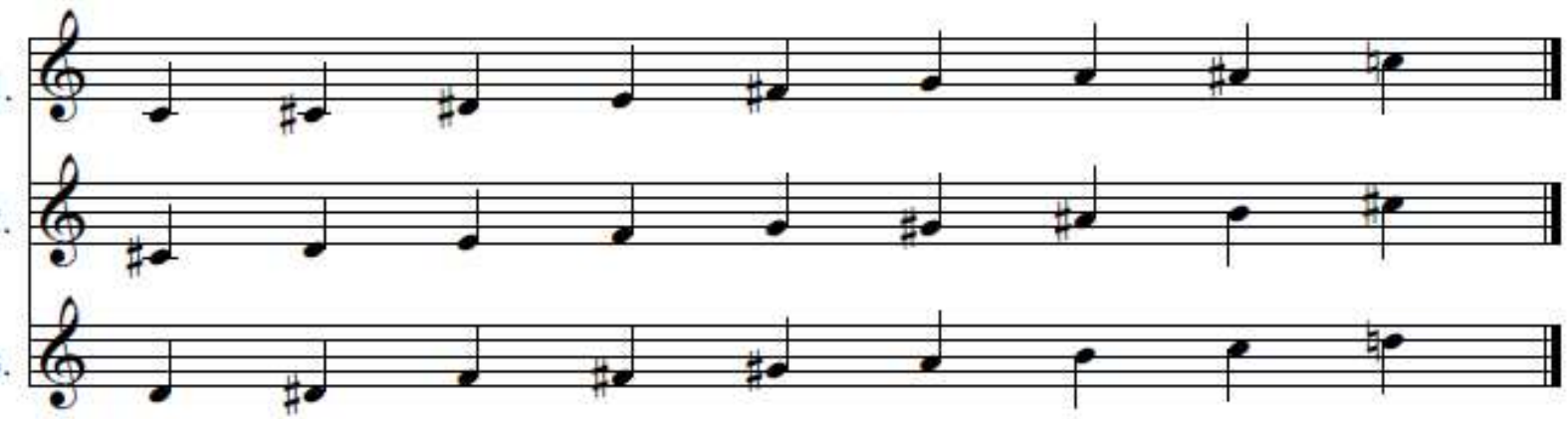

Example 3.1a

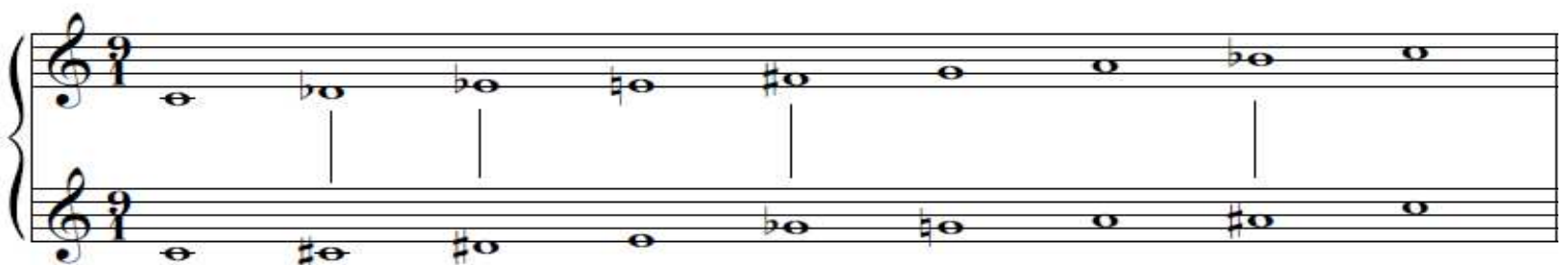

\section{Example $3.1 b$}

In the first four measures, both hands play in unison at the dynamic of $p p$. With each succeeding measure, the dynamic increases by one level (Example 3.1c). From measure 5, an imitation occurs between the hands when the right hand takes a lead and the left hand imitates at the same pitch. The imitation continues for two measures before the two voices diverge (Example 3.1d). The perpetual sixteenth notes keep ascending until both hands arrive at a C\# marked by a Sforzando at measure 14. A series of broken triads in both hands descend to the pitch E accompanied by a crescendo sign (Example 3.1e).

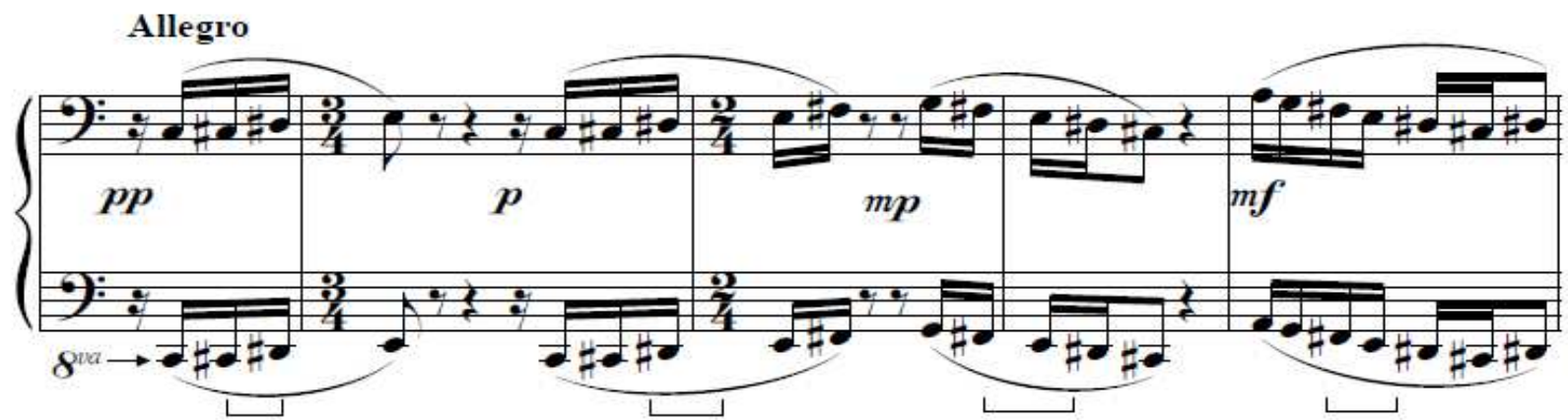

Example 3.1c Prelude, mm. 1-4 


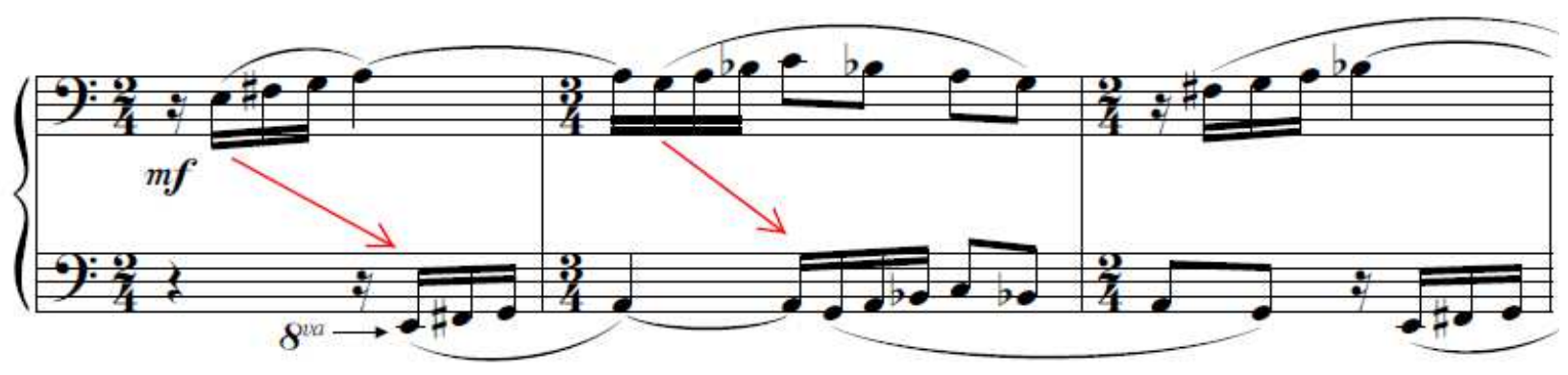

Example 3.1d Prelude, $\mathrm{mm}$. 5-7

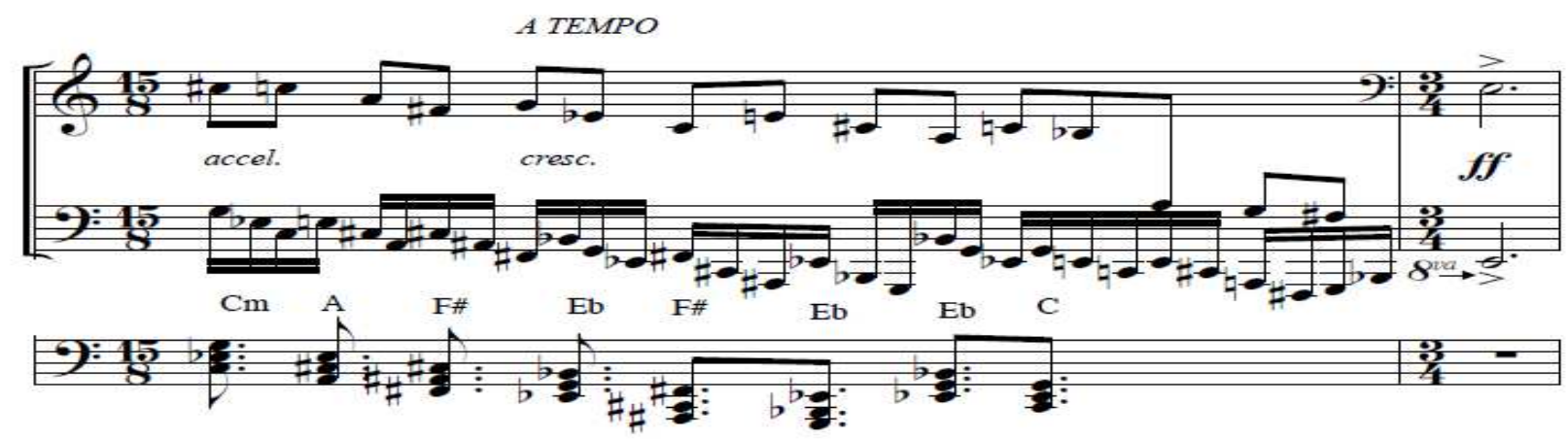

Example 3.1e Prelude, mm. 16-17

The material in measures 21 and 24 is presented as a response to measures 20 and 23 .

The antecedent is the unison in $f f$ dynamic. The consequent is a staccato eighth note at the dynamic of $p$. In addition to melodic gestures presenting the octatonic scale, the music presents the octatonic scales harmonically by stating two different diminished seventh chords in arpeggio form together (Example 3.1f)

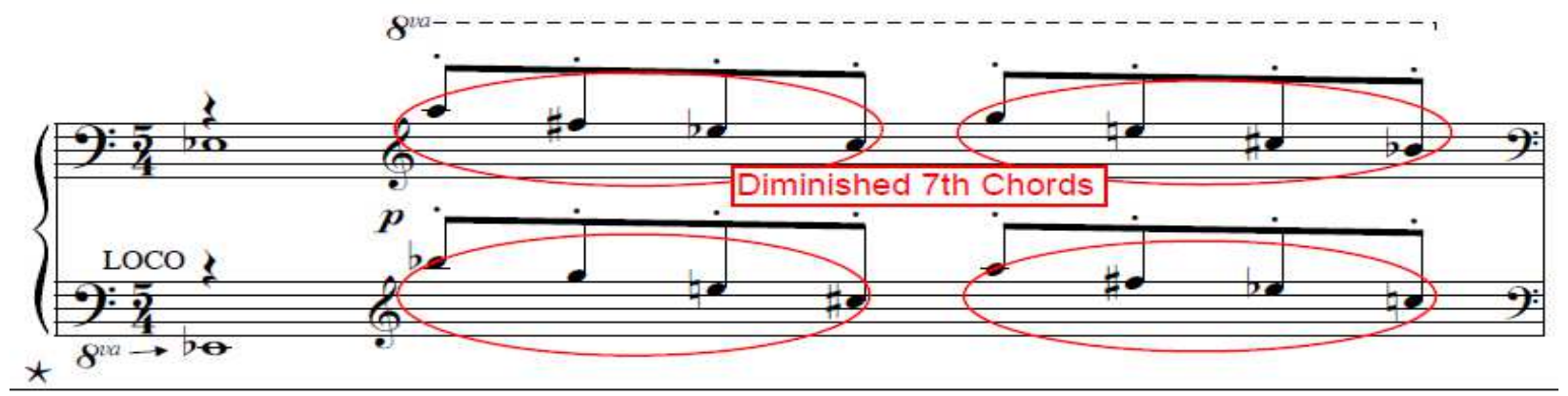

Example 3.1f Prelude, m. 21 
The B section starts with a tempo change to Adagio. From measures 25 to 28 , a new version of the octatonic scale is presented. This scale centers on C\# like version 2 in Example 3.1a (Example 3.1g). From measures 29 to 32, another row of the octatonic scale is observed similar to the previous 4 measures. At measure 33, each hand plays a tetrachord from a different octatonic scale. The right hand plays octatonic scale version 2 and the left hand plays octatonic scale version 1 (Example 3.1h).

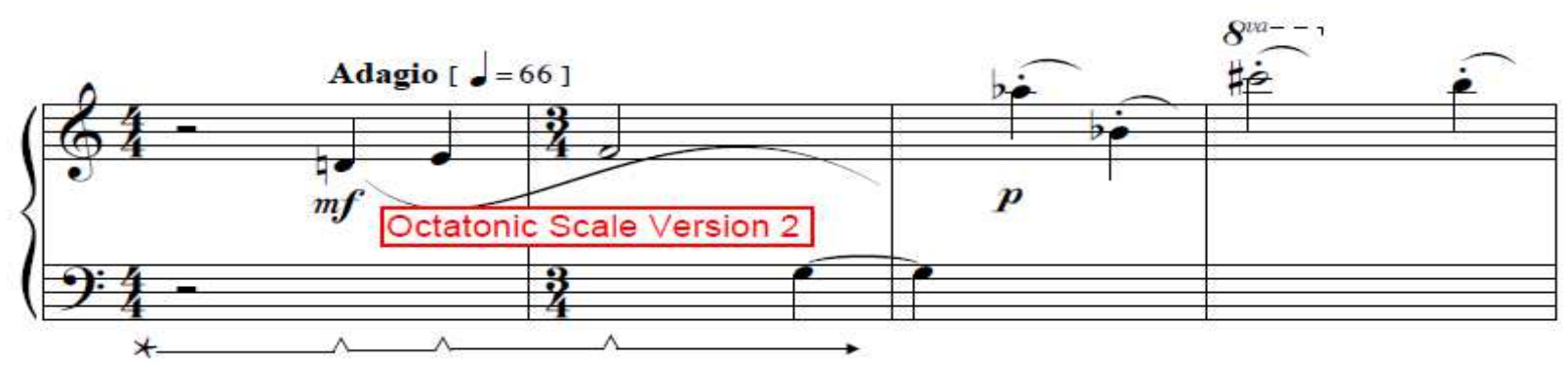

Example 3. $1 \mathrm{~g}$ Prelude, $\mathrm{mm}$. 25-28

Example 3.1h Prelude, mm. 33-34

The A section returns when Tempo $I$ is indicated. The version 1 octatonic scale row is used predominantly throughout this section. Like the previous A section, there are many instances of imitation that are followed by non-imitative ideas. Gradually the dynamic level rises and the register moves up until arriving at measure 55 at which point the instances of imitation stop. Here, both hands play sixteenth notes melodically in broken triads and move down the keyboard. The piece ends with a tritone interval that marks sffz (Example 3.1i). 

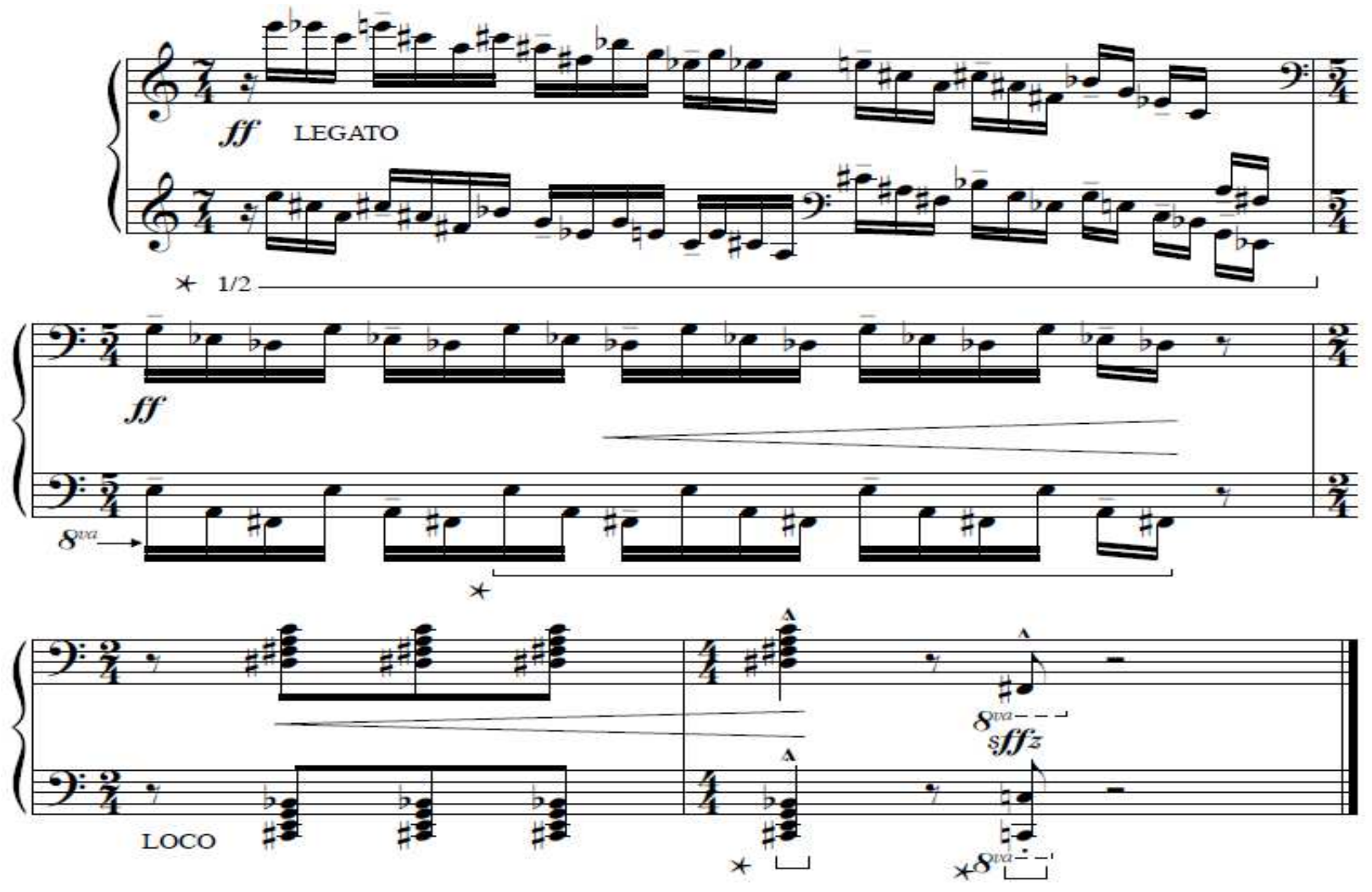

Example 3.1i, Prelude, mm. 55-58

In terms of pedaling, the composer indicates a few specific pedal markings. ${ }^{52}$ In the A section, for the places where the composer does not indicate pedaling, the author feels there are some instances where a touch of pedal in the middle of the slur will enhance the legato playing, such as measures 1 to 4 (Example 3.1c). At measure 21, the low E note should sustain under the eighth-note staccato arpeggio of the upper register; it is recommended to play those eighth notes with the fingertips and a quick release (as if the key is on fire) to create a different sound effect (Example 3.1f). In the B section, the tempo changes to adagio. To depict the tranquil mood of this section, a soft and delicate tone quality is necessary. It is recommended to play with flat fingers and selectively use the una corda pedal to produce various shades of sound. Young changes pedal on every note; however, the author finds blending two notes sometimes can be

\footnotetext{
${ }^{52}$ All pedal markings are those of the author of this paper, except those noted by an asterisk, which are the composer's.
} 
effective in creating different colors (Example 3.lg). Furthermore, delaying the pedal and overlapping the notes can help contribute to this effect.

The author feels there are two challenges to the performer of primary concern in this piece. The first challenge lies in the contrapuntal texture. The performer should be able to bring out the rise and fall of each line. The imitations should be clearly presented. It is recommended to practice hands separately so finger independence can be achieved. The second challenge is the broken triads in measures 16 and 55. The performer should practice blocking the chords as it outlines on the bottom stave in Example 3. le before attempting to play them as written. This is an appropriate piece for younger students to learn the formation of octatonic scales because it does not require a big hand to play. In addition, this is a good study in dynamics, its range extending from $p p$ to $f f$.

\subsection{From the Dark Woods}

Along with the Prelude in 3.1, From the Dark Woods was also commissioned by NJMTA in 1991. This piece has four sections. A brief analysis of this piece is presented in the table below:

\begin{tabular}{|c||c|c|}
\hline Section & Measures & Tonal Emphasis \\
\hline \hline I & $1-8$ & Octatonic Scale Centered on C (Version 1) \\
\hline II & $9-19$ & Octatonic Scale Centered on C (Version 1) \\
\hline III & $20-32$ & Octatonic Scale Centered on C (Version 1) \\
\hline IV & $33-42$ & Octatonic Scale Centered on C (Version 1) \\
\hline
\end{tabular}

The title suggests that this piece explores the eerie and haunting sounds from the woods. The score denotes Allegro and suggests that a quarter note $=100-120$. The first section starts with a repeated drone on a low A and lasts for seven measures. The score indicates misterioso at 
measure 2 when the right-hand melody enters. This melody incorporates pitches $\mathrm{C}, \mathrm{D} b, \mathrm{E} b$, and $\mathrm{E}$ which is an octatonic tetrachord (Example 3.2a). This four-note gesture repeats for the second time at measure 4. When it is repeated the third time, it is extended and increased in volume.

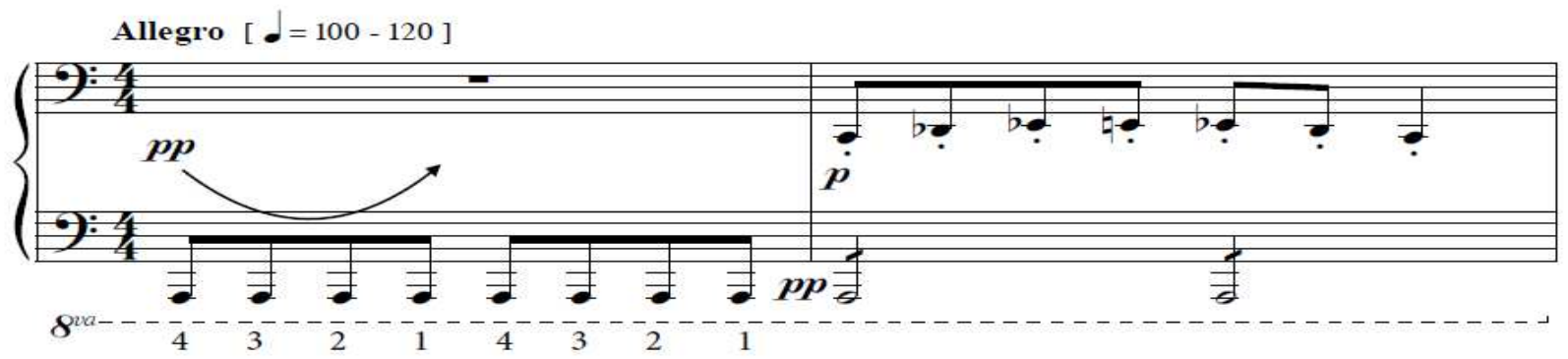

Example 3.2a, From the Dark Woods, mm. 1-2

The second section starts at measure 9 . The gesture that is established in the first section is presented in imitation at two beats away (Example 3.2b). At measure 15, a polyrhythm is introduced. The right-hand gesture remains in $4 / 4$ time; the left-hand pattern is grouped in three (Example 3.2c).

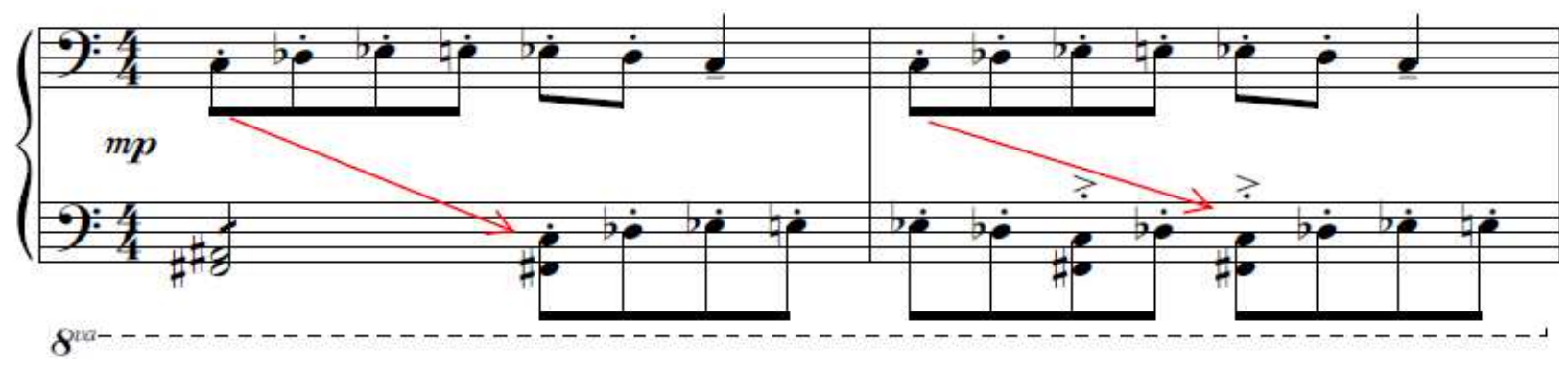

Example 3.2b, From the Dark Woods, mm. 9-10 


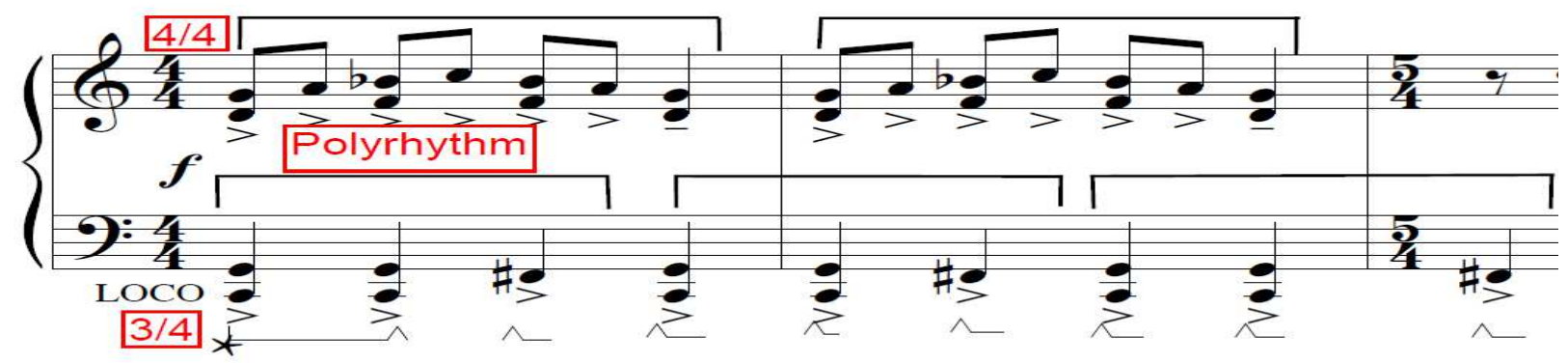

Example 3.2c, From the Dark Woods, mm. 15-17

The third section starts at measure 20. The imitative texture returns. Unlike measure 9, in which the entrance of the imitation is displaced by two beats, this one is displaced by only one beat (Example 3.2d). At measure 23, Young introduces sixteenth notes, the first instance in this piece. This passage involves the alternation of hands. The left hand plays intervals of seconds and thirds on the black keys and the right hand plays seconds on the white keys (Example 3.2e). At measure 25, the four-notes gestures are presented in both hands forming parallel fifths. The right hand plays a tetrachord in version 1. The left hand presents pitches Eb, F, Gb, Ab, which is version 3 in Example 3.1a (Example 3.2f).

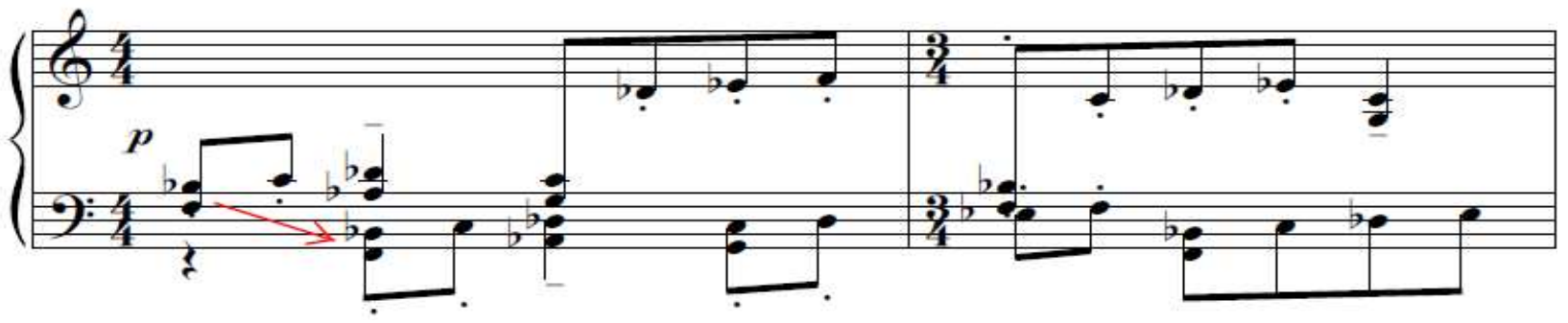

Example 3.2d, From the Dark Woods, mm. 20-21

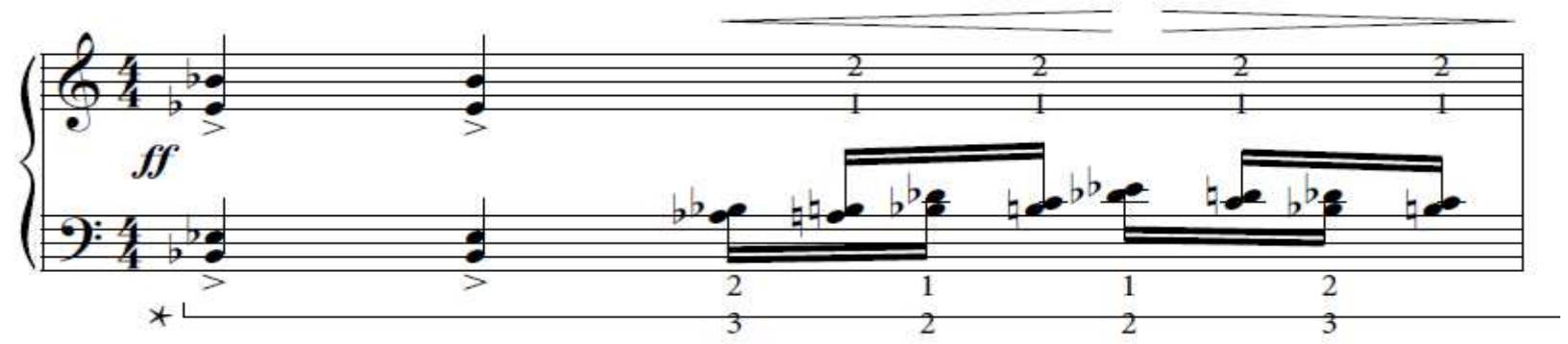

Example 3.2e, From the Dark Woods, m. 23 


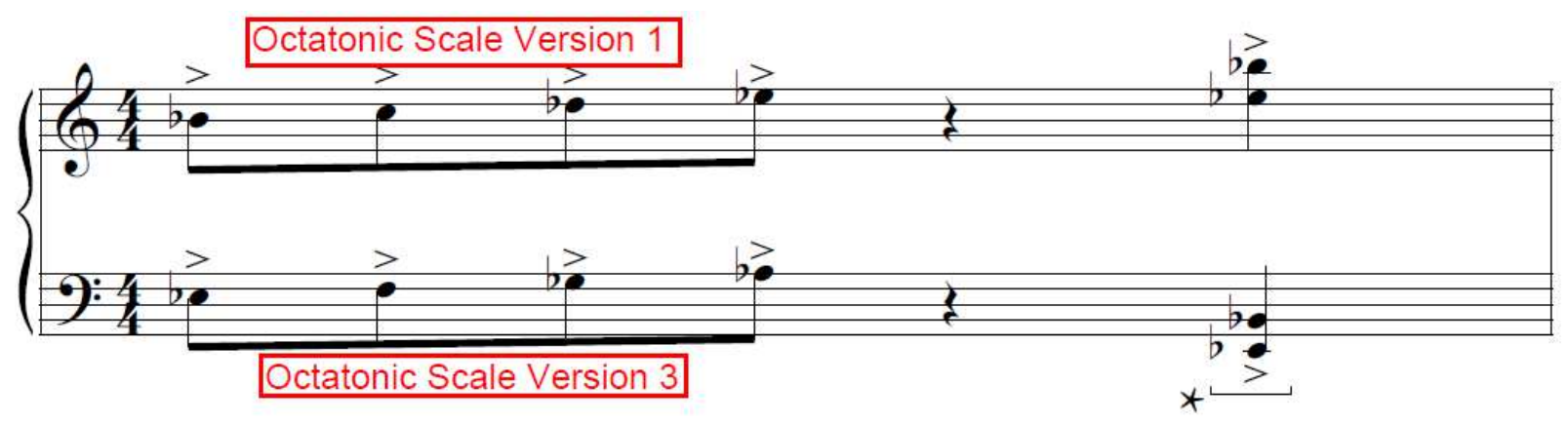

Example 3.2f, From the Dark Woods, $m .25$

The fourth section starts at measure 33. The sixteenth note hand-alternating gesture returns. Unlike measure 23 in which one hand plays white keys and the other plays black keys, this one focuses on the intervals. The left hand plays fourths and the right hand plays fifths. Accompanied by a long crescendo, the dynamic reaches $f f$. A cadenza immediately follows when a variation of the four-note octatonic tetrachord is presented. Not only does the gesture ascend $(\mathrm{C}, \mathrm{D} b, \mathrm{E} b, \mathrm{E})$, it also descends $(\mathrm{E}, \mathrm{E} b, \mathrm{D} b, \mathrm{C})$. Both hands start from the top of the register and gradually descend. Toward the end of the sequence, the four-note gesture is presented as a subtractive process: three notes, two notes, and then one note (Example $3.2 \mathrm{~g}$ ).

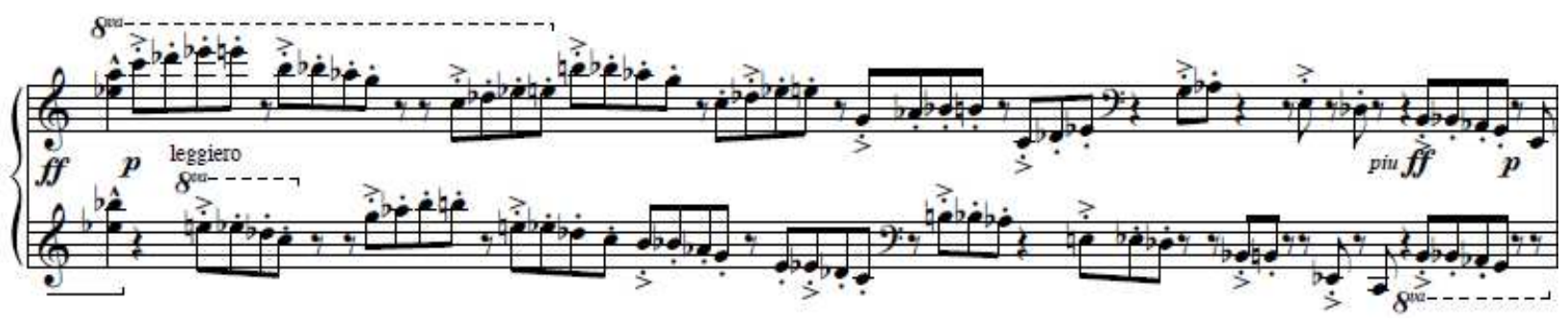

Example 3.2g, From the Dark Woods, $m .34$

At measure 36 , the meter changes to $9 / 2$, the four-note gesture is repeated nine times. The score denotes non legato and a crescendo to the middle of the phrase and decrescendo back. At measure 37, the low A drone note returns. The right hand plays the descending octatonic scale gesture. In the second appearance, it is divided by rests and sounds fragmented (Example 3.2h). Lastly, there is a subito forte on low C and A. Those two notes are to be played secco and 
a decrescendo to the end (Example 3.2i).

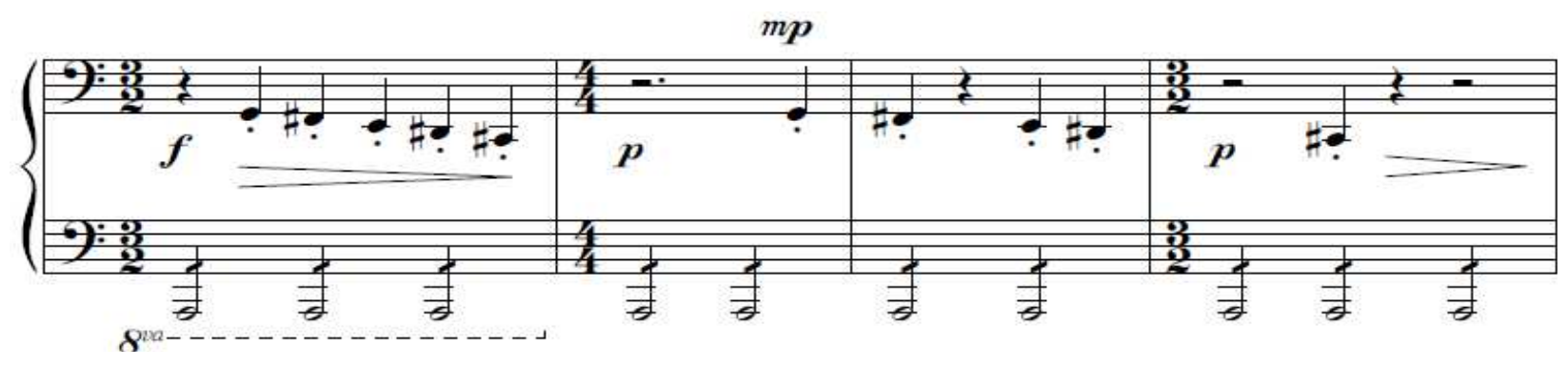

Example 3.2h, From the Dark Woods, $m m$. 38-41

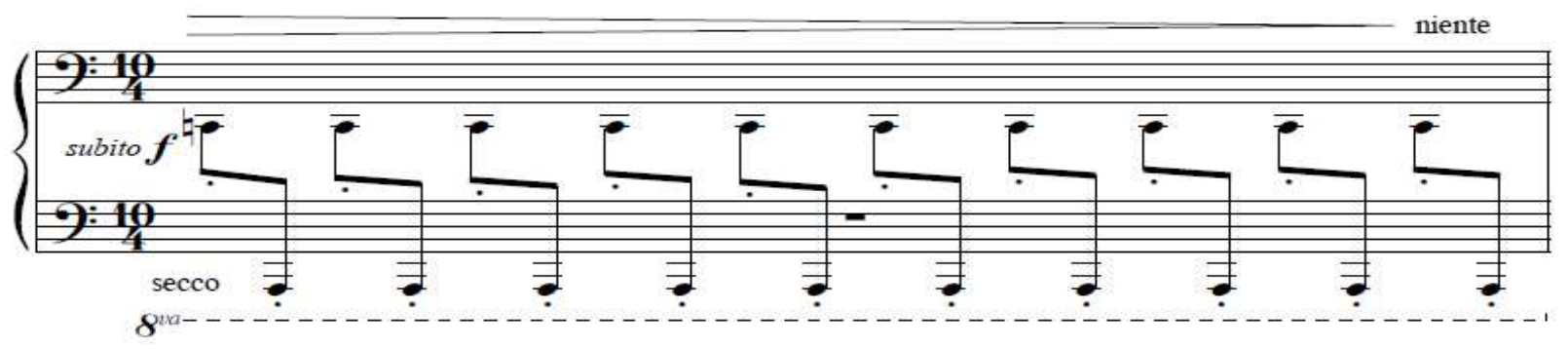

Example3.2i, From the Dark Woods, $m .42$

In terms of pedaling, the author feels that the composer has thoroughly marked the places where to change the pedal. By following it carefully, the performer will find the authenticity the composer intended. In general, the staccato passages are meant to be dry; however, a touch of pedal can occasionally add fullness and smoothness to the sound.

The author feels there are five challenges to the performer of primary concern in this piece. The first challenge lies in the contrapuntal texture at measures 9 and 20. The performer should be able to bring out the entry of each imitation clearly without over accenting it (Examples $3.2 b$ and $d$ ). The second challenge is the frequent changes of meters. Keeping the eighth note steady is necessary regardless of simple or compound times. The third challenge is the hand alternating gesture at measure 23. It seems difficult but the performer must take into account that the left hand plays all black keys and the right hand plays all white keys. The left hand should be placed close to the fallboard while the right hand should be placed under the left 
hand and close to the keys. Furthermore, the performer can try the fingering suggested in the Example 3.2e. Using the thumb, pointer, and the middle fingers for this passage can help moving in and out of the keys easily. Finally, incorporate by a crescendo and decrescendo, this would be very effective in demonstrating technical proficiency (Example 3.2e). The fourth challenge is the cadenza at measure 34 (Example 3.2g). Though this passage is based on the octatonic tetrachord, the difficulty lies in the hand coordination. The performer must know precisely the number of notes overlapping between the entry of each hand. The fifth challenge is to convey the right effect. The title suggests a mysterious mood. Carefully observing the articulation and dynamic can help achieve this. The staccato passages require a hammer-like touch which can be achieved by striking the key bed with firm fingers and with energy originating from the wrist. As for the repeated left-hand eight notes from measures 1 to 7 , it is recommended to think of four notes as one unit that are completed by one motion. In order not to stiffen up the muscle, with each unit, drop the wrist on the first note and gradually lift through the remaining three notes. The performer can try the fingering indicated in Example 3.2a. By changing finger on every note, the wrist will not lock in a stiff position. This is an appropriate piece for younger students to learn the formation of octatonic scales because it does not require a big hand to play. In addition, this is a good study in dynamics, its range extending from $p p$ to $f f$.

\section{$\underline{3.3 \text { Meditation }}$}

This piece was written for Young's student, Fang Ting Liu in 2002. She studied piano and theory with Young for many years at the Westminster Choir College of Rider University. Fang Ting spent a lot of time studying eastern philosophy and religions. Young's inspiration comes from Fang Ting's devotion to Buddhist teachings. Fang Ting programmed this piece on 
her final master's recital at Westminster Choir College. This piece has four sections. A brief analysis of this piece is presented in the table below:

\begin{tabular}{|c|c|c|}
\hline Section & Measures & Tonal Emphasis \\
\hline I & $1-9$ & Pitch D/Pentatonic Scale/Major Scale \\
\hline II & $10-29$ & C\# Pentatonic Scale/ C Whole Tone Scale \\
\hline III & $30-50$ & C Whole Tone Scale \\
\hline IV & $51-68$ & Pentatonic Scales/Major Scale \\
\hline
\end{tabular}

From measures 1-4, Young presents two ideas. The first idea incorporates a pentatonic scale with a major scale. This running passage should be played freely as the score indicates. The second idea is a static bass line comprised of parallel fourths; another feature of this idea is the bell-tone $\mathrm{D}$ in the right hand. The score denotes thoughtfully to convey a sound that is warm and peaceful (Example 3.3a). Those two ideas repeat in measures 5 to 9 although slightly varied and extended.

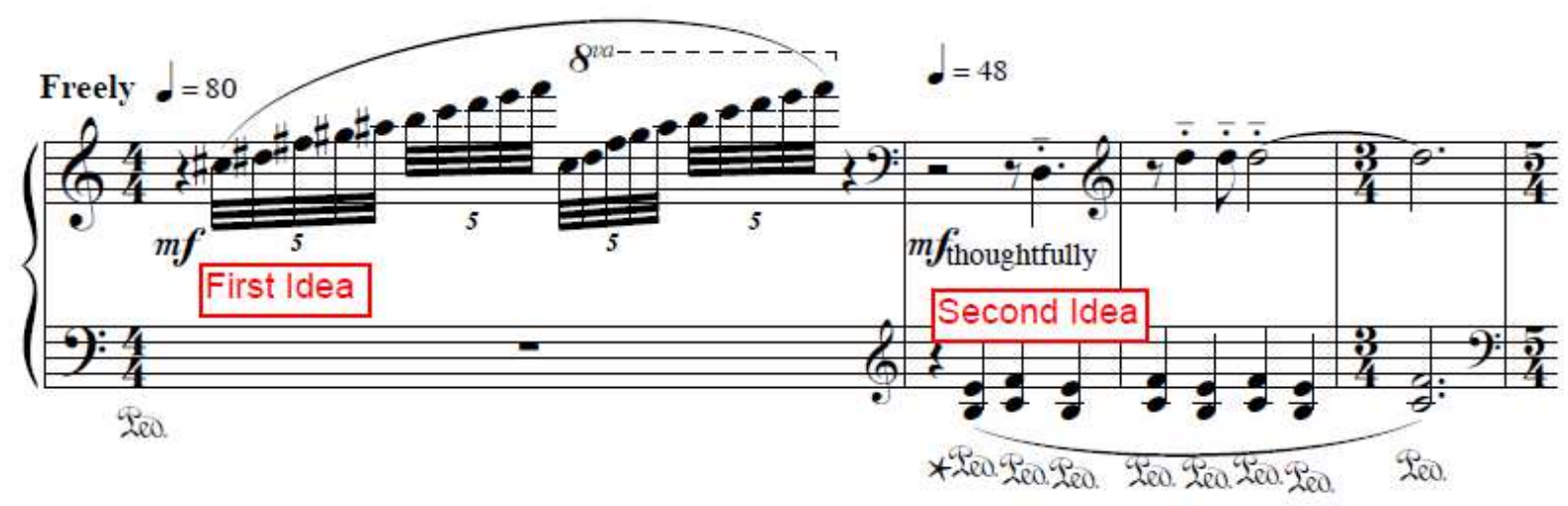

Example 3.3a, Meditation, mm. 1-4

In the second section, Young marks many poco piu mosso to increase the tempo. At measure 10, the pentatonic scale is presented like a chant in the low register. There are four instances of the chant: measures $10,12,16$, and 19. Each appearance is interrupted by either the calm bell sound or the hypnotic static bass line (Example 3.3b). At measure 22, a pentatonic 
glissando is presented in the right hand. This is accompanied by a crescendo and accelerando to the top of the keyboard (Example 3.3c). Forte is reached and both hands play in unison and descend down to the low G\# on a fermata sign. This descending passage is like the striking of a gong. Each note should be articulated as it is marked staccato and accent (Example 3.3c).

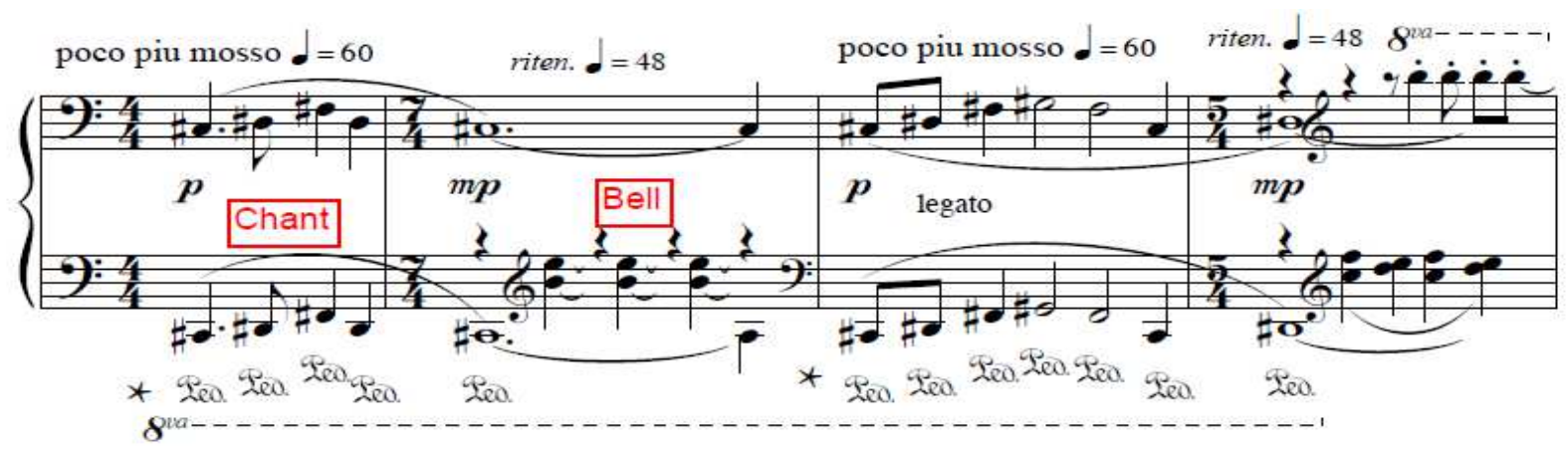

Example 3.3b, Meditation, $\mathrm{mm} .10-13$

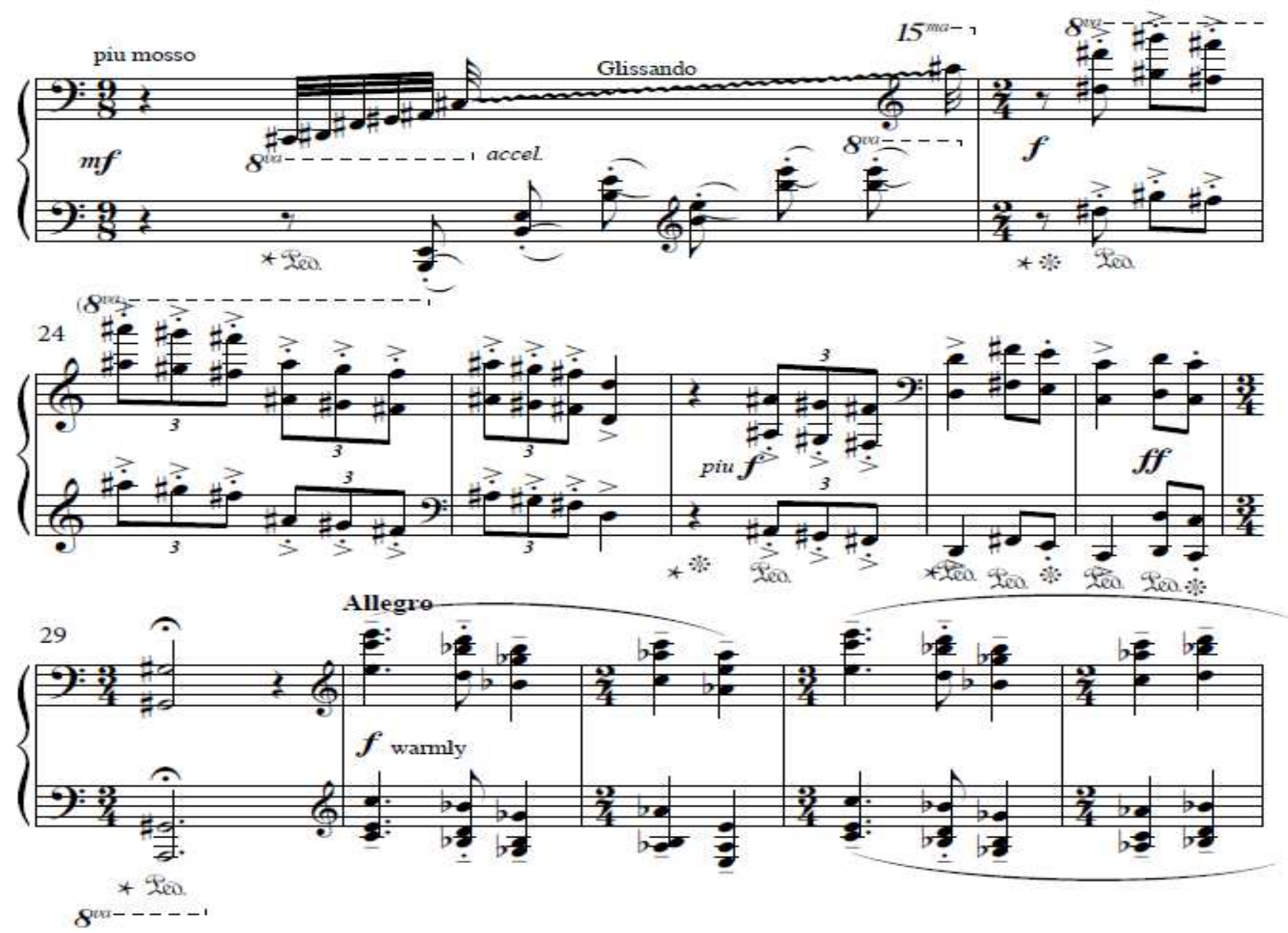

Example 3.3c, Meditation, mm. 22-33 
The third section starts with a new tempo marking, Allegro, at measure 30. The texture becomes thicker; octaves are filled in with thirds. Those parallel chords are derived from the whole tone scale: $\mathrm{C}, \mathrm{D}, \mathrm{E}, \mathrm{G} b, \mathrm{~A} b, \mathrm{~B} b$. It is intended to be played warmly (Example 3.3c). In measures 35 to 38 , the parallel chords are repeated again, this time bearing the indication brilliant. From measures 39, the two ideas from the A section return. The first idea is the ascending scale; however, it is constructed on a whole tone scale instead of a pentatonic scale. The second idea is the bell tone marked sparkling in measure 40 (Example 3.3d).

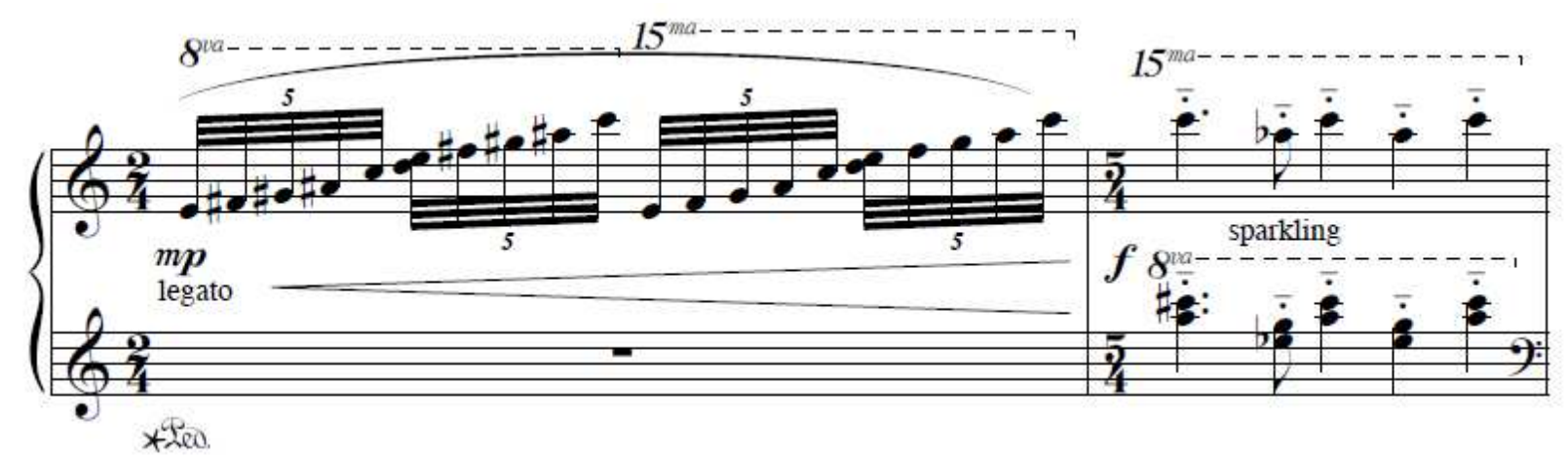

Example 3.3d, Meditation, mm. 39-40

The fourth section starts at measure 51. A new tempo marking is indicated, Andante. This section is like the second section where a chant melody is presented then interrupted by bell-like material. The chant melody starts at measure 51. The bell-like material consists of triplets in bitonality at measure 53. The right hand plays a broken F major chord while the left hand alternates with a broken $\mathrm{E} b$ major chord (Example 3.3e). At measure 61, a pentatonic scale mixed with a major scale is presented like the beginning, except this one starts from the top and descends (Example 3.3f). It repeats for the second time with an extension. The whole piece ends peacefully with three iterations of a low A (Example 3.3g). 


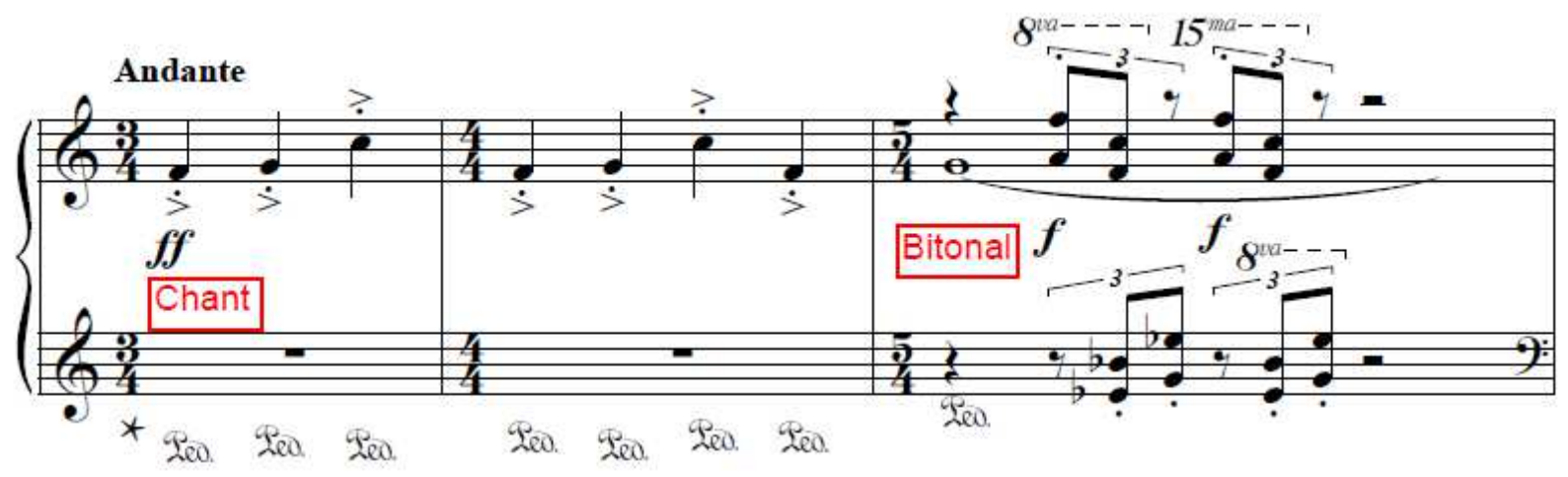

Example 3.3e, Meditation, mm. 51-53

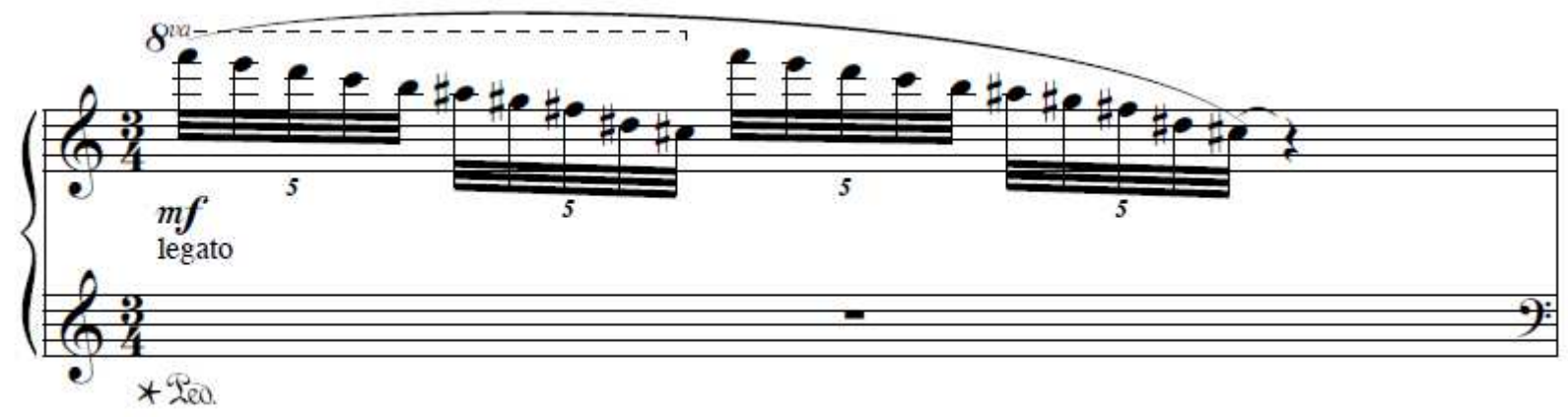

Example 3.3f, Meditation, $m .61$

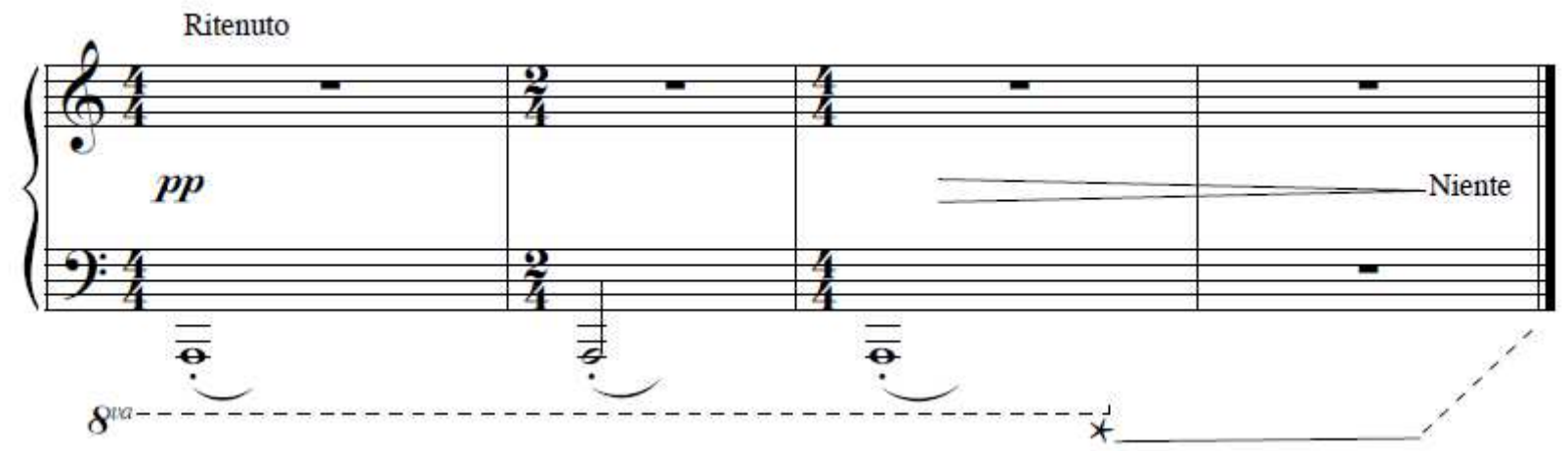

Example 3.3g, Meditation, mm. 65-68

In terms of pedaling, the composer indicates many pedal markings in the score. The damper pedal helps to blend the harmonies and sustain the bass. The author feels the only instance of the una corda pedal should be at measure 63 to the end. Try to achieve the soft tones not only with the pedal but also with the hand. In measures 29 to 38 , there are two phrases of 5 measures. Each phrase begins with low octaves that sustain under a series of parallel chords in 
the high register (Example 3.3c). The performer might fear holding the damper pedal under the changing harmonies would blur the sound, but without the low octaves support, the effect sounds less rich and full. Another possibility is to use the sustenuto pedal for the low octaves while engaging the damper pedal for the parallel chords.

The author feels there are four challenges to the performer of primary concern in this piece. The first challenge deals with legato playing. In measure 1, the passage should be played smoothly without bumps when one hand transfers to another. In order to avoid an accent on every first note of the group, it is recommended that the performer listen carefully between the last note of one hand and the first note of the other hand. The author recommends starting the phrase stronger, and then creating a decrescendo to the end. All the notes should be played smoothly with one gesture and without agitation (Example 3.3a). The chant-like parallel octaves should be legato at measures $10,12,16$, and 19. Imagine the flesh part of the fingers glued to the key so the weight transfers from one finger to another (Example 3.3b). The second challenge occurs in measure 22. The time signature is $9 / 8$. Though an accelerando is marked, it is recommended not to glissando too fast before the left hand is finished playing from beats four to nine. A glissando can go too fast if it is not timed (Example 3.3c). The third challenge is the ability to voice the chords at measure 30 (Example 3.3c). Leaning on the fifth finger of each hand will bring out the outer voice prominently. Be sure the fingers support the power from the forearm. During the chord progressions in measures 30 to 38 , it is crucial to use the hand as one unit to achieve the same tone quality. The last challenge is conveying the correct atmosphere. The performer should refer to the title, Meditation. As the listener finishes hearing this piece, they should have gone through a meditative journey like a pilgrimage to a Tibetan temple. The composer includes many additional expressive markings such as thoughtfully, hearty, warmly, 
brilliant, and sparkling. How one interprets those markings will have an effect on how one uses the physical apparatuses: fingers, wrists, forearms, upper arms, and shoulders. The performer can experiment creating different sounds using the muscles in these body parts to achieve expressive results.

\section{$\underline{3.4 \text { La Guitarra }}$}

La Guitarra was composed for Andrea Fang, a daughter of Young's student, Jen Ciao Fang, in 1993. The Fangs and Youngs were very close; Stefan Young was an honorary uncle to Andrea. This piece was written with simple technique yet very idiomatic to the instrument.

This piece is in three (ABA) sections. A brief analysis of this piece is presented in the table below:

\begin{tabular}{|c||c|c|}
\hline Section & Measures & Tonal Emphasis \\
\hline \hline A & $1-19$ & A \\
\hline B & $20-37$ & A and G \\
\hline A & $38-52$ & A \\
\hline
\end{tabular}

The score denotes Allegretto Flamenco at the beginning. The Spanish music style, Flamenco, usually involves singing, dancing, and guitar accompaniment. This rhythmic folk music comes from the region of Andalusia in southern Spain. ${ }^{53}$ In the A section, there are two main ideas. The first idea is an arpeggio like the strumming of strings. The first four measures are like a calling for attention. The second idea is the parallel motion of chords in measure 5 (Example 3.4a). The chords presented in the A section are G major, F major, and E major. This is derived from the Andalusian cadence, a descending progression comprised of four descending

\footnotetext{
${ }^{53}$ Israel J. Katz. "Flamenco." Grove Music Online. Oxford Music Online. Oxford University Press, accessed March 14, 2015, http://www.oxfordmusiconline.com/subscriber/article/grove/music/09780.
} 
chords in stepwise motion (Am-G-F-E). ${ }^{54}$ The descending parallel chords are taken a step further by adding more adjacent notes at measures 13 and 17 . This eventually leads to the $\mathrm{E}$ major chord that concludes this section.

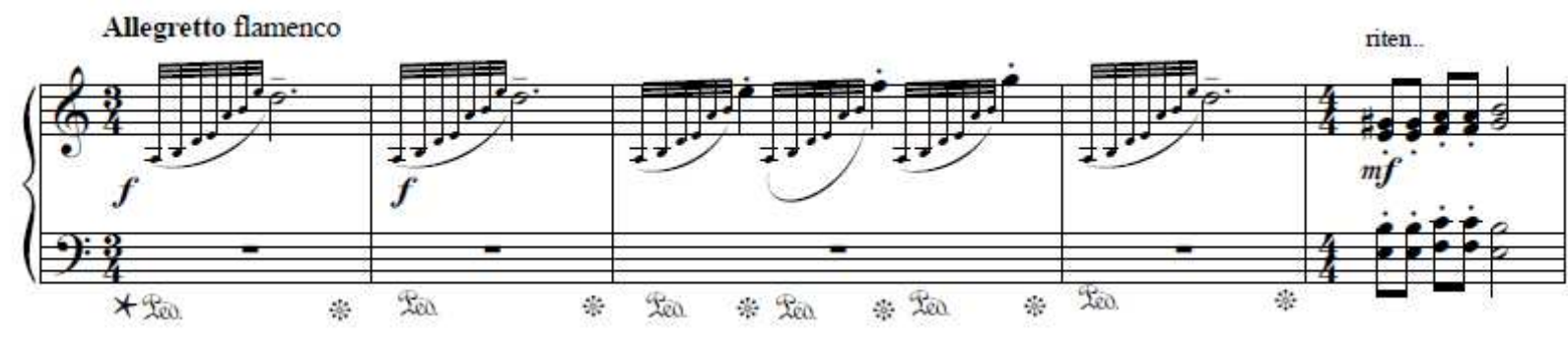

Example 3.4a, La Guitarra, mm. 1-5

The B section starts at measure 20 and contains three phrases. The right hand plays the melody and the left hand plays the syncopated accompaniment. Young indicates legato and warmly in this section. This provides a contrast to the A section. The first phrase starts with an A major tonal emphasis and ends in $\mathrm{G}$ minor (Example 3.4b). The second phrase starts in $\mathrm{G}$ minor and ends in A major. The third phrase starts in A major and extends in a presentation of parallel thirds. With each parallel third, it rises in pitch culminating in the strumming gesture, a reference to the A section (Example 3.4c).

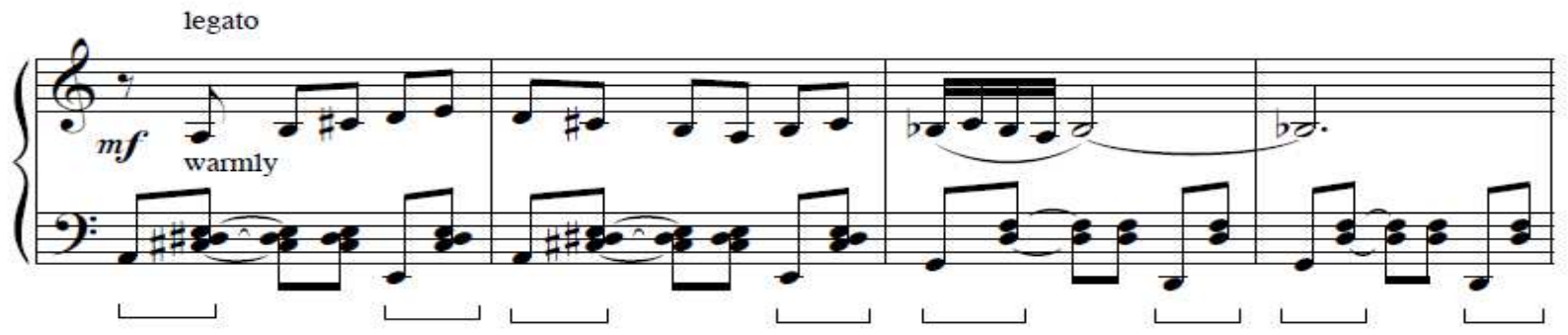

Example 3.4b, La Guitarra, mm. 21-24

54 Ibid. 

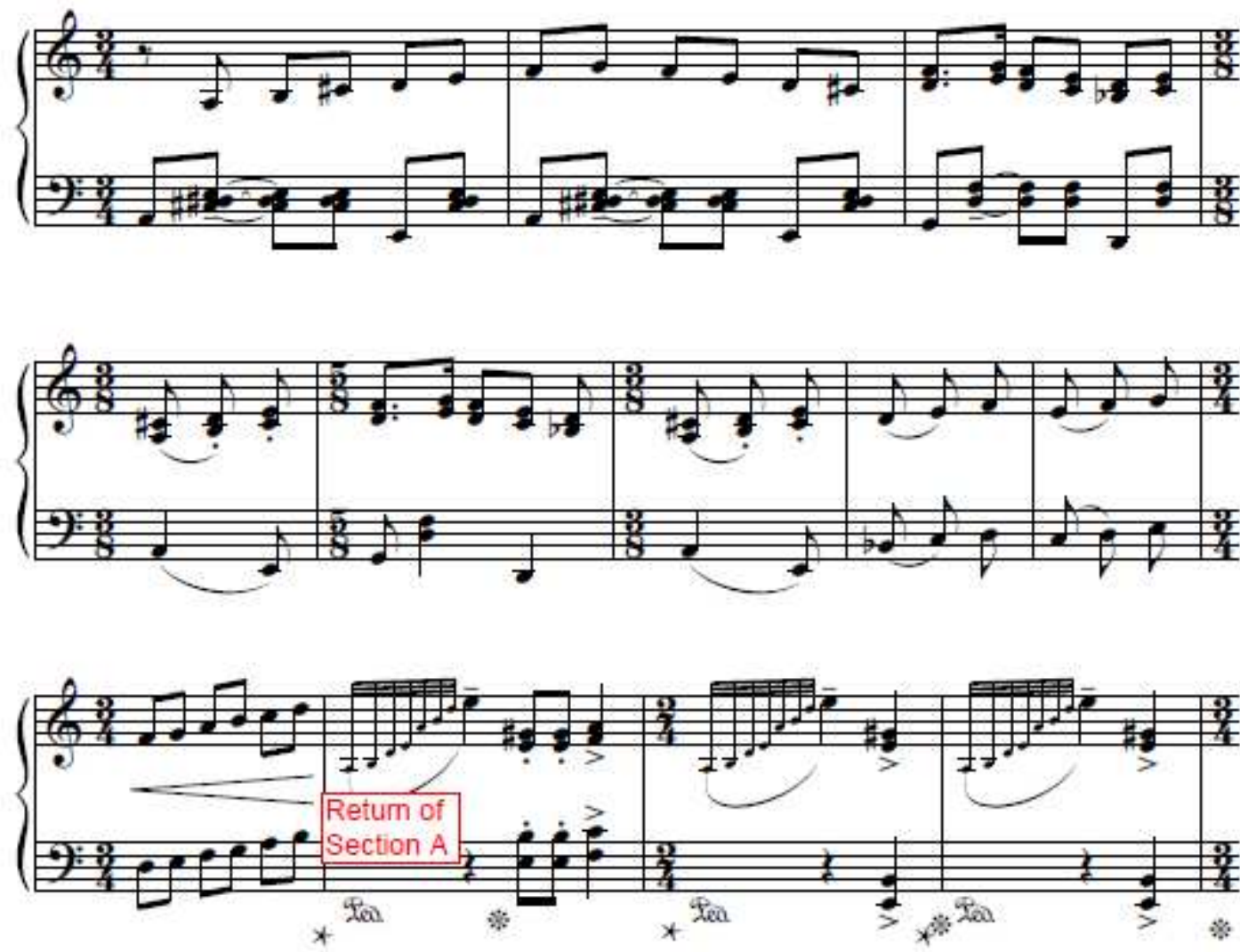

Example 3.4c, La Guitarra, mm. 29-40

The A section returns at measure 38. Parallel chords are common in this section. Most of them are in similar motion until measure 45, at which point they are presented in contrary motion. The right hand presents E-F\#-G\#-A and the left hand descends from E-D-C-B-A. This helps to solidify the tonal emphasis of A (Example 3.4d). After the cadence, there is a hand-alternating passage of sixteenth notes, like a cadenza. The lyrical A major theme from the B section returns to interrupt the second cadenza (Example 3.4d). The piece ends with repeated chords centered on A. 


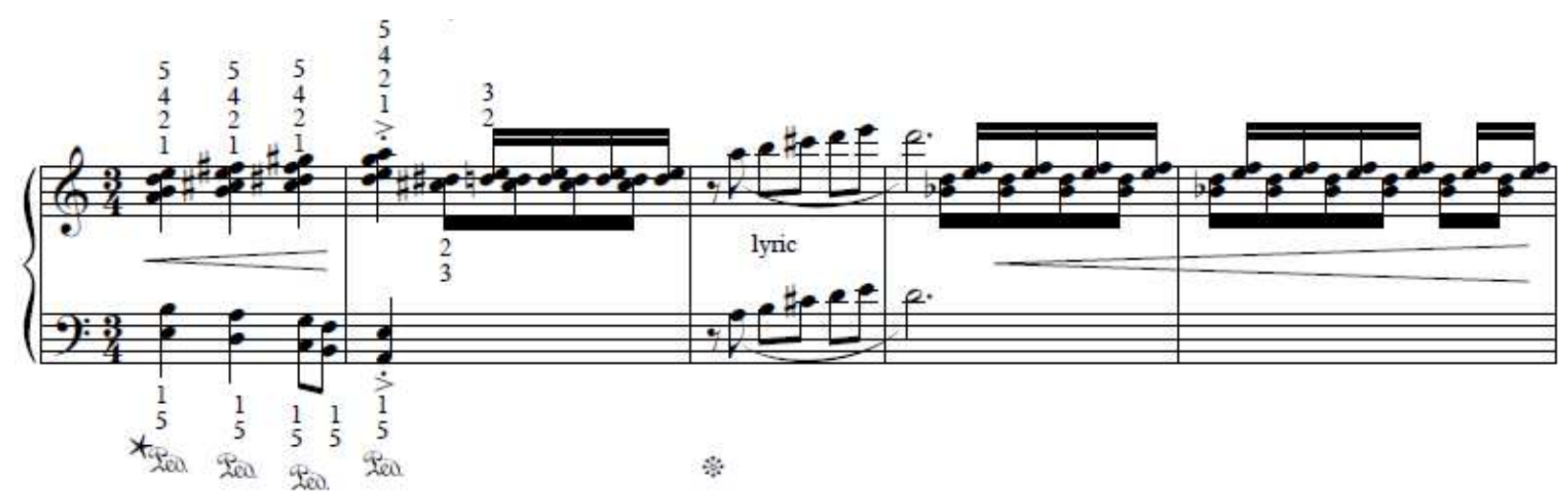

Example 3.4d, La Guitarra, mm. 45-49

In terms of pedaling, Young indicates some pedaling in the score. As a general rule, every strumming chord should be accompanied by a damper pedal. For the parallel chords in the A sections, a touch on each quarter note is good to maintain the beat. In the B section, the performer can experiment with a quarter note pedal on every first and the third beat (Example $3.4 b)$.

The author feels there are five challenges to the performer of primary concern in this piece. The first challenge is the strumming arpeggio in the beginning. Though they are marked to be played forte, each arpeggio should have a direction to the top so it creates momentum imitating the strumming of a guitar (Example 3.4a). The second challenge is the B section where the first legato sign appears in measure 21 (Example 3.4b). The score denotes legato for the right-hand melody. The left hand syncopated rhythm should not be legato and the second eighth note of each measure should be emphasized. Transferring the weight in-between fingers in the right hand is necessary in order to create a smooth melodic line. The third challenge is the frequent changes of meters in measures 31 to $33(3 / 4,3 / 8,5 / 8)$. Keeping the eighth note steady is necessary regardless of simple or compound times (Example 3.4c). The fourth challenge is the alternating hand gesture in the cadenza. The performer should practice in different rhythms and groupings so it does not sound uneven (Example 3.4d). The last challenge is the flamenco style. 
In a series of parallel chords, the performer can experiment with rubato at various places (Example 3.4e). They may be seen as all eighth notes but they do not have to sound evenly. A good way to do it is to start the phrase slower, move through the middle part, and slow down at the end of the phrase. In addition, the performer should consider using the same fingering as illustrated in Examples 3.4d and 3.4e. This will help to solidify the notes.

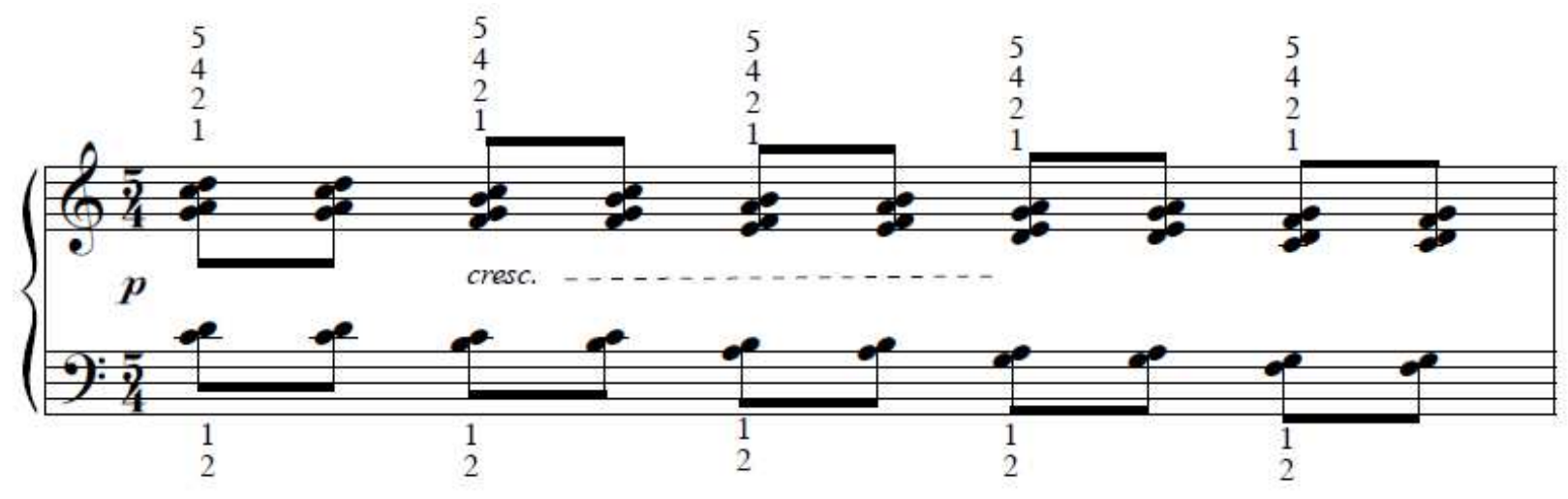

Example 3.4e, La Guitarra, m. 13

To summarize, Young's Prelude, From the Dark Woods, Meditation, and La Guitarra contain a variety of writing. Prelude and From the Dark Woods were commissioned by NJMTA in 1991. Both compositions are based on the formation of an octatonic scale which includes three versions (Example 3.1a). In terms of tempo, both pieces are labeled with Allegro. Young suggests a metronome marking (quarter $=100-120)$ only for From the Dark Woods but the author feels it is suitable for the Prelude as well. For Pedaling, Young is very specific. However, for the places where Young does not indicate, the author feels a touch of pedal can sometimes provide a variety of color to the overall sound palette. Lastly, meter changes from simple time to compound time or vice versa are frequent which can make keeping the rhythm difficult. It is recommended to observe them carefully.

Meditation was written most recently compared to the other three compositions by Young in this research project. The writing is similar to an impressionist work by Debussy because 
Young incorporates many pentatonic scales, whole tone scales, and parallel chords. For tempo, metronome, and pedal markings, Young gives very specific indications to the performer. In terms of the meter, the changes from simple time to compound time or vice versa frequently occurred. It is recommended to observe them carefully.

La Guitarra was written as an imitation of a guitar playing. The formal structure is in ABA form. This piece has a clear tonal emphasis on A. For the pedaling, Young only provides markings for the A sections. The author feels there is a need for the pedal in the B section; therefore, it is suggested in the music examples. Like the other three pieces by Young in this research project, meter changes are very common; the performer should pay attention to them carefully. 


\section{CHAPTER IV}

\section{SUMMARY AND RECOMMENDATIONS FOR FURTHUR STUDY}

\section{$\underline{\text { Summary }}$}

The purpose of this research document is to introduce compositions by two living composers: David Gordon Duke and Stefan Young. When speaking of contemporary music (music written in the last 50 years), one common misconception is that most of the repertoire is inaccessible, especially at the elementary and intermediate levels. However, the selected compositions in this research project represent several appealing and attractive works that provide an alternative to the existing repertoire. They serve well to introduce contemporary compositional techniques to young pianists. My intent is to stimulate an appreciation and understanding of these composers' music, to encourage music teachers to widen their knowledge and experience of new works, and to support composers of our day.

The various levels of piano literature can be generally divided into three main categories:

elementary, intermediate, and advanced. Each of these categories may be further subdivided into early, middle, and late. For the compositions in this research project, they are ranged from early elementary to early advanced (Example 4.1). The majority belong to the elementary and intermediate levels. The most difficult selection is the Sonatina by Duke. 


\begin{tabular}{|l||l|l||}
\hline \multicolumn{1}{|c|}{ Levels: } & \multicolumn{1}{|c|}{ David Gordon Duke } & \multicolumn{1}{|c|}{ Stefan Young } \\
\hline Early Elementary & Prelude No. 3 & \\
\hline Middle Elementary & Postcard No. 1, 5 & \\
\hline Late Elementary & $\begin{array}{l}\text { Prelude No 1, 4 } \\
\text { Postcard No. 2 }\end{array}$ & From the Dark Woods \\
\hline Early Intermediate & $\begin{array}{l}\text { Prelude No. 6 } \\
\text { Postcard No. 3, 6 }\end{array}$ & Prelude \\
\hline Middle Intermediate & $\begin{array}{l}\text { Prelude No. 2, 7 } \\
\text { Postcard No. 4 }\end{array}$ & La Guitarra \\
\hline Late Intermediate & Preludes No. 5 & Meditation \\
\hline Early Advanced & Sonatina & \\
\hline
\end{tabular}

Example 4.1

In Chapter I, a brief introduction is presented. Other information includes the purpose, need, and limitations for the study. Lastly, related literature is presented.

In Chapter II, David Gordon Duke's biography and three sets of his selected compositions are discussed. In Duke's compositions, musical excerpts are incorporated into the text. The seven Preludes maintain the essence of the past; however, the harmonic language is more typical of the twentieth century. The six Postcards recall Debussy's Preludes. Each contains an annotation and descriptive title. The pieces by Duke, Preludes and Postcards, can be played individually or as a set. They range from early elementary to late intermediate level. These pieces are short and provide excellent opportunities for students to develop sound control, note reading abilities, an understanding of musical structure, and an understanding of the twentieth-century harmonic language. Teachers can choose the appropriate and suitable piece depending on a student's abilities. The Sonatina is a postmodern work that combines several compositional techniques from the past. All three movements are considered at the early advanced level and are the most challenging works in this research project. Each movement can 
stand on its own on the concert stage; however, the author recommends playing them as a whole which makes a more cohesive work.

In Chapter III, Stefan Young's biography and four of his selected compositions are discussed. In Young's compositions, musical excerpts are incorporated into the text. The Prelude and From the Dark Woods both explore the formation of octatonic scales. With the emphasis on the independence of the fingers, appealing rhythm, and creative characters, these two pieces would make excellent alternatives to Mikrokosmos by Bartók. Meditation investigates the pentatonic scales, whole tone scales, and parallel chords along with musical imageries. This piece will provide preparation for more complex, intricate voicing in multiple layers of texture found in the standard repertoire by composers like Debussy. La Guitarra brings a taste of Spanish Flamenco style. The sound world often heard in Spanish music, usually associated with the guitar, is useful in awakening the students' imagination. With a virtuosic ending that shows off the pianist's technique, this piece would be an excellent encore. These four pieces are ranged from late elementary to late intermediate level. They are creative and appealing and can hopefully stimulate student's interest to the understanding of contemporary music.

For each piece, a brief analysis of the formal structure is provided. In addition, the challenges and difficulty of each are discussed. Pedagogical and performance suggestions are subjective and intended to provide some of several possible interpretations and ideas.

It is hoped that an analysis of the compositional techniques inherent in the pieces of these two composers will intrigue musicians; it is also hoped that identifying the pedagogical possibilities of these works will inspire teachers and students to seek out and perform them. Though these pieces are steeped in the techniques of twentieth century, they are still attached to 
the long tradition of piano music and so are not terribly taxing on audiences. They provide refreshing contrasts to the staples of piano repertoire. In addition, students need not be afraid to try these pieces; they are approachable at an intermediate level and easily grasped with normal practice. Performing these compositions is a joy. They will capture students' interest, demand musicality, and foster technical achievement. Furthermore, the variety of musical tastes (style) found in these compositions will prepare students to play more advanced twentieth-century repertoire.

\section{$\underline{\text { Recommendations for Further Study }}$}

The research for this document was limited to the selected seven compositions by two living composers: David Gordon Duke and Stefan Young. A number of additional topics related to the study and performance of other compositions by those two composers are also worth exploring.

The following are the author's recommendations for further study:

1. Duke wrote a companion piece for the piano Sonatina, titled Sonatina semplice for piano and violin. It is in three movements that follow the conventional formal structure. This topic would include a comparison and contrast between those two compositions.

2. Duke's mentor and teacher, Jean Coulthard wrote a Sonatina for piano. Since Coulthard had much influence on her students, this topic would include a comparison and contrast of the Sonatinas by both composers.

3. Young's serial solo piano compositions include, Akouete, which explores 12-tone technique and $20^{\text {th }}$-century contemporary technique (plucking and tapping string, string tremolos and glissando, playing with palm and elbows). Young also wrote 5 miniatures that are similar to Akouete but on a smaller scale. This topic would include formal analysis and performance practices of those compositions. 


\section{SELECTED BIBLIOGRAPHY}

\section{$\underline{\text { Books and Dissertations }}$}

Albergo, Cathy, Reid Alexander, and Marvin Blickenstaff. Celebration Series Perspectives: Handbook for Teacher. Ontario: The Frederick Harris Music Co. Limited, 2015.

Butler, Samuel. Guide to the Best in Contemporary Piano Music. Metuchen, New Jersey: The Scarecrow Press, Inc., 1973.

Canaday, Alice. Contemporary Music \& the Pianist. New York: Alfred Publishing Co., Inc., 1974.

Hahn, Christopher Charles. "Canadian Pedagogical Piano Repertoire Since 1970: A Survey of Contemporary Compositional Styles and Techniques." D.M.A. document, University of Oklahoma, 2005

Ross, Susan. "Music Reflects Duke's Current Interest." The Music Scene No. 334 (NovemberDecember 1983): 5, 22

Thompson, Ellen. Teaching and Understanding Contemporary Piano Music. San Diego: Kjos West Publishing, Inc., 1976.

Turabian, Kate L. A Manual for Writers of Term Papers, These and Dissertations. $6^{\text {th }}$ ed. Chicago: The University of Chicago Press, 1996.

Vinton, John, ed. Dictionary of Contemporary Music. New York: E.P. Dutton \& Co., Inc., 1974.

Young, Stefan Hayden. "Andante and Allegro for Piano and Orchestra: An Original Composition and Analysis." Ph.D. Thesis, Rutgers University, 1981

\section{$\underline{\text { MUSIC SCORE }}$}

Published Piano Music

(All Scores are used with the permissions from the composers)

Coulthard, Jean, David Duke and Joan Hansen. Music of Our Time, 9 Vols. Waterloo: Waterloo Music Company Limited, 1977-80. 
Coulthard, Jean, David Duke and Sylvia Rickard. Music in Many Forms. Waterloo: Waterloo Music Co. Limited, 1981.

Duke, David. Aria and Recitative. Canadian Music Centre, 1977.

. Concerto Grosso. Canadian Music Centre, 1987.

. Festival Collection. Palmerston: Julyn Music Publication, 2002.

. Magical Years of the Chinese. Waterloo: Waterloo Music Co. Limited, 1990.

. Music for Orland. Canadian Music Centre, 1986.

. Sonata da Chiesa. Canadian Music Centre, 1975.

. Special Days: A Musical Year for Children. Waterloo: Waterloo Music Co. Limited, 1994.

. Sonatina. Waterloo: Waterloo Music Co. Limited, 1985

\section{Unpublished Piano Scores}

(All Scores are used with the permissions from the composers)

Duke, David. Postcards. Score, 1980s, available from the composer.

. Preludes. Score, 1980s, available from the composer.

Young, Stefan. From the Dark Woods. Score, 1991, available from the composer.

. La Guitarra. Score, 1993, available from the composer.

. Meditation. Score, 2002, available from the composer.

. Prelude. Score, 1991, available from the composer

\section{Discography}

Young, Stefan. Liner Notes. Anthology of Art Song. Stefan Young, (piano). Arabesque Recordings, 2000. Compact disc. 